\title{
Reproductive ecology, condition, and the physical environment of a temperate protogynous hermaphrodite at a small spatial scale
}

\author{
by \\ Maria Genevieve Oliver
}

\begin{abstract}
A thesis
submitted to Victoria University of Wellington

in partial fulfillment of the

requirements for the degree of

Master of Science

in Marine Biology
\end{abstract}

Victoria University of Wellington

2013 


\begin{abstract}
Hermaphroditic reef fish display remarkable diversity in mating strategies, social structure, and the timing of sex change. Understanding spatial variation in reproductive ecology and physiological condition is important in the design of marine reserve systems and fisheries management for species that change sex. I investigated patterns in reproductive ecology, condition, and the influence of the underlying physical environment, for a temperate protogynous (female first) hermaphrodite, the spotty (Notolabrus celidotus) at a small spatial scale. First, I used SCUBA surveys to visually estimate density, sex ratio, and size-frequency to describe the social structure of two populations of spotties located at either end of a $9 \mathrm{~km}$ gradient in swell exposure. I then collected individuals from both locations to estimate growth, mortality, and the timing of maturation and sex change for each population. To estimate and compare physiological stress and condition of individuals sampled from these two locations, I used otoliths to quantify fluctuating asymmetry (a measure of stress) and I compared this to other commonly used condition indices. Lastly, I estimated spatial variation in social structure and a set of environmental variables at 30 sites along a gradient of swell exposure to investigate correlations between the physical environment and the density, sex ratio, and size-frequency of spotties.

The results revealed that social structure differed markedly between two populations but not always as expected. A low ratio of males to females in sheltered Kau Bay suggested that the rate of sex change was constrained for this population (relative to Wahine Park, a more swell-exposed site, where males were more abundant in the population). Individuals from Kau Bay exhibited slower growth and higher mortality estimates, and in line with predictions of the size advantage model, females appeared to change sex at an early age and smaller size relative to Wahine Park. Contrary to expectations, however, low levels of fluctuating asymmetry suggested the population at Kau Bay was less stressed than Wahine Park, despite evidence for reduced physiological condition (Fulton's condition factor K) and high density at Kau Bay. Differences in fluctuating asymmetry between sexes and size classes suggested that sex-specific fluctuating asymmetry and stressors later in the life history are important in these populations. Furthermore, correlations between social structure and the physical environment were inconclusive and highlight the necessity for large sampling efforts.
\end{abstract}


Overall, this study concludes that availability of spawning-territory may limit the rate of sex change and influence reproductive potential in this species. This process may be applicable to other protogynous species that rely on territory-defense as a mating strategy. Sex-specific expression of fluctuating asymmetry should be considered in hermaphroditic reef fish and the impact of stressors acting on specific stages in the life history of individuals requires further investigation. Furthermore, my results suggest that condition indices and fluctuating asymmetry cannot be used interchangeably to estimate health for these populations (the metrics may provide complementary information). Overall, these results emphasise complex and variable patterns in the reproductive ecology of hermaphroditic species and my work is among the first to demonstrate such patterns over a small spatial scale. Further work can clarify questions raised in this study and benefit the conservation of hermaphroditic reef fish. 


\section{Acknowledgements}

I am deeply grateful to everybody that has provided help and support during the development of this thesis. It would not have been possible without the guidance, feedback, encouragement, and advice of my supervisor, Jeff Shima. Thanks Jeff, for allowing me the freedom to chase my own goals and helping me to reign these goals back in when they got out of control. Your advice has kept me on track and working at VUCEL and with you has been an amazing opportunity for me. Simon Lamping, you have supported me constantly throughout this whole project. Thank you for help with fieldwork, help with lab work, comments on written work, for dinner, lunch, pep talks, moving my house (twice), and especially for your patience. You have been amazing. Thanks also to mum for taking time to critique chapter drafts near the end. Shane Geange, Paul Mensink, Abi Powell, Daniel McNaughtan, Max Schofield, and Jeannine Fischer also provided comments on my written work and I am very grateful. Thank you Shane, Paul, Cesar Cardenas, Natalie Renier, Steve Jenkins, Simon, and Daniela Guisado for fieldwork support and for never (completely) losing morale in the Wellington weather. Shane and Paul especially, thank you for all your help in a number of different aspects of this thesis. I am grateful to Snout for constantly providing logistical advice on diving, fieldwork, and lab work. Everyone in the Shima-lab provided ideas and advice during the development of my sampling designs and I would particularly like to thank Shane for introducing me to $\mathrm{R}$ and giving me advice on statistics. I would also like to thank John for boating and technical help and everyone at VUCEL (and the VUCEL bbq) for making my time here such an awesome experience. A number of friends have been supportive in more ways than I can list and I appreciate the help from all of you. Thank you Brendon and Oliver.

Finally, I would like to thank my family. Mum, Dad, Jesse, Sandra, John, Maggie, Indi - you guys rock. You have been a constant source of inspiration, entertainment, and love. I'm here because of all of you. Thank you, and rock on.

I received two scholarships that greatly supported me during my MSc degree: the Victoria Graduate Award and Victoria Master's (by thesis) Scholarship. Research costs for my work were supported by VUW, and with additional grants from Marsden (to J. Shima) and MBIE (a collaboration between NIWA and J. Shima). 


\section{Table of Contents}

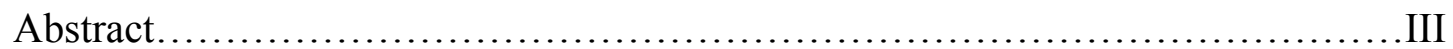

Acknowledgments...................................................

List of Figures...........................................................

List of Tables...............................................................

List of Appendices.........................................................

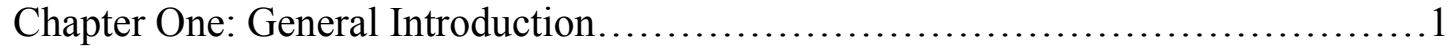

Chapter Two: Variation in social structure and life history of Notolabrus celidotus at a small spatial scale

2.1 Introduction.................................................. 9

2.2 Methods........................................................ 11

2.3 Results..........................................................

2.4 Discussion.......................................................... 31

Chapter Three: Fluctuating asymmetry and condition of Notolabrus celidotus at a

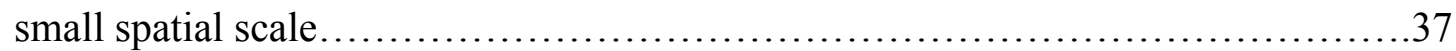

3.1 Introduction.......................................................

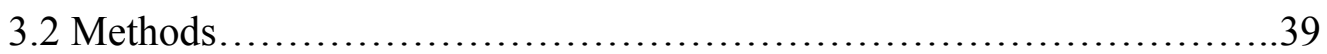

3.3 Results....................................................... 44

3.4 Discussion.................................................... 59

Chapter Four: Environmental drivers of variation in social structure of populations of

Notolabrus celidotus .......................................................65

4.1 Introduction...................................................65

4.2 Methods........................................................67

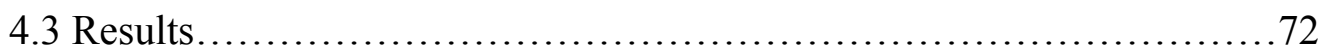

4.4 Discussion................................................. 77

Chapter Five: General Discussion....................................... 81

5.1 Summary of findings.............................................. 81

5.2 Future directions............................................... 85

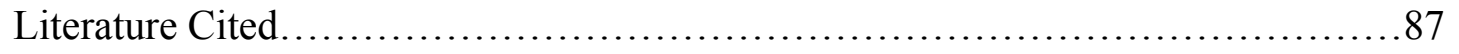

Appendix............................................................. 101 


\section{List of Figures}

Figure 1.1: The size advantage hypothesis (printed in Munday et al. 2006) showing (a) conditions for protogyny and (b) conditions for protandry .3

Figure 1.2: Sexual dimorphism in spotties (Notolabrus celidotus) showing (a) the initial phase (female) with a dark lateral spot and (b) the terminal phase (male) with dorsal barring pattern (Francis 2001) ........................................ 8

Figure 2.1: Position of study sites, Kau Bay and Wahine Park, on Miramar Peninsula in Wellington Harbour. Kau Bay is on the north shore of Miramar Peninsula and is protected from southerly wind and swell. Wahine Park is at the harbour entrance and is exposed to southerly wind and swell 13

Figure 2.2: Annual rings of a sagittal otolith from a spotty (Notolabrus celidotus) collected in this study. Red circles indicate the completion of one annual ring. One annual ring includes one opaque and one translucent band. This individual was female and estimated to be four years old.

Figure 2.3: Size-frequency distribution of spotties (Notolabrus celidotus) observed on surveys at Kau Bay (black bars) and Wahine Park (grey bars). Twenty-four surveys split evenly between 4 depths $(3,6,9,12 \mathrm{~m})$ were conducted on SCUBA at each site during the spawning season. Numbers.

Figure 2.4: Proportion of juvenile (hatched), initial phase (black), and terminal phase (grey) spotties (Notolabrus celidotus) observed at four depths from (a) Kau Bay and (b) Wahine Park. The total number of individuals observed at each depth is given above each bar. At Kau Bay.... 22

Figure 2.5: (a) Mortality and (b) survivorship estimates with 95\% confidence intervals for spotties (Notolabrus celidotus) from Wahine Park and Kau Bay. Mortality (Z) was estimated as 0.74 at Wahine Park and 1.14 at Kau Bay. The upper limit at Wahine Park

Figure 2.6: Von Bertalanffy growth function fitted for spotties (Notolabrus celidotus) from Kau Bay (black line) and Wahine Park (grey line). Growth appears to be slower 
at Kau Bay initially but the function reaches a higher mean asymptotic length than at Wahine Park

Figure 2.7: Average length- ( $\pm 1 \mathrm{SE})$ at-age for spotties (Notolabrus celidotus) from Wahine Park (grey) and Kau Bay (black). Fish are significantly smaller at Kau Bay at age 2, 3, and 4, but larger at Kau Bay at age six. Age classes 1 and 5 are missing due to insufficient sample sizes. .28

Figure 2.8: Proportion of spotties (Notolabrus celidotus) that were juvenile (black bars), initial phase females (dark grey), initial phase males (hatched), and terminal phase males (light grey) in each age class at (a) Wahine Park and (b) Kau Bay. The total number of individuals in each age class

Figure 2.9: Total number of female (black) and male (grey) spotties (Notolabrus celidotus) caught in each size class from (a) Kau Bay and (b) Wahine Park. At Kau Bay, the first males appear between $135 \mathrm{~mm}-144 \mathrm{~mm}$ and females are observed in size classes up to $215 \mathrm{~mm}-224 \mathrm{~mm}$. At Wahine Park .30

Figure 3.1: Boxplots showing outliers in the unsigned (absolute) distribution of residual fluctuating asymmetry (FA) indices measured in otoliths of spotties (Notolabrus celidotus) collected from Wahine Park and Kau Bay. FA did not differ significantly between sites, but there .50

Figure 3.2: Boxplots showing the unsigned (absolute) distribution of residual fluctuating asymmetry (FA) indices measured in otoliths of spotties (Notolabrus celidotus) collected from Wahine Park and Kau Bay. FA does not differ significantly between sites but there is a non-significant trend.

Figure 3.3: Linear least-squares regression between fluctuating asymmetry (FA) and Fulton's condition factor $(\mathrm{K})$ for 4 variables of otolith size: perimeter $(\mathrm{P}=0.007)$, axis (major) showing 3 outliers in far right of the distribution $(\mathrm{P}=0.1)$, axis (minor) $(\mathrm{P}=0.02)$, and weight $(\mathrm{P}=0.001)$. FA is measured

Figure 3.4: Linear least-squares regression between condition $(\mathrm{K})$ and fluctuating asymmetry (FA) in area showing (a) relationship with outlier $(\mathrm{P}=0.07)$ and $(\mathrm{b})$ 
relationship after the outlier is removed $(\mathrm{P}=0.01)$. FA is measured in otoliths of spotties (Notolabrus celidotus). The relationship is positive.

Figure 3.5: Linear least-squares regression between condition $(\mathrm{K})$ and fluctuating asymmetry (FA) in axis (major) after three outliers were removed $(\mathrm{P}=0.07)$. FA is measured in otoliths of spotties (Notolabrus celidotus). There is a positive relationship between FA and condition $(\mathrm{K})$.

Figure 3.6: Boxplot showing the distribution of Fulton's condition factor (K) measured in spotties (Notolabrus celidotus) at Kau Bay and Wahine Park. The bold horizontal line indicates the median value of $\mathrm{K}$ at each site. The top and bottom of each box show the first and third quartiles .55

Figure 3.7: Scree plot for a principal components analysis incorporating 5 variables of fluctuating asymmetry measured in otoliths of spotties (Notolabrus celidotus). Bars indicate the relative importance of each principal component. The first three together explain $85 \%$ of the variation present

Figure 3.8: Loadings of each variable of fluctuating asymmetry (FA) along the first two principal components. The principal components analysis (PCA) incorporated 5 variables of FA measured in otoliths of spotties (Notolabrus celidotus). The first principal component (Comp. 1) explains 51.78\% .58

Figure 3.9: Fluctuating asymmetry (FA) in otoliths collected from spotties (Notolabrus celidotus) showing (a) extreme FA between otoliths from an outlier collected at Kau Bay and (b) directional asymmetry between two otoliths from an individual collected at Wahine Park that was missing

Figure 4.1: Exposure gradient extends along the east coast of the Miramar Peninsula at the Wellington Harbour entrance. Kau Bay is situated inside the harbour while Palmer Head is on the exposed south coast. Thirty study sites were place randomly between Kau Bay and Palmer Head. An extended

Figure 4.2: Linear least-squares regression between density of spotties (Notolabrus celidotus) and the four environmental variables location, temperature, substrate 
(Substrate1; principal component one) and substrate holder (Holder1; principal component one) indicating the presence of an outlier (at top of all plots)

Figure 4.3: Loadings from principal components analysis (PCA) of 5 substrate variables (sand, gravel, cobble, boulder, bedrock) along the first two principal components axes. The first principal component (Comp. 1) explains 62\% of the variation and the second principal 75

Figure 4.4: Loadings from principal components analysis (PCA) of substrate holder variables along the first two principal components axes (crustose coralline algae, fleshy red algae, bare rock, sand, or sand/shall/gravel where no substrate holders dominate the substrate, and a selection.................................... 76

Note: some captions are abbreviated from that in the figure 


\section{List of Tables}

Table 2.1: Average density (per $100 \mathrm{~m}^{2}$ ) of initial and terminal phase spotties (Notolabrus celidotus) observed at four depths from Wahine Park and Kau Bay. Observations are from 24 transects conducted on SCUBA that were split evenly between 4 depths $(3,6,9,12 \mathrm{~m})$ at each site and. .20

Table 2.2: AICc, $\triangle \mathrm{AIC}$, AIC weight, and log-likelihood of each model possible for describing differences in the growth parameters $t_{0}, L_{\infty}$, and $\mathrm{K}$ fitted from the von Bertalanffy growth function for spotties (Notolabrus celidotus) at Wahine Park and Kau Bay. The best-fit model (shown in bold). .25

Table 2.3: Estimated growth parameters $\mathrm{L}_{\infty}, \mathrm{K}$, and $\mathrm{t}_{0}$ from the von Bertalanffy growth function fitted for spotties (Notolabrus celidotus) from Wahine Park and Kau Bay. The mean asymptotic length $\left(\mathrm{L}_{\infty}\right)$ is higher at Kau Bay, and the growth rate coefficient $(\mathrm{K})$ and hypothetical.

Table 2.4: Results of the Kruskal-Wallis non-parametric ANOVA for mean length-atage of spotties (Notolabrus celidotus) from Wahine Park (WP) and Kau Bay (KB). The sample size (n) of each age class is given for each site. Mean length is significantly smaller.

Table 3.1: Relationship between fluctuating asymmetry (FA) and trait-size of otoliths from spotties (Notolabrus celidotus) collected from Wahine Park and Kau Bay. Pvalues and rho are calculated from Spearman's Rank Correlation Coefficient for five variables of otolith size: area, perimeter.

Table 3.2: Skew in the distribution of fluctuating asymmetry (FA) values measured in otoliths of spotties (Notolabrus celidotus) for five variables of otolith size: area, perimeter, axis (major), axis (minor), and weight. Otoliths were collected from two sites, Kau Bay and Wahine Park, and skew

Table 3.3: Kurtosis in the distribution of fluctuating asymmetry values measured in otoliths of spotties (Notolabrus celidotus) for five variables of otolith size: area, 
perimeter (Perim), axis major (Amj), axis minor (Amn) and weight (W). Otoliths were collected from two sites, Kau Bay and Wahine.

Table 3.4: Results from one sample t-tests for the mean of fluctuating asymmetry values measured in otoliths of spotties (Notolabrus celidotus). Five variables were measured for asymmetry: area, perimeter (Perim), axis major (Amj), axis minor (Amn) and weight (W). Samples were. .47

Table 3.5: Variance components computed from nested analysis of variance for each of five variables repeatedly measured in otoliths from spotties (Notolabrus celidotus): area, perimeter (Perim), axis major (Amj), axis minor (Amn), and weight (W) .....48

Table 3.6: Relationship between site, Fulton's condition factor $(\mathrm{K})$, and fluctuating asymmetry (FA) in the otoliths of spotties (Notolabrus celidotus). FA is measured in 5 variables of otolith size: area (a), perimeter (b), axis major (c), axis minor (d), and weight (e). Analysis of covariance was performed with

Table 3.7: Fulton's condition factor (K) measured in spotties (Notolabrus celidotus) differs significantly between two sites Kau Bay and Wahine Park (ANOVA). P-value significant at $\alpha=0.01$ is shown in bold. .55

Table 4.1: Results of multiple regression run for four response variables describing the social structure of spotties (Notolabrus celidotus): density, median size, lower size range, and upper size range. Density was.

Note: some captions are abbreviated from that in the table

\section{List of Appendices}

Appendix A: Accuracy in diver estimation of total length of fish underwater. 101

Appendix B: Analysis of variance (ANOVA) tables for nested ANOVA to assess measurement error in repeated measurements of otoliths collected from spotties (Notolabrus celidotus) 


\section{Chapter 1: General Introduction}

Hermaphroditism, whereby organisms can function as both females and males throughout their lifetime, is a natural phenomenon found across a diverse array of taxa (Policansky 1982). In the marine environment, a large number of invertebrates and teleost fishes are hermaphroditic and display a variety of sex change strategies (Policansky 1982, Warner 1975). Simultaneous hermaphrodites have the ability to reproduce as males and females at the same time, while sequential hermaphrodites start life as one sex and can change sex later in development. When individuals start life as female and change to male, they are termed protogynous hermaphrodites, while protandrous hermaphrodites start life as male and can change to female. The age or length at which individuals change sex can differ between individuals, generations, populations, and between species (Charnov et al. 1978, Munday et al. 2006). This allows hermaphroditic populations to mold their reproductive strategy and maximise reproductive output across a range of environmental and social conditions (Emlen and Oring 1977, Munday et al. 2006).

Hermaphroditic species fill a variety of economically and ecologically important roles. Worldwide, a large number of commercial and artisanal fisheries species are hermaphroditic (e.g. Ellis and Powers 2012, Hawkins and Roberts 2004, Kleczkowski et al. 2008, Lloret et al. 2012). In many ecosystems, protogynous reef fish are important predators (e.g. Hamilton et al. 2011, Pérez-Matus \& Shima 2010a), agents of bioerosion (Ong \& Holland 2010), herbivores (e.g. Kopp et al. 2010), and ectoparasite 'cleaners' (Cole 2010, Robertson 1972). Considering these roles, conserving the diversity of hermaphroditic species is important for maintaining productive fisheries stocks and a variety of balanced ecosystems worldwide. Hermaphrodites, however, may respond differently to marine reserve protection relative to their non-sex-changing counterparts, or gonochores (Chan et al. 2012, Mumby 2006). A thorough understanding of the reproductive biology and ecology specific to hermaphrodites is an important component of fisheries stock modeling (Alonzo et al. 2008, Caselle et al. 2011) and marine reserve design (Afonso et al. 2008). As the expression of sex change can vary considerably across species and among populations within species (Munday et al. 2006), case-specific knowledge of 
reproductive biology and ecology will be important in shaping conservation of hermaphrodites.

The leading theory regarding the evolution of sex change is termed the size advantage model or hypothesis (Ghiselin 1969, Warner 1975). First coined by Ghiselin (1969), this theory suggests that sex change might evolve in populations if the reproductive success of individuals was maximised at different sizes for each sex (Figure 1.1). Individuals would be able to maximise their reproductive output by taking advantage of this mismatch between reproductive success, size and sex, by reproducing first as the sex that reproduces most successfully when small and then switching to reproduce secondly as the sex that achieves higher reproductive success when large (Warner 1975, 1988, Figure 1.1). In this case, protandry would be favoured when female fecundity increased rapidly with size and mating was random with respect to size, whereas protogyny would be favoured if some factors acted to reduce male fecundity at a small size, such as inexperience, mate selection, and territoriality or dominance (Warner 1975; Figure 1.1).

The first mathematical simulations of the size advantage model assumed that the timing of sex change was genetically determined for a species (Warner 1975); however, accumulating evidence suggests that genetically connected populations display clear differences in the timing of sex change, refuting this assumption (Gust 2004; Munday et al. 2006). Despite this, the size advantage model can be used to predict the optimum age or length at sex change for individuals (Charnov 1979, 1982; Leigh et al. 1976; Warner et al. 1975). Incorporating the reproductive value of an individual, or its future expectation of reproductive success weighted by survival, explains how individuals can vary from one another in the timing of sex change (Warner 1988). The optimum size at sex change is determined when the reproductive value of the other sex begins to increase more rapidly than it does for its own sex (Figure 1.1; Warner 1988). 
(a)

(b)

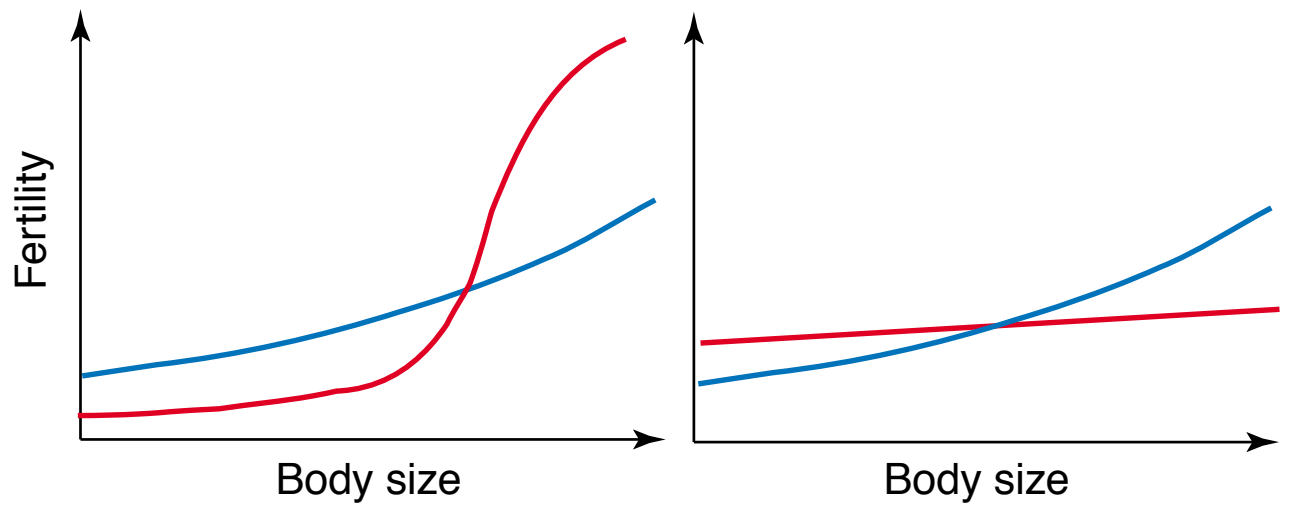

Figure 1.1: The size advantage hypothesis (printed in Munday et al. 2006). Sex change is predicted to be favoured in populations if the reproductive success of an individual is best achieved at a specific size for a specific sex. Individuals can maximise reproductive output by reproducing first as the sex that achieves greater reproductive success at a small size, and reproducing second as the sex that achieves greater reproductive success by being large. (a) Female fitness (blue line) increases more slowly than male fitness (red line) with respect to body size; protogynous sex change is favoured and is predicted to occur when these two lines intersect. (b) Male fitness (red line) increases more slowly with size than does female fitness (blue line) indicating there is a smaller advantage to being a large male; protandrous sex change is favoured and is predicted to occur where these two lines intersect.

The reproductive value of an individual inherently depends on the fecundities of others in the reproductive population, as this determines the frequency of mating opportunities and the number of eggs fertilised. Changes to the social structure of the population, such as sex ratio, size-frequency (as size is related to fecundity), and density, should alter an individual's reproductive value, and manifest as differences in the expression of sex change. The influence of social structure on the expression of sex change has been documented for a wide variety of species (McCormick et al. 2010, Munday et al. 2006, Muñoz and Warner 2003a, Robertson 1972, Sakai 1997, Shapiro 1987, Warner 1982). Populations of the bluehead wrasse display a remarkable example of socially mediated sex change. At low density, mating opportunities are monopolised by a dominant male, sex ratio is skewed towards females, and there is rarely overlap in the size-frequency distribution of males and 
females (Warner and Hoffman 1980). As density increases, more individuals start to change sex to male at smaller sizes and younger ages, the sex ratio becomes much less skewed, and overlap in the size-frequency of males and females increases (Warner and Hoffman 1980). The authors suggest this is because the reproductive success of small males increases at high density when large dominant males have difficulty defending mating events (Warner and Hoffman 1980).

Considering reproductive value and social structure also helps to explain situations where sex change is predicted but does not appear to occur (Muñoz and Warner 2003b). Due to the nature of protogynous sex change the largest fish are typically male (Warner 1975, Warner et al. 1975) and the size advantage model falls short of explaining populations that have a few large females and many small sex changed males (Muñoz and Warner 2003b). Muñoz and Warner (2003b) showed how a process they termed size-fecundity skew could explain why large females might defer sex change. They explained that if a large skew in the fecundity of females exists, which can occur if a female is large relative to others in the population, then the situation may arise where the fecundity of a large female is greater than the combined fecundities of all other females in the population. In this case, the future reproductive success of a large female would not be increased by changing sex, but would be increased if a smaller female changed sex (Muñoz and Warner 2003b). This would result in large females deferring sex change and small females changing sex instead. Size-fecundity skew is suggested to exist in populations of Caribbean parrotfish (Muñoz and Warner 2004) and the New Zealand butterfish (Trip et al. 2011b).

In addition to the social structure of a population, an assessment of reproductive value requires an individual to evaluate its own fecundity and expected survivorship. As such, sex change is linked to, and varies with, traits such as growth, maturation, and mortality (Warner 1975). The size advantage model predicts that sex change will occur earlier in populations characterised by high mortality, slow growth, or both (Warner 1975, Warner 1988). This trend is also supported in the literature (Cowen 1990, Hamilton et al. 2007, Jones 1980, Schärer and Vizoso 2003). In the Great Barrier Reef, researchers compared populations of parrotfish between outer and inner reefs and showed that high mortality on the outer reef was associated with slow growth and early sex change compared to the inner reef where growth was faster, mortality was lower, and sex change was delayed (Gust 2004, Gust et al. 2002). 
Growth, maturation, sex change, and mortality are all traits that describe an individual's life history (Stearns 1976). The development of life history traits is driven by the distribution or availability of natural resources, such as food, shelter, and spawning grounds (Stearns 1976, 1977). Resource limitation and other environmental stressors can alter growth and mortality rates with clear implications for sex change (Emlen and Oring 1977) and the physiological condition of individuals (Sutton et al. 2000). Classic condition indices relate the length and weight of an individual to produce a standardised measure that is thought to reflect physiological condition (Sutton et al. 2000). An alternative method is to investigate fluctuating asymmetry, which is thought to reflect condition or health (Palmer 1996) and fitness (Bjorksten et al. 2000, Clarke 1995, Møller 1994). Fluctuating asymmetry refers to developmental asymmetry in naturally symmetrical traits and is correlated with resource limitation in juvenile fish (Grønkjaer and Sand 2003, Somarakis et al. 1997). However, it is not known if environmental stressors that result in asymmetry and reduced physiological condition also give rise to specific life histories in hermaphroditic fish, such as slow growth, high mortality, and early sex change. If this is true, fluctuating asymmetry and condition indices can be used to infer the quality and fitness of a particular life history. An in depth literature review revealed no studies between life history and fluctuating asymmetry for hermaphroditic species.

Social structure (density, size-frequency, and sex ratio) can also be shaped by external factors such as habitat composition, availability, and continuity, the temporal and spatial distribution of resources, and even geographic location (Emlen and Oring 1977, Robertson and Warner 1978). For example, when seagrass is available as habitat for populations of parrotfish, it is expected to increase the reproductive success of small males engaging in sperm competition (Robertson et al. 1982). Sperm competition is an alternative male tactic and occurs when non-territorial males interfere with mating events between a dominant male and female by either 'streaking' in to release sperm during the apex of a spawning event or 'sneaking' to induce females to spawn that are awaiting their chance to mate with the dominant male (Warner et al. 1975). Seagrass may offer additional cover for males engaging in sperm competition, and by increasing the reproductive value of small males, alter the social structure of the population as well as the sex change schedules and life histories of individuals (Robertson and Warner 1978). Investigations of the relationship between variation in sex change schedules and aspects of habitat or resource 
availability are "badly needed" (Robertson and Warner 1978) but rare in recent literature. Papers that have examined sex change and environment indicate that the relationship between the two is important (Breitburg 1987, Wong et al. 2005).

This thesis investigates issues related to sex change in a temperate protogynous hermaphrodite, Notolabrus celidotus, commonly known as the spotty. Spotties are endemic, abundant, and widespread in coastal New Zealand waters and are associated with rocky (Anderson and Millar 2004, Jones 1981, 1984a, Schiel and Hickford 2001) and sandy (Schiel and Hickford 2001) substrates. They are a demersal and diurnal species (Pankhurst 1989) that forages generally on small percarid crustaceans, bivalves, crabs, ophiurids, and urchins with diet preference shifting with ontogeny (Jones 1984b). Juveniles recruit to shallow algal habitats (Jones 1984b) and expand their home ranges as they grow (Jones 1984a). Spotties display sexual dimorphism. Juveniles and females have a large dark lateral spot (the initial phase) that is traded by males for a dorsal barring pattern (the terminal phase; Choat 1965; Figure 1.2). Some males can retain the initial phase colour pattern, while females displaying the terminal phase colour pattern have never been caught (Choat 1965, Jones 1980). As an abundant predator and crucial link in coastal food chains (PérezMatus and Shima 2011a) spotties are an important component of ecosystems around New Zealand. Furthermore, as spotties are not a major target of fisheries, patterns in reproductive ecology and distribution are unlikely to be altered from original states by anthropogenic influence to the extent that many fisheries species are affected. For these reasons, they are an ideal model species for investigating natural variation in social structure, sex change, and condition, which is important in fisheries modeling and marine reserve design. Spotties exhibit variation in social structure and the timing of life history traits between Leigh in the north of the North Island and Wellington in the south of the North Island (Jones 1980), but estimates of these traits are not available at a smaller spatial scale.

In this thesis, I investigate social structure, life history traits, classic condition indices and fluctuating asymmetry to determine how these vary across a small spatial scale in two populations of spotties, and follow with an investigation of the environmental drivers of variation in social structure. This thesis is split into five chapters.

Chapter two focuses on social structure and life history traits. In this chapter, I estimate density, sex ratio, and size-frequency to describe differences in social 
structure between two populations of spotties separated by roughly 9 kilometres. In addition, I evaluate growth, maturation, mortality, and the age and length at sex change, and compare these to predictions made by the size advantage model. Examining populations separated by only 9 kilometres presents a small scale investigation of life history traits relative to the scales over which fisheries operate and marine reserves are expected to have influence.

In chapter three, I use the same specimens collected in chapter two to investigate how differences in life history are reflected in the health and condition of the population. I estimate classic condition indices and a measure of fluctuating asymmetry to assess condition and fitness, and discuss the usefulness of these methods for adult sex changing populations.

Chapter four focuses on the environmental drivers of variation in social structure. In this chapter, I assess the density, sex ratio, and size-frequency of spotties at multiple sites along the Wellington Harbour entrance, and compare these to variation in habitat composition and complexity, substrate type, geographic location, and density of other fishes.

The following chapters have been written as independent scientific papers. There may be some repetition between subsequent chapters and this general introduction. All data was approved and collected in accordance with animal ethics policy of Victoria University. 
a.

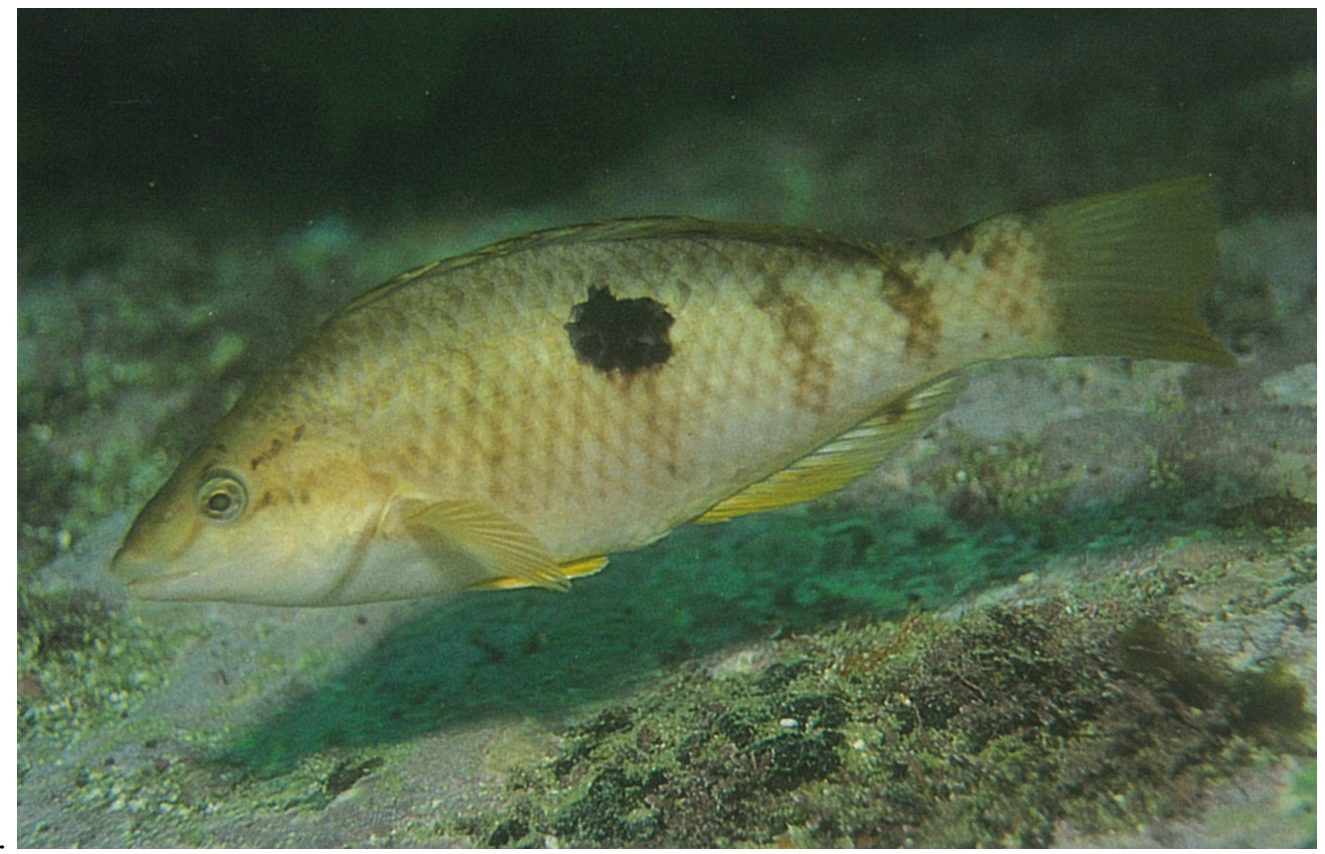

b.

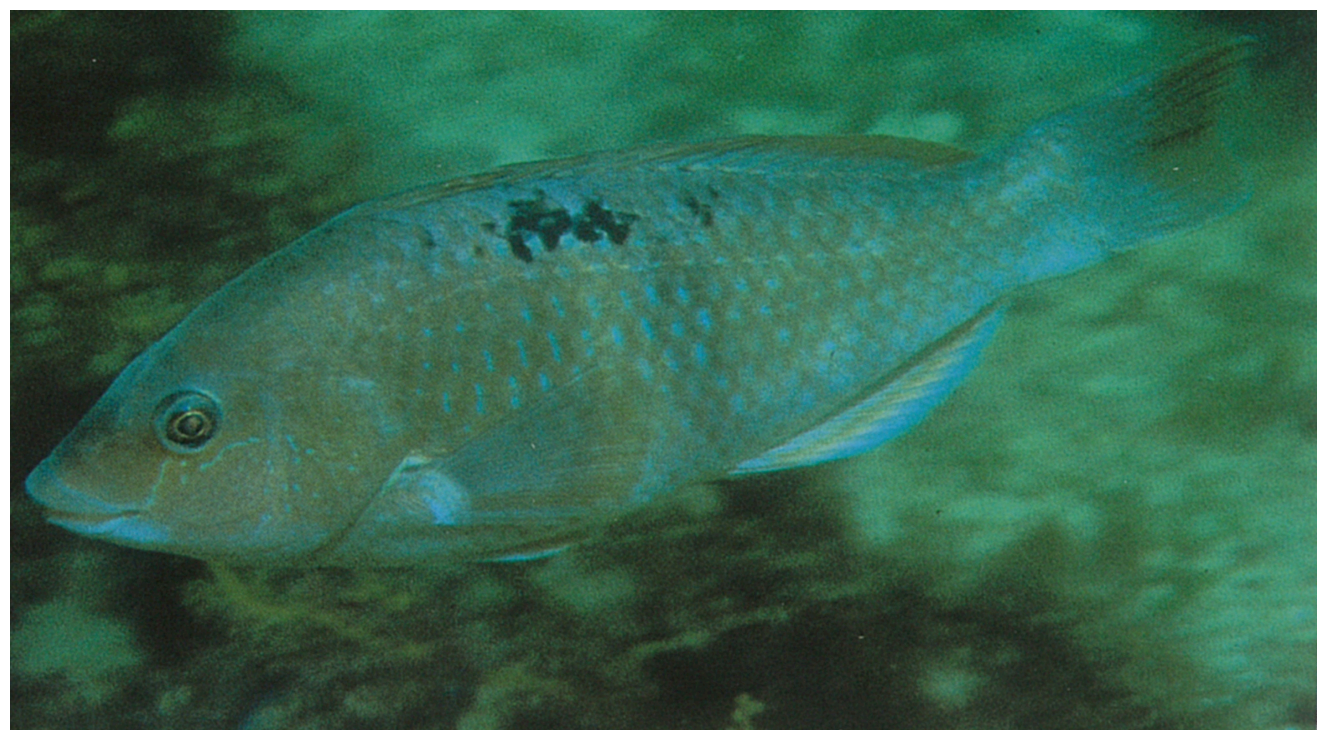

Figure 1.2: Sexual dimorphism in spotties (Notolabrus celidotus) showing (a) the initial phase (female) with a dark lateral spot and (b) the terminal phase (male) with dorsal barring pattern (Francis 2001). 


\section{Chapter 2: \\ Variation in social structure and life history of Notolabrus celidotus at a small spatial scale}

\subsection{INTRODUCTION}

Growth, maturation, and mortality, are examples of life history traits (Stearns 1976). Although a genetic basis underlies the development of these traits, the phenotypic expression of life history traits is remarkably plastic (Scheiner 1993). Phenotypic plasticity allows for local adaptation of traits to specific environmental conditions and results in population-specific life history tactics (Stearns 1976, 1977). Fish, in particular, are known for a remarkable diversity of life history tactics (Stearns 1977). In the typically unstable marine environment, phenotypic plasticity is predicted to benefit organisms by maximising survivorship and reproductive output in the face of constantly changing and unpredictable conditions (Pigliucci 2001, Warner 1991). As a result, species can exhibit strong inter-population differences in growth rate, the timing of maturation, and mortality rate across spatial scales as small as tens of kilometres or less (Clifton 1995, Gust et al. 2002), to hundreds of kilometres (Cowen 1990, Hamilton et al. 2007), and up to thousands of kilometres (Sala-Bozano and Mariani 2011, Williams et al. 2007).

Variation in life history traits within small spatial scales is important; however, large-scale investigations of life history traits, such as those that obtain data from fisheries, tend to overlook variation present across smaller distances (Gust 2004). Failure to take into account small scale variation can confound estimates of growth, maturation, and mortality, which are often used to infer the effects of fishing (Gust 2004, Russ 1991) and are frequently used in conservation biology monitoring programs (Clarke 1995). Moreover, estimates of life history traits provide the basis for fisheries modeling and the fisheries management that develops from these models is frequently applied to fisheries stocks at a large spatial scale, while overlooking differences between individual populations (Williams et al. 2007). This can lead to over-fishing of some populations, and fishing below the maximum yield at others (Williams et al. 2007). Therefore, an understanding of the natural variation of life history traits across small spatial scales may be important to the success of fisheries management and conservation biology (Gust 2004). 
Many fish species of recreational and commercial interest are hermaphroditic. Populations of hermaphroditic species can respond differently to fishing pressure or marine reserve design than populations of gonochoristic species (Chan et al. 2012, Mumby 2006). As a number of fisheries species are hermaphroditic (Brulé et al. 2003, Carbines 2003, Clua and Legendre 2008, DeMartini et al. 2010, Pinca et al. 2012, Trip et al. 2011a), the timing of sex change is a life history trait that needs to be considered when designing fisheries management (Alonzo et al. 2008, Caselle et al. 2011) and marine reserves (Afonso et al. 2008, Chan et al. 2012). However, studying natural variation in the timing of sex change across small spatial scales is made difficult by the already present impacts of fishing observed in the life histories of many populations (Gust 2004, Hamilton et al. 2007). Accordingly, this study examines natural patterns of variation at a small spatial scale in an unexploited protogynous hermaphrodite, the spotty (Notolabrus celidotus), as a model for natural variation in life history traits.

Small scale variation in life histories of hermaphrodites is driven by plasticity in the timing of sex change for a number of species (Munday et al. 2006). The size advantage model is the most widely accepted hypothesis used to predict variation in the timing of sex change (Ghiselin 1969, Warner 1975). It states that the optimum time for sex change will be when the reproductive success of an individual increases more rapidly for the other sex than for its present sex (Warner 1988, Chapter 1). As reproductive success is sensitive to growth, maturation, and mortality, changes in these traits are expected to influence the timing of sex change (Warner 1988). Specifically, populations characterised by slow growth, high mortality, or both, are predicted to experience early maturation and sex change, whereas longer-lived populations under low mortality regimes are expected to delay sex change (Warner 1975, 1988). Hamilton and colleagues (2007), for example, showed that populations of California sheephead subjected to high fishing pressure exhibited sex change and maturation at a smaller size and younger age relative to populations under less fishing pressure, while Gust (2004) found that two species of parrotfish under high natural mortality rates on outer reefs exhibited slower growth (Gust et al. 2002) and early maturation and sex change relative to populations on inner reefs with lower mortality.

As the timing of sex change is sensitive to the reproductive success of an individual it is also affected by social cues and can vary widely depending on the density, sex ratio, and size-frequency distribution of the reproductive population 
(reviewed in Munday et al. 2006). As a result, the social structure of a population can be used to predict changes in the timing of sex change (Muñoz and Warner 2003a). High density, for example, is frequently accompanied by early sex change, a higher proportion of males to females, and an overlap in the size-frequency of males and females in many wrasse (McCormick et al. 2010, Warner and Hoffman 1980, Warner and Robertson 1978) and parrotfish species (Muñoz and Warner 2003a, Robertson and Warner 1978). In addition, shifts in the social structure and the number of individuals changing sex can affect the reproductive potential of a population (Hawkins and Roberts 2003). In populations of Caribbean parrotfish, Hawkins and Roberts (2003) showed that the number of males present at some locations was so low it was unlikely that the population was self-sustaining. Investigating social structure can provide insight into the reproductive capabilities of a population.

Spotties (N. celidotus) exhibit plasticity in the timing of sex change (from female to male). Jones (1980) demonstrated that spotties from one site in Leigh in the north of the North Island changed sex at an earlier age than populations at one site in Wellington in the south of the North Island, where sex change was delayed. No further studies have investigated spatial variation in life histories of spotties. Here, I investigate natural variation at a small spatial scale by examining differences in social structure and the life history traits growth, maturation, mortality, and sex change between two populations of spotties within the Wellington region, separated by roughly $9 \mathrm{~km}$ along Miramar Peninsula. I hypothesised that 1) social structure will vary between these two populations, 2) high density will be associated with a high proportion of males to females and an overlap in the size-frequency distribution of males and females, and 3) early sex change will be related to slow growth and high mortality as predicted by the size advantage model. In addition, I expect to find that maturation is delayed when growth is slow or density is high as shown by Jones (1980) and Jones and Thompson (1980) for spotties.

\subsection{METHODS}

\subsubsection{Study species}

Spotties are protogynous (change sex from female to male) hermaphrodites (Jones 1980) and display sexual dimorphism. The initial phase (female) is white with 
a dark lateral spot that is lost following sex change (Choat 1965, Chapter 1). Terminal phase spotties (male) develop a dorsal barring pattern (Choat 1965) and some males can retain the initial phase colour pattern (Jones 1980). Individuals display ontogenetic shifts in habitat preference, with juveniles displaying a strong preference for dense algal habitat (Jones 1984b) and adults developing larger home ranges over rocky substrate (Jones 1984a). Hickford and Schiel (2001) suggested that adult spotties are abundant over sandy substrate also. Spotties are not a major target of any fishery but are often caught and collected by line fishing from popular wharves about Wellington City (personal observation). The spawning season starts in July and can continue as late as December (Jones 1980). New recruits begin to enter the population in December (Jones 1980). Their reproductive strategy is described as "resource defense polygyny" (Jones 1981) whereby males defend a resource critical to females (Emlen and Oring 1977). For spotties, this resource is desired spawning territory, characterised by a rocky area with central algal cover and a boulder (Jones 1981). Sex change occurs from November to May (Jones 1980). The change in colour pattern follows sex change and can take up to two months (Jones 1980). As there is no evidence to suggest regional genetic differentiation (Scott 2010), I assume that populations in this study are strongly connected by gene flow.

\subsubsection{Study sites}

This study was conducted at two sites on Miramar Peninsula: one site within the harbour (Kau Bay) and one located at the harbour entrance on the south coast (Wahine Park). These two sites represent contrasting extremes on an environmental gradient related to swell exposure, with the south coast frequently experiencing swells

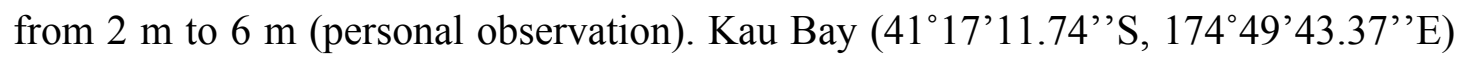
is a sheltered north facing site on the northern shore of Miramar Peninsula and is protected from southerly wind and swell (Figure 2.1). It is comprised of shallow sandy habitat, which slopes gently towards the shipping channel. The only hard benthic substrate is a small rocky reef that runs parallel to shore at depths of about 1 $5 \mathrm{~m}$, and is densely covered with Carpophyllum maschalocarpum, and sparsely with

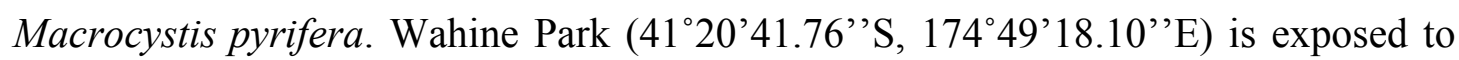
southerly wind and swell (Figure 2.1). The benthic substrate consists of bed rock and boulder, and is covered with a variety of algal species of which M. pyrifera, Lessonia variegata, Ecklonia radiata, and C. maschalocarpum are most abundant. Crustose and 
coralline algae are also common in this area. Wahine Park is deeper than Kau Bay with rocky reef extending quickly to $15 \mathrm{~m}$. These study sites occur farther east than a south coast site at Island Bay originally investigated by Jones (1980). I chose these two sites over reinvestigating the population originally studied by Jones (1980) as they are closely situated but experience strongly contrasting environmental conditions. Furthermore, Jones (1980) pooled Wellington samples from Island Bay and Makara, a site $30 \mathrm{~km}$ to the north and sheltered from southerly swell, where he sampled when the weather prevented his team from accessing Island Bay. Thus, his results may not explicitly characterise Island Bay.

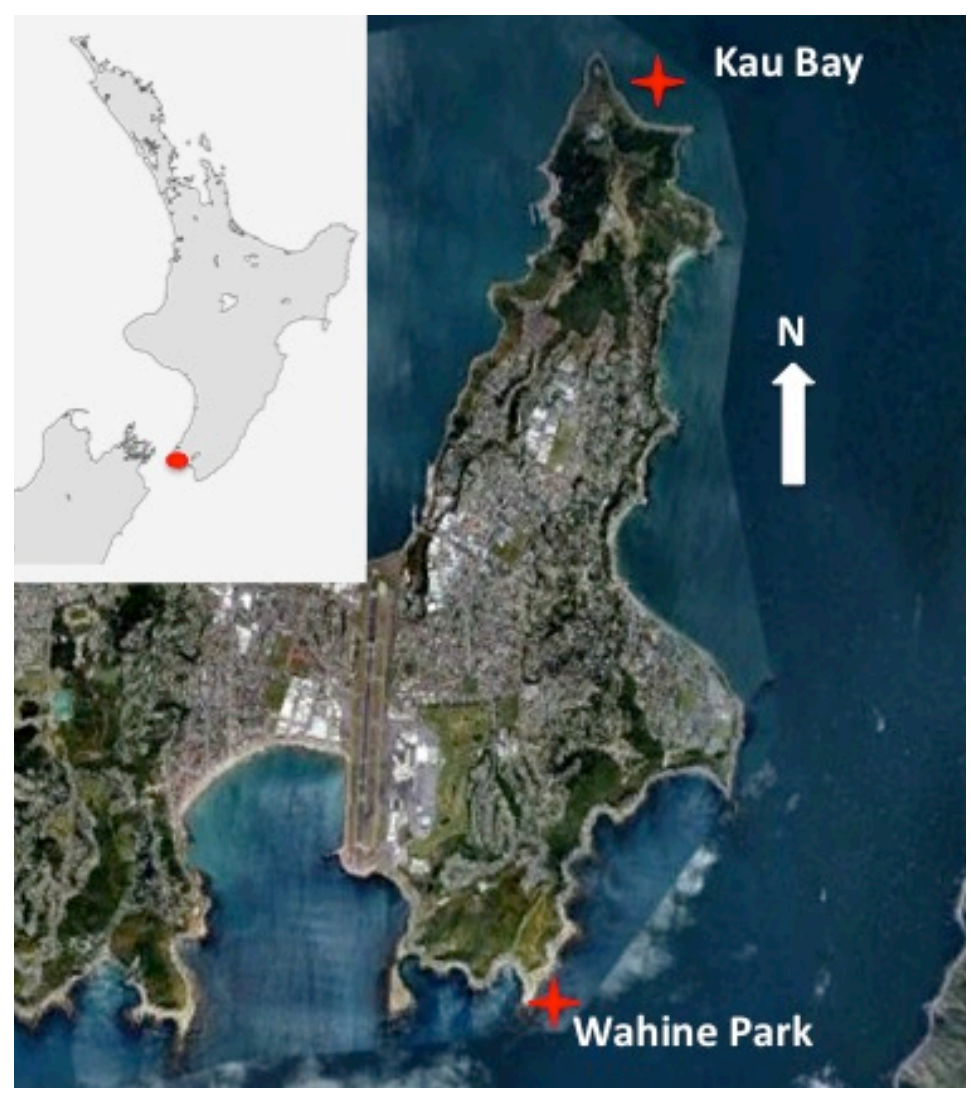

Figure 2.1: Position of study sites, Kau Bay and Wahine Park, on Miramar Peninsula in Wellington Harbour. Kau Bay is on the north shore of Miramar Peninsula and is protected from southerly wind and swell. Wahine Park is at the harbour entrance and is exposed to southerly wind and swell. Location of Miramar Peninsula in the North Island is shown in the upper left corner. 


\subsubsection{Social structure}

In October 2011, I conducted underwater surveys to assess the social structure (density, sex ratio, and size-frequency) of the population of spotties at each Kau Bay and Wahine Park. Surveys took place near the end of the spawning season and preceding the sex change season. Twenty-four $30 \times 2 \mathrm{~m}\left(60 \mathrm{~m}^{2}\right)$ transects were conducted on SCUBA at each site, with 6 transects at each of 4 depths $(3,6,9,12 \mathrm{~m})$. These depths were chosen to encompass ontogenetic shifts in depth distribution (Choat 1965, Denny 2005, Jones 1980, 1984a, Pérez-Matus and Shima 2010b, Willis and Anderson 2003). Surveys were split evenly at each depth between the author and one other diver. For each transect, the scuba diver visually estimated the total length of all spotties (to the nearest $10 \mathrm{~mm}$ ), and classified individuals as initial or terminal phase (based on the colour pattern, see Study species above). To determine the accuracy of visual estimations of total length, each diver also estimated the total length of plastic fish of known size. I used linear least-squares regression to fit the estimated data to known values. Estimates of total length closely matched known data for both myself and the other diver $\left(\mathrm{R}^{2}=0.981\right.$ and $\mathrm{R}^{2}=0.975$ respectively; Appendix A).

\subsubsection{Sex change and related life history traits}

I collected spotties from Wahine Park and Kau Bay during the austral summer $2011-2012$ in order to evaluate growth, age at maturation, age and length at sex change, and mortality. I used a combination of fishing methods (line fishing, bait trapping, and gillnetting) to ensure I captured a minimum of 15 individuals from each demographic (juvenile, mature initial phase, terminal phase). At Wahine Park, juveniles were rare and only 3 were caught. Maturity is assumed to occur at $130 \mathrm{~mm}$ total length (see 2.2.5 Data analyses - Social structure). I collected specimens from depths of $1 \mathrm{~m}-13 \mathrm{~m}$ at each site. Fish were euthanised by cold slurry immediately following capture and processed while fresh. For each fish, I recorded total length (to the nearest $\mathrm{mm}$ ) and wet weight (to the nearest $\mathrm{g}$ ) and determined sex by macroscopic examination of the gonads. Female gonads were large, rounded, and a smooth white colour. In contrast, male gonads were considerably smaller, a pale peach orange colour, and never appeared swollen as female gonads did.

To age individuals, I extracted left and right sagittal otoliths (ear stones). I cleaned otoliths with a small amount of ethanol to remove any remaining tissue, let 
them air-dry, and then stored otoliths in eppendorf tubes for later processing. I used left otoliths for age estimates and these were hand sanded to obtain a transverse section displaying annual rings from the nucleus to the outer edge of the otolith (Walker and McCormick 2004, Wilson and McCormick 1997). I set each otolith onto a slide using crystal bond. The outer margin of the otolith nucleus was aligned with the edge of the slide, with the end suspended off the slide. I then sanded the otolith down to the slide edge using 600 and 1200 grit sand paper. The crystal bond was then melted and the otolith reorientated so that the polished side lay flat against the slide and the unsanded end protruded. I then sanded and polished the protruding edge until only a thin transverse section remained, allowing a count of the annual rings to be estimated (Figure 2.2). Annual rings have been validated in spotties (Jiang 2002). I estimated the number of rings twice for each otolith, with at least 6 weeks separating readings. Where readings did not match, I took a third reading and used the age if it matched one of the previous two readings. A total of 147 otoliths were read, 86 from Kau Bay and 61 from Wahine Park. Thirty-eight otoliths required a third reading and none were subsequently excluded.

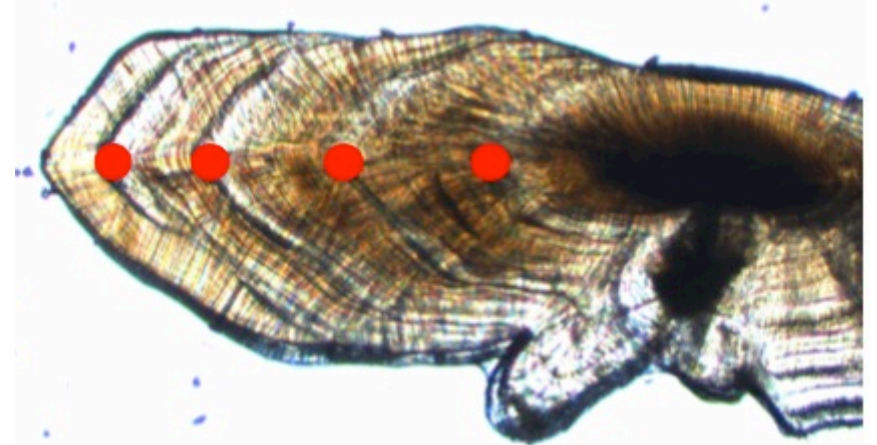

Figure 2.2: Annual rings of a sagittal otolith from a spotty (Notolabrus celidotus) collected in this study. Red circles indicate the completion of one annual ring. One annual ring includes one opaque and one translucent band. This individual was female and estimated to be 4 years old.

\subsubsection{Data analyses}

Social structure 
I evaluated density, size-frequency, and sex ratio, from survey data to describe the social structure of the populations at each site. I calculated density as the mean number of spotties recorded per transect at each depth and converted this to density per $100 \mathrm{~m}^{2}$. To compare the size-frequency distribution between sites I used a Kolmogorov-Smirnov test. I compared mean and variance with an F-test and a Welch 2-sample t-test respectively between sites.

At each site, I compared the sex ratio of mature individuals (operational sex ratio) to 1:1 using a chi-square test. I also compared the operational sex ratio between sites with a two-way contingency table chi-square test. Operational sex ratio is presented as the proportion of mature initial phase to terminal phase individuals observed at each depth and sex is assumed from the colour pattern displayed by the individual. In addition, I present the proportion of juveniles at each depth. I assumed that individuals larger than or equal to $130 \mathrm{~mm}$ were mature. Jones (1980) found maturation could not reliably be estimated from histological sections of gonads of spotties outside of the breeding season. Furthermore, Jones (1980) found that two populations of spotties, which differed with respect to growth and sex change, matured at a critical size between $105 \mathrm{~mm}-110 \mathrm{~mm}$ standard length. As I was logistically constrained from sampling during the spawning season, I instead estimated size at maturity. I conservatively selected $110 \mathrm{~mm}$ standard length as the size at maturation, and converted this to total length. To do this I used a conversion factor that I calculated from a subset of spotties between $85 \mathrm{~mm}$ and $145 \mathrm{~mm}$ for which both total length and standard length were recorded. The conversion factor (1.18) gave the total length $129.8 \mathrm{~mm}$, which I rounded to $130 \mathrm{~mm}$.

\section{Sex change and related life history traits}

I evaluated mortality, growth, maturation, and sex change from collected specimens to assess whether the timing of sex change differed between sites and was related to other life history traits as predicted by the size advantage model.

\section{Mortality}

I used the Chapman-Robson equation (Chapman and Robson 1960) to estimate mortality at each site. This equation calculates mortality from age based catch curves and can be more precise and less biased than regression methods for estimating mortality (Dunn et al. 2002). An age-based catch curve shows the 
logarithm of total catch in each age class plotted against each age class. The Chapman-Robson equation focuses on the descending limb of the age-based catch curve (where catch starts to decrease) and uses a geometric probability distribution to derive a maximum likelihood estimator for the survival parameter of the distribution (Chapman and Robson 1960). This gives an estimate of $\mathrm{Z}$, or the instantaneous mortality rate, which describes how the natural log of the number of individuals declines annually, or how the number of individuals declines instantaneously. $Z$ is converted to a more easily interpreted parameter S, annual survivorship, which describes the proportion of individuals in a population that survive each year.

In this study, I used annual age classes (1 through 9). Catch peaked at 4 years old and I excluded age classes in which no individuals were caught (age 7 and 8 at Wahine Park, age 7 and 9 at Kau Bay). The resulting estimation of mortality indicates total mortality and is the sum of fishing mortality and natural mortality. I assumed that fishing-related mortality was negligible at each site as neither site has a wharf nor is expected to be under high-fishing pressure. Thus, mortality calculations in this study are thought to estimate natural mortality. Mortality rates can differ between initial and terminal phase individuals as a result of sexual dimorphism or differences in foraging patterns and basic ecology; however, it is impossible to distinguish between mortality and sex change for initial phase individuals (Gust et al. 2002, Jones 1980). For this reason, all individuals have been pooled for mortality estimates. I computed $95 \%$ confidence intervals for $\mathrm{Z}$ and $\mathrm{S}$ at each site. All analyses were calculated in R statistical software (R Development Core Team 2012) using two packages NCStats (Ogle 2012a) and FSA (Ogle 2012b).

\section{Growth}

I estimated growth by two methods: von Bertalanffy growth function and mean length-at-age. The von Bertalanffy growth function is expressed as:

$$
\mathrm{E}[\mathrm{L} \mid \mathrm{t}]=\mathrm{L}_{\infty}\left(1-\mathrm{e}^{-\mathrm{K}(\mathrm{t}-\mathrm{t} 0)}\right)
$$

where $E[L \mid T]$ is the expected or average length at time $t, L_{\infty}$ is the asymptotic average length, and $\mathrm{t}_{0}(\mathrm{t} 0)$ is largely hypothetical and said to represent the time or age when the average length was 0 (Haddon 2001). $\mathrm{K}$ is the growth rate coefficient and has units time $^{-1}$ (Haddon 2001). I fitted the von Bertalanffy growth function to length-at- 
age data by non-linear least squares regression in $\mathrm{R}$ statistical software using the packages NCStats (Ogle 2012a), FSA (Ogle 2012b), and nlstools (Baty and Delignette-Muller 2011).

To compare the growth curves between sites I used a method of model selection that involved Akaike Information Criterion (Burnham and Anderson 1998). This information theoretic approach compares and ranks a series of hypotheses, which are each presented as a model (Anderson et al. 2001). The models are ranked and the 'best' model is identified from the accompanying AIC value, change in AIC ( $\triangle \mathrm{AIC})$, AIC weight, and log-likelihood (Anderson et al. 2001). In this study, the models represented alternative hypotheses describing which of the growth function parameters, $\mathrm{L}_{\infty}, \mathrm{K}$ and $\mathrm{t}_{0}$, differed significantly between sites. Each model hypothesised that different parameters differed significantly between sites. There were eight models: three models in which either $\mathrm{L}_{\infty}, \mathrm{K}$, or $\mathrm{t}_{0}$, differed significantly between sites; three models in which either $\mathrm{L}_{\infty}$ and $\mathrm{K}, \mathrm{L}_{\infty}$ and $\mathrm{t}_{0}$, or $\mathrm{K}$ and $\mathrm{t}_{0}$ differed significantly between sites; one model where no parameters differed significantly between sites; and one model in which all parameters differed significantly between sites. These models were ranked against one another depending on how well they fit the data. I used the second order criterion (AICc) in place of the first order criterion (AIC) as this better represents small samples sizes (Anderson et al. 2001).

In addition to fitting the von Bertalanffy growth function, I investigated length-at-age by comparing the mean lengths for each age class between the two sites with Kruskal-Wallis non-parametric ANOVA. Growth function parameters are sensitive to the youngest and oldest ages classes of datasets, which are typically characterised by the lowest sample sizes also (Haddon 2001, B. Moore et al. 2011). Comparing mean length-at-age is one method that accounts for this (Haddon 2001, B. Moore et al. 2011). Individuals from Wahine Park in age class 1, and Kau Bay in age class 4 , and all individuals in age classes above 6 at both sites, were excluded from the length-at-age analysis due to insufficient sample sizes.

Maturation and sex change

To evaluate age at maturation and age at sex change I examined the proportion of juveniles, mature females, initial phase males, and terminal phase males, by age class. Maturation is assumed to occur at $130 \mathrm{~mm}$ (see 2.2.5 Data analyses - Social 
structure). I calculated mean and minimum age and length at sex change from collected specimens.

The minimum age at sex change is the age at which males are first observed to appear in the population. The mean age at sex change is defined as the age at which $50 \%$ of the final proportion of males are present in the population (Gust 2004). The final proportion of males present was determined from observational data as this was assumed to better reflect natural sex ratios. At Wahine Park, 15 of 127 individuals observed were male, resulting in a final proportion equal to $11.8 \%$ male. The mean age at sex change at Wahine Park was determined to occur at the age at which a proportion of males equal to or higher than 5.9\% was present. At Kau Bay, 6 of 705 individuals observed were male, resulting in a proportion equal to $0.85 \%$ male. The mean age at sex change at Kau Bay was determined to occur at the age at which a proportion of males equal to or higher than $0.425 \%$ was present. In spotties, sex change occurs during a specific season each year, and not year round as is the case for many tropical harem-forming species (Jones 1980). Where I conclude individuals to change sex at a certain age, for example 4 years old, I suggest they change sex in their fourth year, during the sex change season (November - May).

I calculated minimum length at sex change and mean length at sex change, where minimum length at sex change is the length at which males are first observed to appear. I calculated mean length at sex change as the length at which $50 \%$ of the final proportion of males was present in the population, by the same method as mean age at sex change (Gust 2004, see above: Maturation and sex change). The final proportion of males present used was the same as for mean age at sex change (see above: Maturation and sex change). The number of female and male individuals collected at each site in each length class is presented. Length classes are in increments of $10 \mathrm{~mm}$ (total length).

\subsection{RESULTS}

\subsubsection{Social structure}

A total of 825 fish were counted on transect, 117 from Wahine Park and 708 from Kau Bay. At Wahine Park, 38 juveniles, 64 mature initial phase individuals, and 15 terminal phase individuals were counted. The smallest and largest fish recorded 
were 70 and $230 \mathrm{~mm}$ total length respectively. At Kau Bay, 566 juveniles, 136 mature initial phase individuals, and 6 terminal phase individuals were counted. The smallest and largest fish recorded were 30 and $260 \mathrm{~mm}$ total length respectively.

\section{Density}

Fish were higher in density at Kau Bay in shallow transects ( $3 \mathrm{~m}$ and $6 \mathrm{~m})$ but roughly even in density between sites in deeper transects $(9 \mathrm{~m}$ and $12 \mathrm{~m}$; Table 2.1 ).

Table 2.1: Average density (per $100 \mathrm{~m}^{2}$ ) of initial and terminal phase spotties (Notolabrus celidotus) observed at four depths from Wahine Park and Kau Bay. Observations are from 24 transects conducted on SCUBA that were split evenly between 4 depths $(3,6,9,12 \mathrm{~m})$ at each site and were conducted during the spawning season. Density is higher at $3 \mathrm{~m}$ and $6 \mathrm{~m}$ at Kau Bay and roughly even between sites at $9 \mathrm{~m}$ and $12 \mathrm{~m}$.

\begin{tabular}{rrrr}
\hline Depth (m) & Wahine Park & Kau Bay \\
\hline 3 & 6.12 & 157.5 \\
6 & 5.8 & 15.0 \\
9 & 15.0 & 17.0 \\
12 & 5.5 & 7.2 \\
\hline
\end{tabular}

\section{Size-frequency distribution}

The size-frequency distribution differed significantly between sites (initial phase and terminal phase pooled, Kolmogorov-Smirnov $\mathrm{P}<0.001)$. At Kau Bay, the majority of fish observed were juvenile, smaller than $130 \mathrm{~mm}$, whereas at Wahine Park, the majority of fish appeared to be distributed about size at maturation (Figure 2.3). Variance and means differed significantly between sites (F-test: $\mathrm{P}=0.009$ and Welch 2-sample t-test: $\mathrm{P}<0.001)$. 


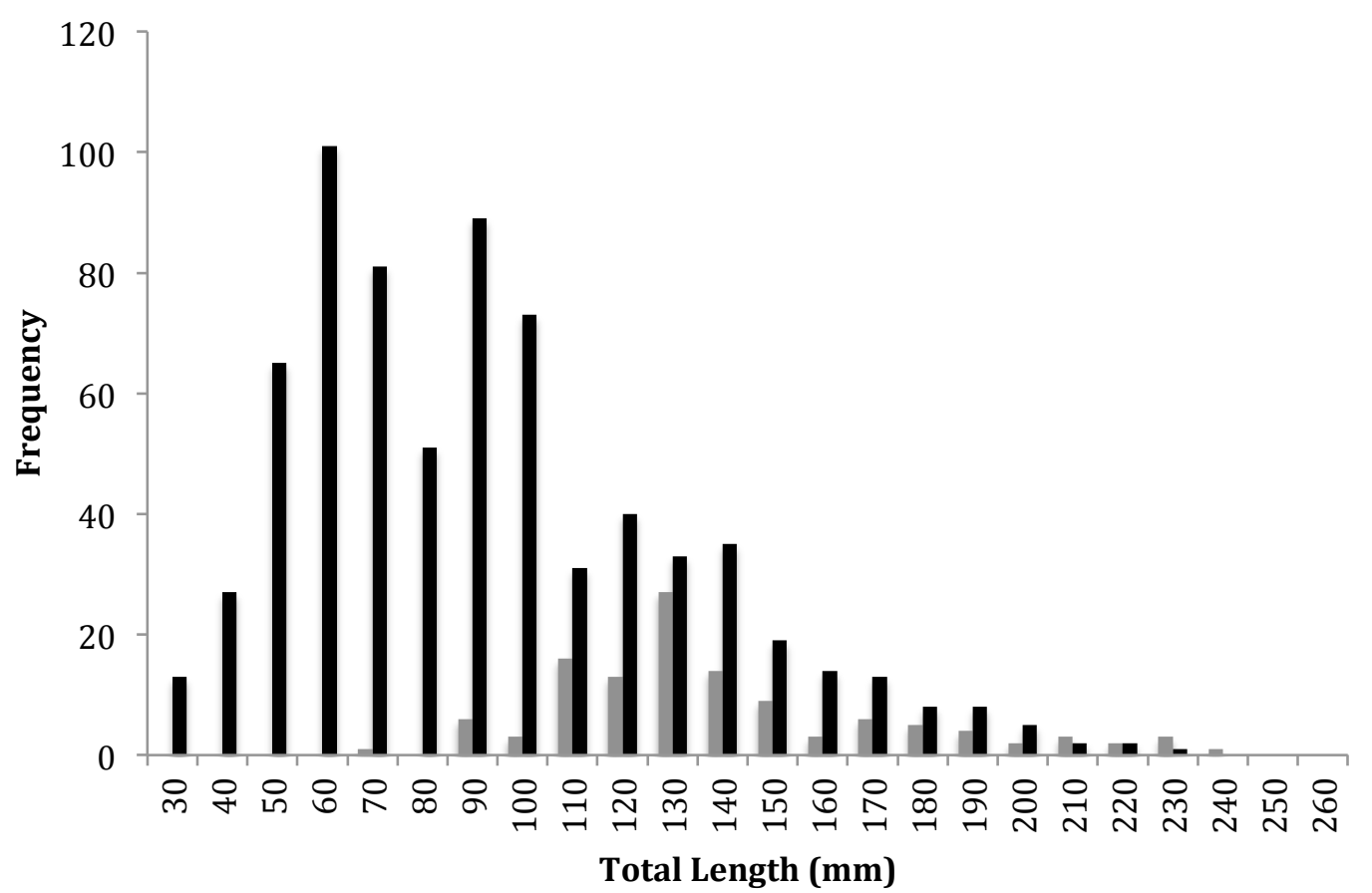

Figure 2.3: Size-frequency distribution of spotties (Notolabrus celidotus) observed on surveys at Kau Bay (black bars) and Wahine Park (grey bars). Twenty-four surveys split evenly between 4 depths $(3,6,9,12 \mathrm{~m})$ were conducted on SCUBA at each site during the spawning season. Numbers presented here are pooled totals at each site for juveniles, initial phase, and terminal phase spotties. At Kau Bay, the majority of spotties were juvenile ( $<130 \mathrm{~mm}$ total length) and at Wahine Park individuals are more evenly distributed about size at maturation $(130 \mathrm{~mm})$.

\section{Sex ratio}

The operational sex ratio (mature initial phase to terminal phase) was 4.3:1 at Wahine Park and 22.5:1 at Kau Bay. The sex ratio at each site differed significantly from 1:1 (chi-square test, $\chi^{2}=30.392$ and $\mathrm{P}<0.001$ for Wahine Park, $\chi^{2}=120.714$ and $\mathrm{P}<0.001$ for Kau Bay). Sex ratio was significantly different between sites $\left(\chi^{2}=\right.$ 12.723, $\mathrm{P}<0.001)$. The proportion of terminal phase males increased with depth at Wahine Park, but not at Kau Bay (Figure 2.4). At Kau Bay, the highest proportion of terminal phase individuals occurred at $6 \mathrm{~m}$ depth, though the majority was observed at $3 \mathrm{~m}$, and none were observed at 9 and $12 \mathrm{~m}$ (Figure 2.4). 
a.

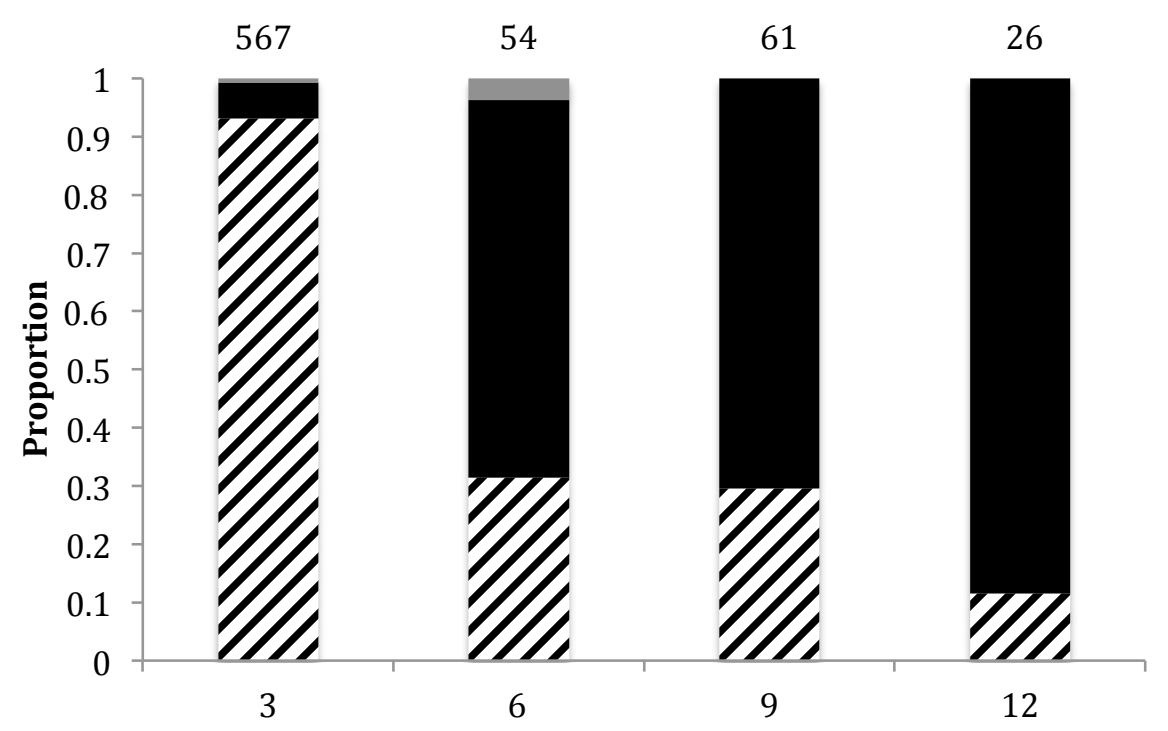

b.

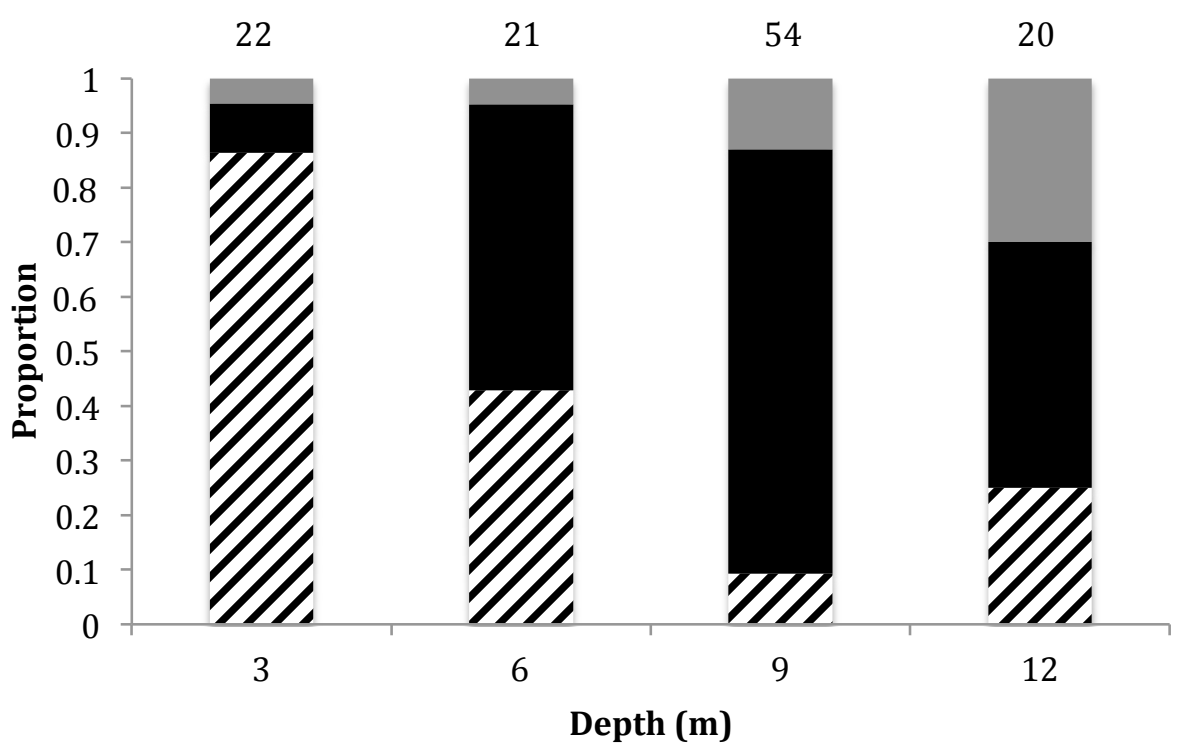

Figure 2.4: Proportion of juvenile (hatched), initial phase (black), and terminal phase (grey) spotties (Notolabrus celidotus) observed at four depths from (a) Kau Bay and (b) Wahine Park. The total number of individuals observed at each depth is given above each bar. At Kau Bay the greatest total number of males was observed at $3 \mathrm{~m}$, and the greatest proportion relative to initial phase individuals was observed at $6 \mathrm{~m}$. No terminal phase individuals were observed at $9 \mathrm{~m}$ and $12 \mathrm{~m}$ at Kau Bay. At Wahine Park the proportion of males increased with depth. Observations are taken from 24 SCUBA surveys split evenly between depths at each site. Maturity was assumed to occur at $130 \mathrm{~mm}$ total length. 


\subsubsection{Sex change and related life history traits}

A total of 152 individuals were caught, 62 from Wahine Park and 90 from Kau Bay. At Wahine Park, 29 individuals displayed terminal phase colouration and were determined to be male. Of the remaining 33 initial phase individuals, 1 was male, and 3 were smaller than $130 \mathrm{~mm}$ and classified as juveniles. At Kau Bay, 16 individuals displayed terminal phase colouration and were determined to be male. Of the remaining 74 initial phase individuals, 2 were male, and 33 were smaller than $130 \mathrm{~mm}$ and classified as juveniles. At Kau Bay, 4 juvenile individuals fell into the estimated range of maturity offered by Jones (1980) and may have already matured.

\section{Mortality}

Instantaneous mortality was higher at Kau Bay (1.14) than at Wahine Park (0.74; Figure 2.5). Annual survivorship (S) was higher at Wahine Park (47.6\%) than at Kau Bay (32\%; Figure 2.5). Confidence intervals overlapped between the two sites (Figure 2.5). 
a.

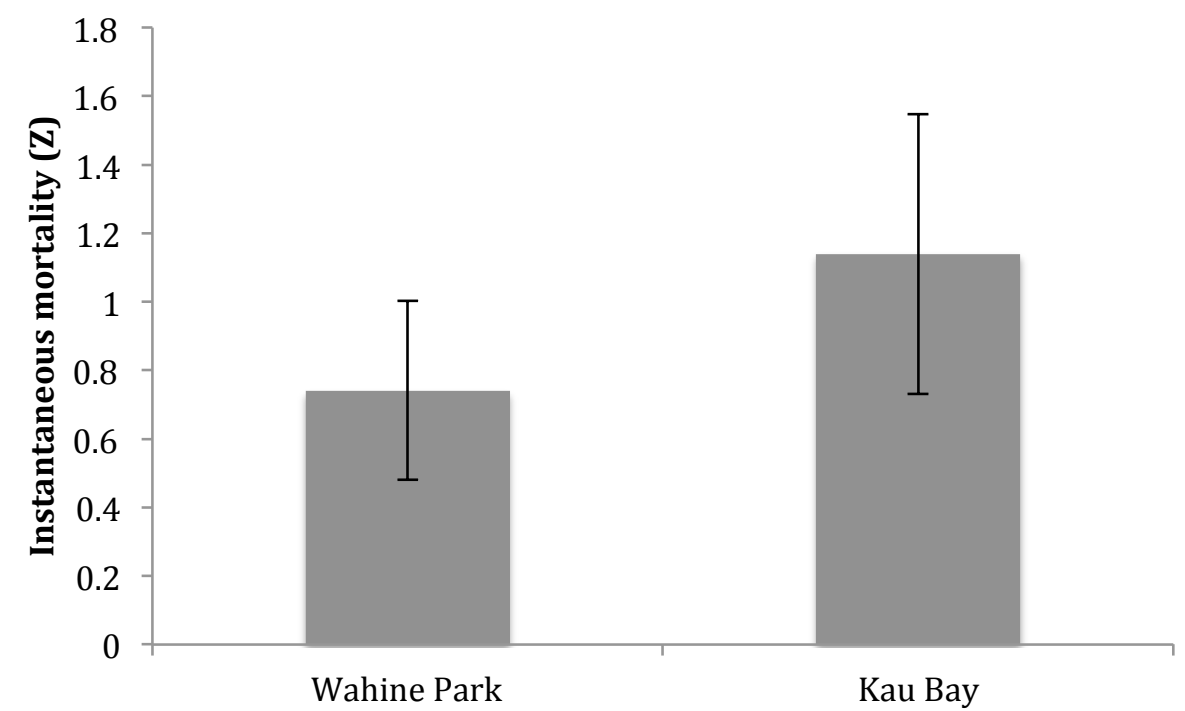

b.

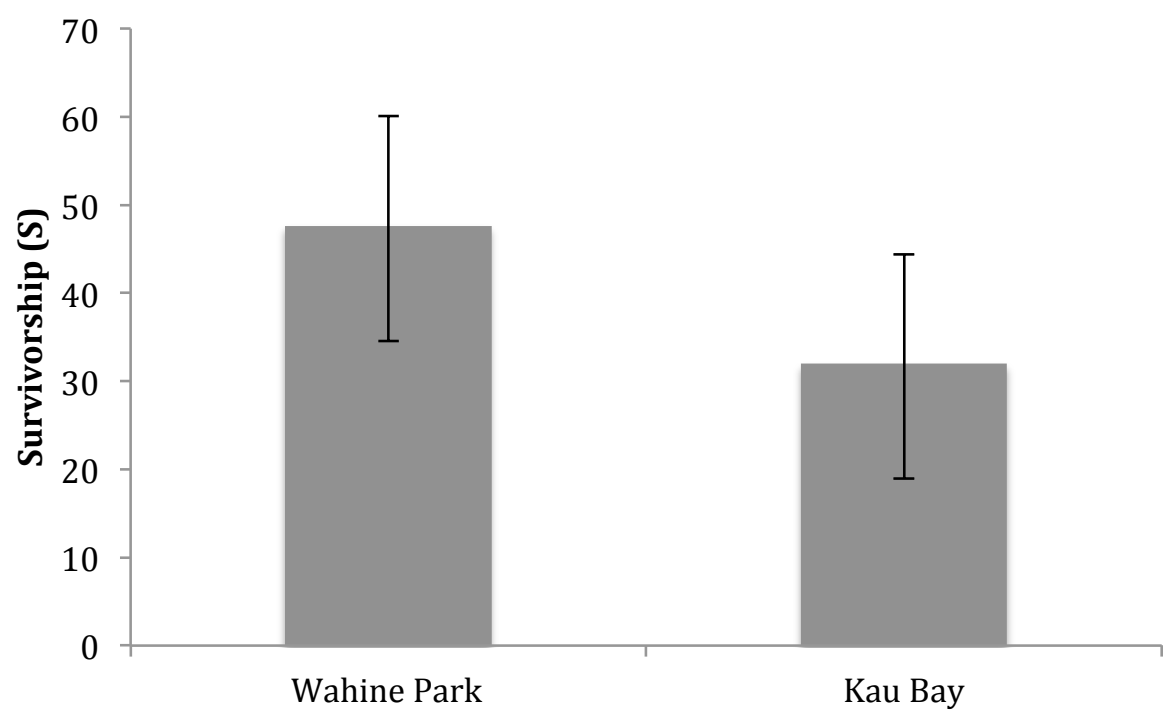

Figure 2.5: (a) Mortality and (b) survivorship estimates with 95\% confidence intervals for spotties (Notolabrus celidotus) from Wahine Park and Kau Bay. Mortality (Z) was estimated as 0.74 at Wahine Park and 1.14 at Kau Bay. The upper limit at Wahine Park overlaps with the lower limit at Kau Bay. Survivorship (S) was estimated as $47.62 \%$ for Wahine Park and 32\% at Kau Bay. The lower limit at Wahine Park overlaps with the upper limit at Kau Bay. Estimates are made using the Chapman-Robson equation. 
Von Bertalanffy growth function

Growth differed between sites (Figure 2.6). The model that best fit the data was one in which $\mathrm{t}_{0}$ was not different between sites, but where mean asymptotic length $\left(\mathrm{L}_{\infty}\right)$, and the growth function $(\mathrm{K})$ were significantly different (" $\mathrm{L}_{\infty} \& \mathrm{~K}$ differ", Table 2.2). Results are presented as suggested by Anderson and colleagues (2001). Estimates for von Bertalanffy growth function parameters are given in table 2.3 .

Table 2.2: AICc, $\triangle \mathrm{AIC}$, AIC weight, and log-likelihood of each model possible for describing differences in the growth parameters $\mathrm{t}_{0}, \mathrm{~L}_{\infty}$, and $\mathrm{K}$ fitted from the von Bertalanffy growth function for spotties (Notolabrus celidotus) at Wahine Park and Kau Bay. The best-fit model (shown in bold) indicates that $\mathrm{L}_{\infty}$ and $\mathrm{K}$ differ significantly between the two sites, but $\mathrm{t}_{0}$ does not.

\begin{tabular}{lrrrr}
\hline Model & AICc & DAIC & AIC weight & log-likelihood \\
\hline $\mathbf{L}_{\infty}$ \& K differ & $\mathbf{1 2 4 1 . 3 6 4}$ & $\mathbf{0}$ & $\mathbf{0 . 3 3 0}$ & $\mathbf{- 6 1 4 . 4 6}$ \\
$\mathrm{t}_{0}$ differs & 1241.696 & 0.332 & 0.279 & -615.70 \\
$\mathrm{~L}_{\infty} \& \mathrm{t}_{0}$ differ & 1243.409 & 2.045 & 0.119 & -615.48 \\
all differ & 1243.529 & 2.165 & 0.112 & -614.45 \\
$\mathrm{~K} \& \mathrm{t}_{0}$ differ & 1243.782 & 2.418 & 0.098 & -615.67 \\
$\mathrm{~K}$ differs & 1244.753 & 3.389 & 0.061 & -617.23 \\
$\mathrm{~L}_{\infty}$ differs & 1251.229 & 9.865 & 0.002 & -620.47 \\
none differ & 1270.674 & 29.310 & $1.42 \times 10^{-07}$ & -631.25 \\
\hline
\end{tabular}




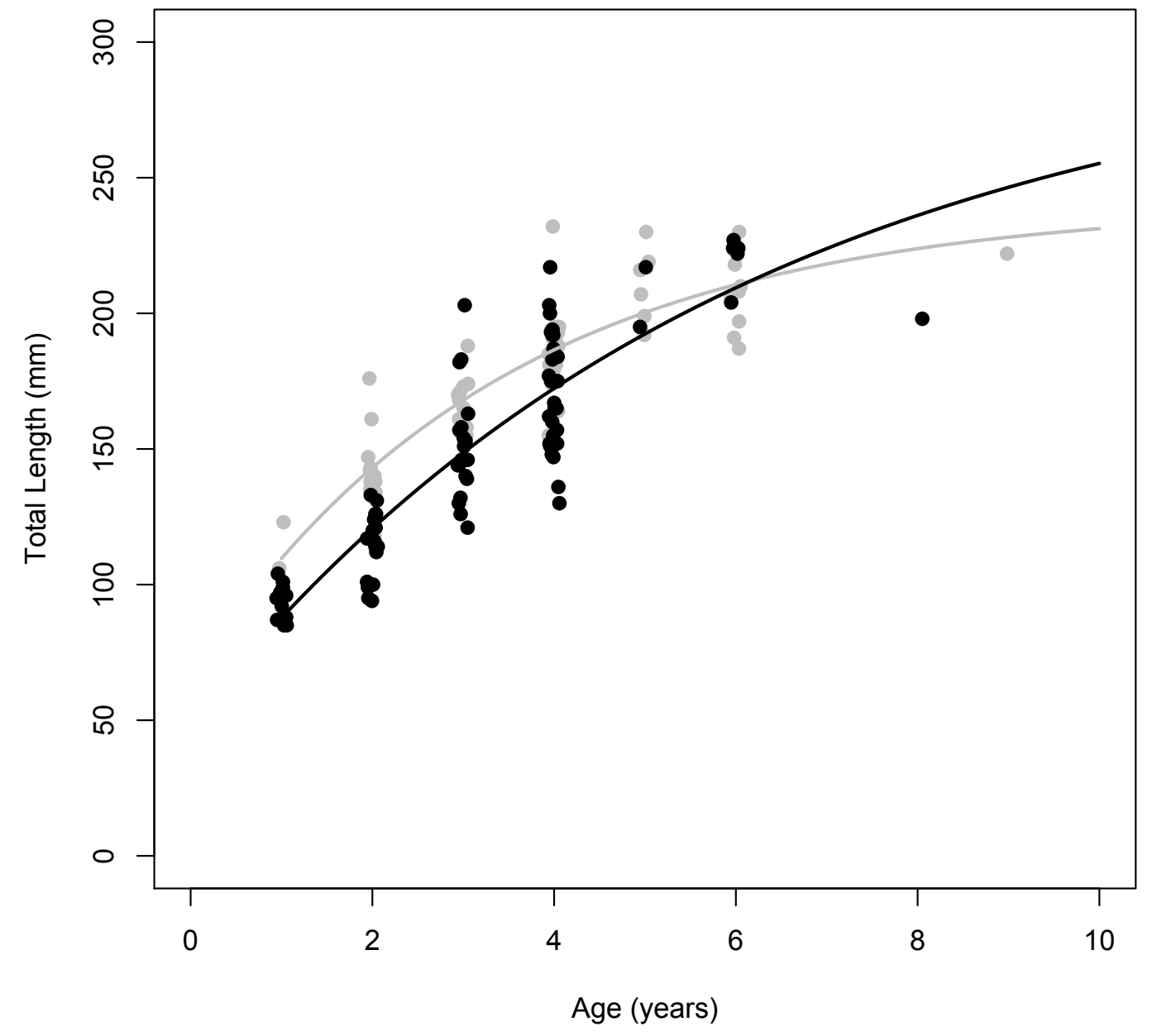

Figure 2.6: Von Bertalanffy growth function fitted for spotties (Notolabrus celidotus) from Kau Bay (black line) and Wahine Park (grey line). Growth appears to be slower at Kau Bay initially but the function reaches a higher mean asymptotic length than at Wahine Park. 
Table 2.3: Estimated growth parameters $\mathrm{L}_{\infty}, \mathrm{K}$, and $\mathrm{t}_{0}$ from the von Bertalanffy growth function fitted for spotties (Notolabrus celidotus) from Wahine Park and Kau Bay. The mean asymptotic length $\left(\mathrm{L}_{\infty}\right)$ is higher at Kau Bay, and the growth rate coefficient $(\mathrm{K})$ and hypothetical length at time $0\left(\mathrm{t}_{0}\right)$ are lower at Kau Bay, relative to Wahine Park. Only $\mathrm{L}_{\infty}$ and $\mathrm{K}$ were significantly different between sites (Table 2.2)

\begin{tabular}{lrrr}
\hline Site & $\mathbf{L}_{\infty}$ & $\mathbf{K}$ & $\mathbf{t}_{\mathbf{0}}$ \\
\hline Wahine Park & 238.53 & 0.31 & -0.99 \\
Kau Bay & 307.16 & 0.16 & -1.08 \\
\hline
\end{tabular}

\section{Mean length-at-age}

Fish were larger at Wahine Park in all age classes investigated until age 6, where fish were larger at Kau Bay (Table 2.4, Figure 2.7). Fish at Kau Bay were significantly smaller at $\alpha=0.05$ at ages 2,3 , and 4 (Table 2.4). This corroborates the results of the von Bertalanffy growth function, which predicted a smaller growth constant $\mathrm{K}$ and a higher mean asymptotic length at Kau Bay (Table 2.3, Figure 2.6). Ages 1 and 5 could not be compared due to insufficient sample sizes.

Table 2.4: Results of the Kruskal-Wallis non-parametric ANOVA for mean length-atage of spotties (Notolabrus celidotus) from Wahine Park (WP) and Kau Bay (KB). The sample size (n) of each age class is given for each site. Mean length is significantly smaller at Kau Bay at age 2, 3, and 4 at $\alpha=0.05$ (shown in bold), but larger at age 6 . Age classes 1 and 5 are missing due to insufficient sample size.

\begin{tabular}{rrrrr}
\hline Age & $\mathbf{n}$ (WP) & $\mathbf{n}$ (KB) & $\boldsymbol{\chi}^{\mathbf{2}}$ & $\mathbf{P}$ \\
\hline 2 & 12 & 19 & 18.85 & $<\mathbf{0 . 0 0 1}$ \\
3 & 13 & 19 & 7.64 & $<0.01$ \\
4 & 17 & 27 & 5.30 & $\mathbf{0 . 0 2 1}$ \\
6 & 9 & 5 & 2.79 & 0.095 \\
\hline
\end{tabular}




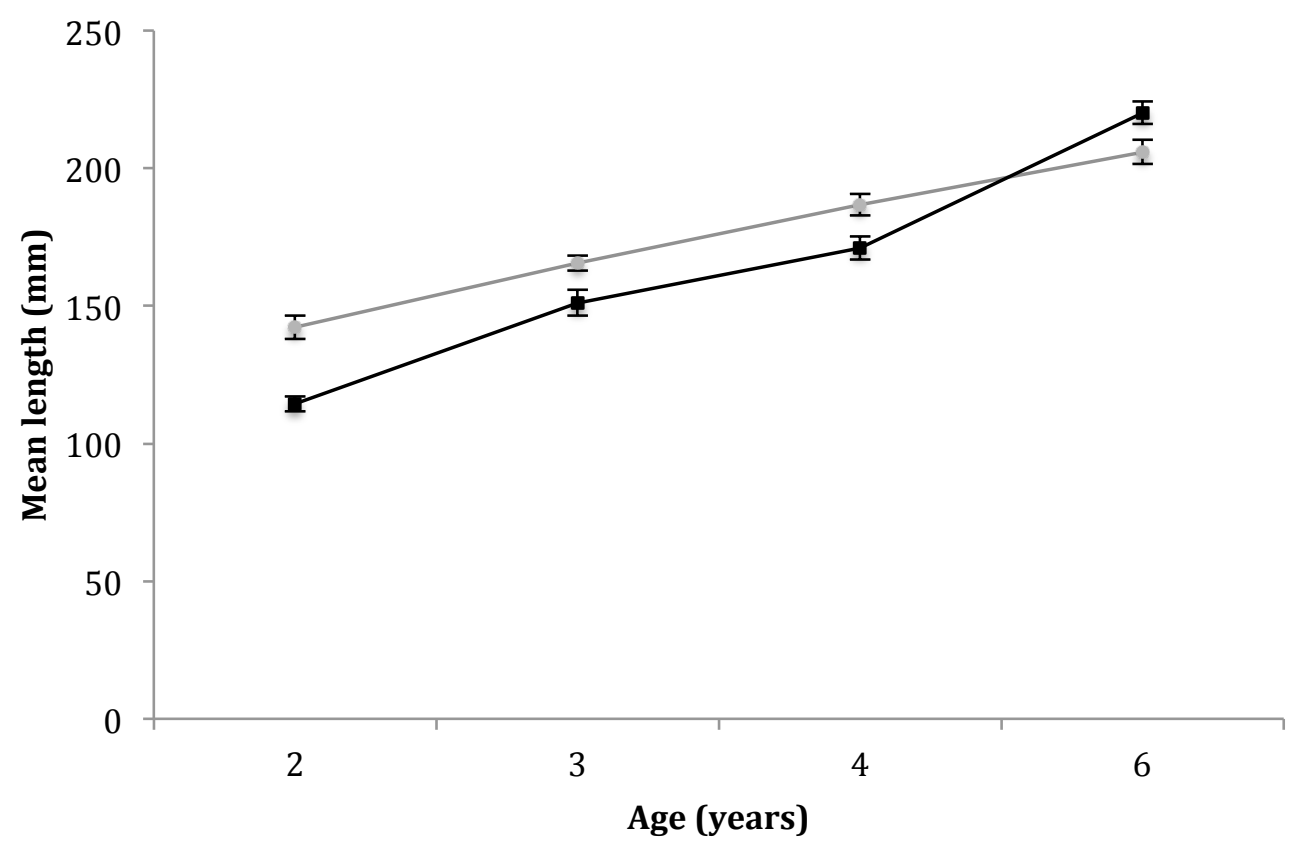

Figure 2.7: Average length-at-age ( $\pm 1 \mathrm{SE}$ ) for spotties (Notolabrus celidotus) from Wahine Park (grey) and Kau Bay (black). Fish are significantly smaller at Kau Bay at age 2, 3, and 4, but larger at Kau Bay at age 6. Age classes 1 and 5 are missing due to insufficient sample sizes.

\section{Maturation and sex change}

The proportion of juveniles, mature females, initial phase males, and males in each age class differed between Kau Bay and Wahine Park (Figure 2.8). The majority of females at Wahine Park reached size at maturation at 2 years old, whereas at Kau Bay the majority did not reach size at maturation until 3 years old (Figure 2.8). At Wahine Park, one male retaining initial phase colouration was caught and at Kau Bay two males retaining initial phase colouration were caught (Figure 2.8). At Wahine Park, both the minimum and mean age at sex change were 4 years old (Figure 2.8). At Kau Bay, both the minimum and mean age at sex change were 3 years old (Figure 2.8 ). At both locations, the majority of individuals appeared to change sex at age 4 , as the largest increase in number of males was observed at this age at each site.

The minimum length at sex change at Wahine Park fell between $155 \mathrm{~mm}-$ $164 \mathrm{~mm}$ and initial phase individuals were not observed in size classes above 185 $194 \mathrm{~mm}$ (Figure 2.9). The mean length at sex change was estimated at between 165 $\mathrm{mm}-174 \mathrm{~mm}$ for Wahine Park. At Kau Bay, the minimum length at sex change fell 
between $135 \mathrm{~mm}-144 \mathrm{~mm}$ (Figure 2.9). The mean length at sex change was estimated at between $135 \mathrm{~mm}-144 \mathrm{~mm}$. In Kau Bay, a few females in large size classes (195 - $204 \mathrm{~mm}$ and $215-224 \mathrm{~mm}$ ) were caught (Figure 2.9).

a.

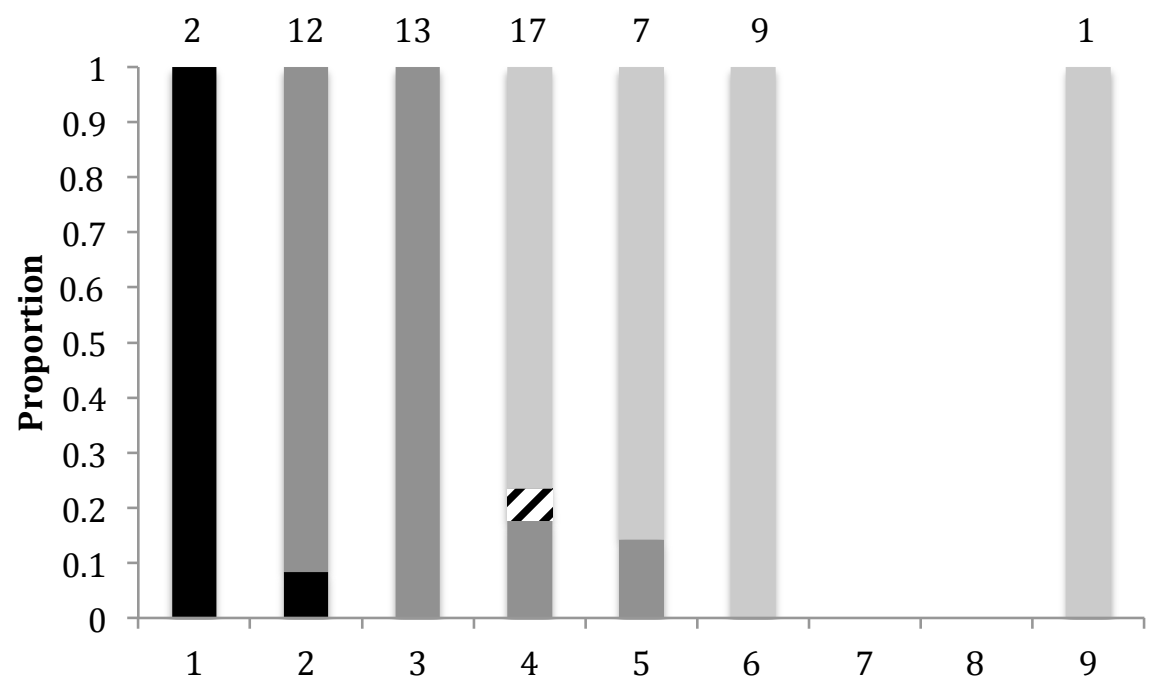

b.

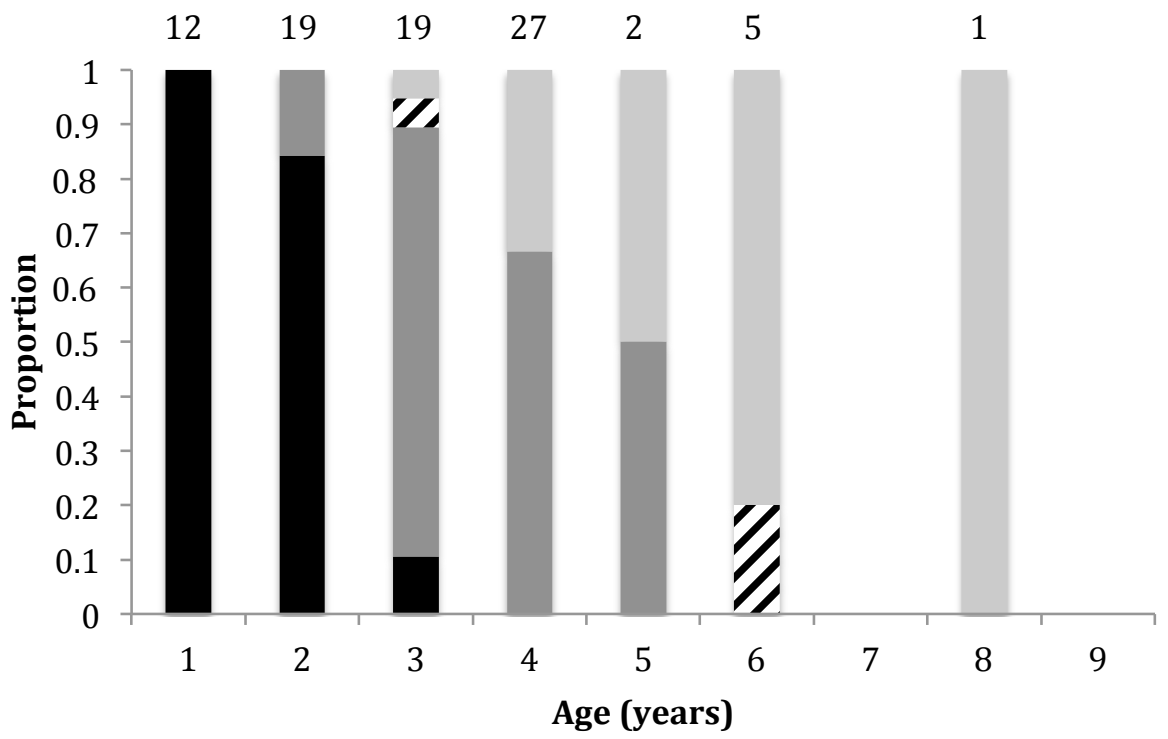

Figure 2.8: Proportion of spotties (Notolabrus celidotus) that were juvenile (black bars), mature females (dark grey), initial phase males (hatched), and terminal phase males (light grey) in each age class at (a) Wahine Park and (b) Kau Bay. The total number of individuals in each age class is given above each bar. At Wahine Park the majority of juveniles reached size at maturation at age 2, while at Kau Bay the majority of individuals did not reach size at maturation until age 3 . The minimum age at sex change was 4 years and 3 years at Wahine Park and Kau Bay respectively. 
a.

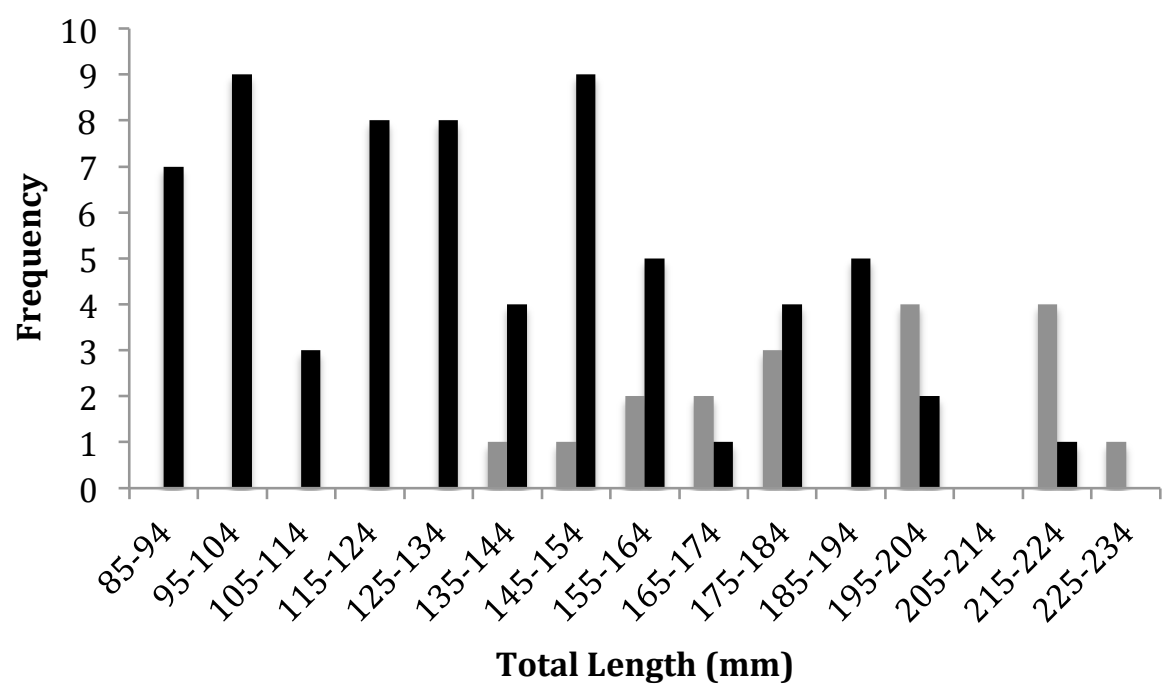

b.

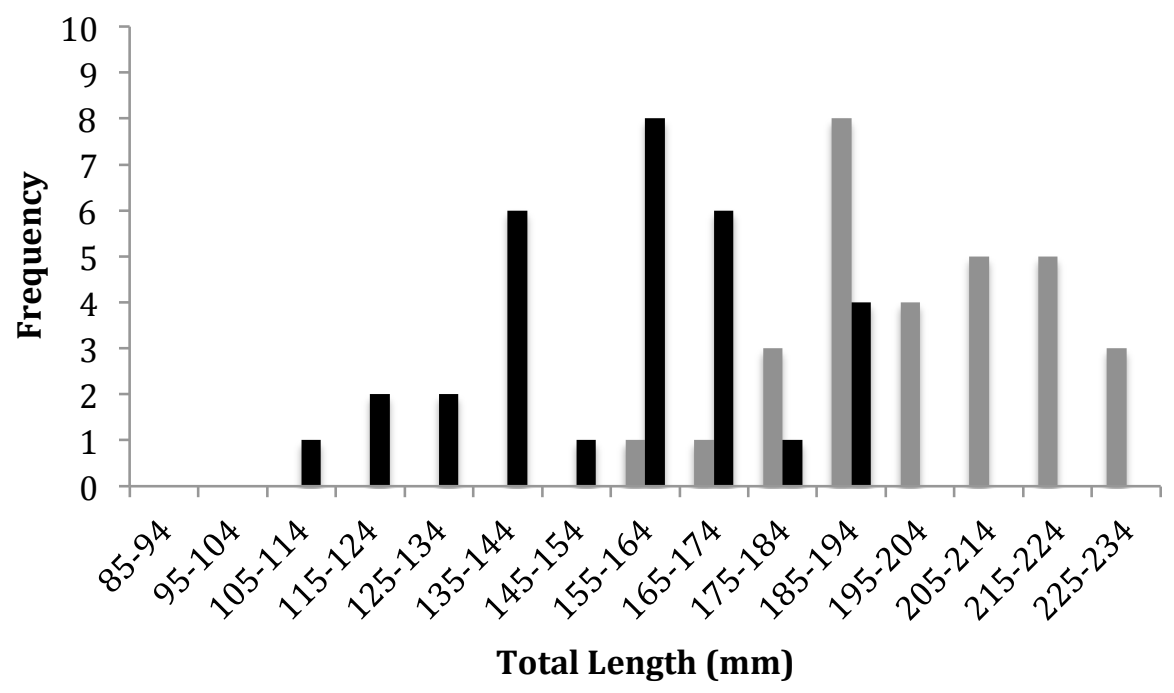

Figure 2.9: Total number of female (black) and male (grey) spotties (Notolabrus celidotus) caught in each size class from (a) Kau Bay and (b) Wahine Park. At Kau Bay, the first males appear between $135 \mathrm{~mm}-144 \mathrm{~mm}$ and females are observed in size classes up to $215 \mathrm{~mm}-224 \mathrm{~mm}$. At Wahine Park, the first males appear between $155 \mathrm{~mm}-164 \mathrm{~mm}$ and females are not observed in size classes larger than $185 \mathrm{~mm}-$ $194 \mathrm{~mm}$. 


\subsection{DISCUSSION}

\subsubsection{Social structure and sex change}

The results suggest that social structure of spotties differed remarkably across a small spatial scale and this may have implications for the reproductive potential of these populations. I expected that increased density would be coupled with an increase in the proportion of males relative to females but found instead that males were more abundant at low density. Similarly, Jones (1980) showed that a population of spotties living at high density in Wellington had a lower ratio of males to females than a population living at lower density at Leigh. However, Jones argued that the proportion of initial phase males increased at high density. Males in the initial phase may achieve high reproductive success by interfering with spawning events occurring between a female and a large dominant male (Robertson and Warner 1978, Warner and Robertson 1978). A similar process may occur in the populations investigated here. A small number of initial phase males were detected in this study (2 at Kau Bay and 1 at Wahine Park); however, these numbers may be meaningful. At Kau Bay, 1 in 8 males caught displayed the initial phase colour pattern, compared to 1 in 30 at Wahine Park. This suggests that initial phase males are more abundant at Kau Bay relative to terminal phase males, and that density of initial phase males increased with population density. Jones (1980) reported that spawning interference by initial phase males was low in spotties based on observations at Leigh. It is possible that the initial phase males in this study were not reproducing but were in the process of changing colour pattern. Observational studies are required to assess the importance of spawning interference in these populations.

Interestingly, the operational sex ratios detected here and those reported by Jones (1980) are markedly different. In Jones' study, the operational sex ratios were 8.7:1 at high density, compared to $3.7: 1$ at low density. In this study, the operational sex ratios were 22.5:1 at high density in Kau Bay and 4.3:1 at low density in Wahine Park. This suggests that relatively few females change sex at Kau Bay compared to Wahine Park and compared to both the high density and low density populations described by Jones (1980). Furthermore, the presence of large females at Kau Bay supports the suggestion that fewer females change sex. The largest females detected at Kau Bay were in size classes larger than the mean length at sex change for this site, 
and larger than the largest females from Wahine Park (Figure 2.9). Size-fecundity skew (Muñoz and Warner 2003b) is one reason why females might not change sex. This theory explains that a female will defer sex change to a smaller female if her fecundity is greater than the fecundity of all other females combined. Size-fecundity skew may be possible if a female is very large relative to all other females in the reproductive population (Muñoz and Warner 2003b). In this study, multiple large females were detected on transect. Transects, however, can run through more than one female home range (Cowen 1990), and thus not all large females detected may interact under natural conditions. The presence of size-fecundity skew cannot be ruled out in this study, but requires further investigation.

I suggest an alternative hypothesis for sex change deferral in this particular study. The two sites investigated are unique in that they differ considerably in habitat composition. Jones (1981) described spotties as resource defense polygynysts; male spotties gain access to mating opportunities by defending desired spawning grounds. Jones (1981) found that spawning success of terminal phase males was most strongly related to the desirability of territory and time spent courting females, rather than size or age. The territory type most preferred by females contained an open rocky area with some central algal cover in which females sheltered immediately following spawning.

If territory availability affects the decision to change sex, differences in habitat composition could drive the differences in sex ratio observed in this study. At Kau Bay, the benthic substrate is primarily sand from a depth of roughly $5 \mathrm{~m}$ and deeper, whereas at Wahine Park, sand is rarely encountered and algal patches are common along the rocky substrate (personal observation). The types of spawning territories suggested to be preferred by females are rare at Kau Bay. A paucity of desirable territory would alter future reproductive success of an individual prior to sex change, and may be enough to prevent an individual from changing sex. In his study on territory in spotties, Jones (1981) showed that an area with substantially less desirable territories was characterised by a strongly female-skewed sex ratio, relative to an adjacent area with a larger number of desirable territories. Furthermore, considerably more males were detected in his study and still only 3 males monopolised mating opportunities. It is likely that Kau Bay would support many fewer males due to territory-limitation, leading to a sex ratio as skewed as that observed here. This hypothesis is supported by the depth distribution of males in this study. At Kau Bay, 
the largest number of males was observed at $3 \mathrm{~m}$, the largest proportion relative to initial phase at $6 \mathrm{~m}$, and none were observed deeper (Figure 2.4). At Wahine Park, the density of terminal phase males increased with depth. These distributions roughly match areas where desirable territories, according to Jones (1981), are likely to be most abundant.

The implication of limiting spawning territory is that reproductive potential in the Kau Bay population may be limited despite high density. The relevance of spawning territory limitation requires further investigation in other species. California sheephead, for example, are protogynous hermaphrodites that defend spawning territories and are a major target of commercial and recreational fisheries (Adreani et al. 2004). Alonzo and colleagues (2008) highlighted the importance of incorporating information on sex change and sex-specific behaviour into fisheries models for sheephead and other hermaphroditic species. If spawning territory limitation plays a role in determining sex change, this may have profound effects on the reproductive potential of a population, and will be an important consideration in fisheries modeling and stock management.

\subsubsection{Size advantage model and life history traits}

The size advantage model predicts that early sex change will occur in populations characterised by slow growth, high mortality, or both (Warner, 1988). Warner's (1975) simulations of the size advantage model indicated that high abundance and low survivorship of the initial phase, or a slow increase in fecundity with age, can also result in early sex change. These patterns describe the population at Kau Bay. At Kau Bay, small length-at-age suggests that fecundity is increasing more slowly with age than at Wahine Park, as fecundity is loosely related to size (Gust 2004), and this is associated with an abundant initial phase and high mortality. Accordingly, sex change occurred at a smaller size and younger age at Kau Bay than at Wahine Park for some individuals (Figures 2.8 and 2.9). These results support the predictions of the size advantage model.

Disentangling the relative importance of individual life history traits for the timing of sex change is difficult, for example, in populations with high mortality and slow growth, it is unclear which influences early sex change more (Cowen 1990, Gust 2004, Jones 1980). In this study, variation in life history traits appeared to be driven by differences in the magnitude of recruitment to each Kau Bay and Wahine Park. 
Recruitment rate can influence the timing of sex change due to its effect on population density (Charnov et al. 1978, Warner 1988). Recruitment in triplefin species, which are ecologically similar to spotties, is higher in Wellington Harbour than about the south coast (Shima and Swearer 2009). It is likely that spotties also recruit in higher abundance at Kau Bay in the harbour than at Wahine Park on the south coast. Jones (1984c) showed that juvenile survivorship and juvenile growth were inversely correlated with initial juvenile density in a population of spotties at Leigh and concluded that the most important density-dependent interaction was food limitation. It is likely that density-dependent food limitation resulted in the patterns of slow growth, reduced size frequency, small length-at-age, and high mortality, at Kau Bay in this study. This is supported by the higher mean asymptotic length predicted at Kau Bay relative to Wahine Park, which suggests that adult growth rate increases as density-dependence is relieved; however, no individuals near the predicted mean asymptotic length were caught. Presumably, high mortality prevents individuals reaching these age classes due to density-dependent stress early in development. These results are similar to other studies that detected high density, slow growth, and high mortality, and concluded that density-dependence drove these patterns (Gust et al. 2002, Jones 1980)

The size advantage model predicts that early maturation is associated with slow growth, early sex change, and high mortality. Jones (1980), however, found that maturation occurred at a critical size in spotties, irrespective of growth and age, and that maturation could be delayed until that size was reached. In another paper, Jones and Thompson (1980) showed that mature initial phase spotties could socially inhibit maturation in juveniles at high density. The results of this study suggest that a majority of individuals at Kau Bay did not mature until age 3, as opposed to age 2 at Wahine Park. Considering the high density of fish, it is likely that either or both slow growth and social inhibition by conspecifics result in delayed maturation at Kau Bay. The estimates in this study rely on a small sample size of juveniles from Wahine Park and the assumption that maturation occurred at $130 \mathrm{~mm}$ (total length). Understanding differences in the timing of maturation across this small spatial scale will be better served by sampling during the spawning season to accurately estimate maturity and by devising effective methods for capturing juveniles when they are in low abundance. 


\subsubsection{Conclusions}

Jones (1980) showed that two populations of spotties separated by over one thousand kilometres differed in the expression of a number of life history traits. This study further suggests that spotties can differ in the expression of life history traits and sex change between populations separated by only 9 kilometres. The results presented here demonstrate that caution must be taken when estimating life history traits from samples collected across a large spatial scale. Furthermore, I suggest here that availability of spawning territory may be a determining proximal cue for sex change in spotties when territories are limited. For hermaphroditic species that are sensitive to spawning territory availability, spatial variation in spawning habitat may be a necessary consideration of species management, in addition to sex change and related life history traits (Alonzo et al. 2008). Further, density may not always be an accurate indication of the reproductive potential of a population. 


\section{Chapter 3: \\ Fluctuating asymmetry and condition of Notolabrus celidotus at a small spatial scale}

\subsection{INTRODUCTION}

Environmental stressors can reduce the physiological condition of individuals (Jones 1984c, Ning et al. 2012, Shoup \& Wahl 2011) and alter life history traits such as growth rate, fecundity, and mortality (Stearns 1976, 1977, Yamahira and Conover 2002). Limiting food resources, for example, can result in small size-at-age and increased mortality in fishes (Ovegård et al. 2012, Shoup and Wahl 2011), and have subsequent impacts on the reproductive potential of a population (Lambert and Dutil 1997, Marshall and Frank 1999). Because of this, life history traits are sometimes used to assess the health or condition of populations of fish (Clarke 1995) or to infer the impact of stressors like fishing pressure (Russ 1991). A goal, however, is to be able to recognise a population under stress before impacts such as high mortality are evident and have affected the reproductive potential of a population (Clarke 1995, Figuerola et al. 2012).

Condition factors relate the length and weight of an individual and are thought to reflect physiological condition by indicating energy reserves (Carscadden and Frank 2002, Froese 2006, Rätz and Lloret 2003). Such metrics are more easily measured than life history traits. Fulton's condition factor $(\mathrm{K})$ is calculated by $\mathrm{K}=$ $100 \times \mathrm{W} / \mathrm{L}^{3}$, where $\mathrm{W}=$ weight and $\mathrm{L}=$ length, and is frequently used in fisheries science as an indication of health and fitness of individuals within a population (e.g. Koops et al. 2004, Mello and Rose 2005, van der Oost et al. 2003). In Atlantic cod, for example, $\mathrm{K}$ was used to monitor the condition of the stock and was shown to decrease rapidly as fish stocks declined prior to the collapse of the fishery (Lambert and Dutil 1997).

Another method of inferring health is by evaluating fluctuating asymmetry (Allenbach 2010, Palmer 1996), though the topic is controversial (Bjorksten et al. 2000, Rasmuson 2002). Fluctuating asymmetry refers to a natural asymmetry between the right and left components of a trait (e.g. arm length, etc.) in bilaterally symmetrical organisms (Palmer and Strobeck 2003, Palmer 1996). Fluctuating asymmetry (hereafter referred to as FA) is thought to arise from stress during an 
organism's development and it may reflect both the magnitude of stress and/or the ability of an organism to cope with stress (Lens et al. 2002, Palmer 1996). Furthermore, some workers believe that FA can reduce the reproductive potential of an individual, and therefore it may be useful as a measure of relative fitness (Clarke 1995, Møller 1994). Critics of FA highlight the inability of a large number of studies to successfully detect FA, or to correlate it with particular environmental stressors (Bergstrom and Reimchen 2000, Bjorksten et al. 2000, Rasmuson 2002). Studies of FA are problematic because the asymmetry can be expressed in some traits and not others (Blanckenhorn et al. 1998, Woods et al. 1999) and the magnitude of asymmetry can depend on the type of stress encountered (Campbell et al. 1998, Roy and Stanton 1999). Furthermore, FA may be reduced in males in populations where females actively select mates (Kodric-brown 1997, Møller 1994) or increased in males due to sex-specific differences in energy demands (Helle et al. 2010, Serrano et al. 2008). Thus, the ability to detect FA can depend on a thorough understanding of the stress- and sex-specific development of FA in the particular trait examined (Lens et al. 2002, Palmer and Strobeck 2003).

In marine fishes, paired otoliths, or 'ear stones', are a convenient trait for measuring FA (Palmer et al. 2010, but see Vignon and Morat 2010). Otoliths are important in the balance and navigation of fishes, and asymmetry in otoliths is believed to indicate reduced physiological condition and fitness (Gagliano et al. 2008). However, studies of FA in otoliths are rare, and they have inconsistently documented correlations between asymmetry and environmental stressors (Palmer et al. 2010). Grønkjaer and Sand (2003) demonstrated in a laboratory experiment that poor nutritional condition of juvenile fish was correlated with increased FA in otoliths. Similarly, both Somarakis and colleagues (1997) and Lemberget and colleagues (2009) found a positive relationship between FA in otoliths and decreased recruitment of larval fish during poor environmental conditions. Alternatively, Folkvard and colleagues (2000) reported no relationship between FA in otoliths and condition, but this may have resulted from only measuring otolith radius. A difficulty associated with trait-specific expression of FA in otoliths (considered a single trait) is that different variables that describe otolith size may express FA differently (Panfili et al. 2005). Lens and colleagues (2002) recommend overcoming trait-specific expression of FA by measuring multiple traits. Panfili and colleagues (2005), however, suggest that integrating a number of different variables describing otolith 
size may be as effective as analysing multiple traits, while Palmer and colleagues (2010) recommend measuring the shape of an otolith.

Here, I investigate the expression of FA in otoliths of a temperate protogynous (female first) hermaphrodite, the spotty (Notolabrus celidotus), and I examine the relationship between FA and other condition indices, components of life history, and sex. Spotties at Kau Bay on the north shore of Miramar Peninsula live at higher density than spotties at Wahine Park on the neighbouring south coast (Chapter 2). High density is accompanied by reduced size-at-age and increased mortality, presumably as a result of density-dependent resource limitation (Chapter 2). Further, female mate-selection determines the reproductive success of males in this species (Jones 1981). In this study, I measured FA from five variables of otolith size and compared these to condition indices within and between sites to determine if these were related to high density, reduced size-at-age, and increased mortality. I compared FA between sexes and size classes, and tested the validity of integrating different variables describing otolith size to overcome difficulties associated with trait-specific expression of FA. I hypothesised that 1) FA would be negatively correlated with condition, 2) FA would be higher and condition lower in the high density population, 3) FA would be less pronounced in males, and 4) different variables pertaining to otolith size would express FA independently of one another.

\subsection{METHODS}

\subsubsection{Species and sampling}

Individuals used for this study are the same specimens that were collected for a study on variation in life history traits (previous chapter); a full description of how these fish were caught and processed is provided in chapter 2. Briefly, individuals were collected (using a range of methods) from two sites: Kau Bay, a sheltered northfacing site in Wellington Harbour, and Wahine Park, a south-facing site at the harbour entrance that is exposed to southerly wind and swell (Figure 2.1, Chapter 2). The population of spotties at Kau Bay was observed to live at higher density and individuals were characterised by slow growth, small size-at-age, a small ratio of males to females, early sex change, and high mortality relative to the population at Wahine Park (Chapter 2). Importantly, for this study I excluded individuals from the 
original collection (i.e. the dataset used for Chapter 2) if two otoliths were not available after processing (sample sizes will differ between the two chapters). For this chapter, I also assume that my methods of capture facilitated a random sample of the focal population. While it is possible that specific phenotypes may be differentially vulnerable to particular methods of capture (Ovegård et al. 2012), I assume that any bias attributable to collection methods is minimal.

\subsubsection{Asymmetry analysis}

To compare FA to classic condition indices and between sites and sexes, I measured the magnitude of asymmetry of five otolith variables related to otolith size: area, perimeter, axis (major), axis (minor), and weight. First, otoliths were weighed to the nearest microgram and converted to grams. Next, I measured area, perimeter, axis (major) and axis (minor) from photographs of each otolith. Images were taken with Qcapture Pro (version 6.0) and analysed in ImageProPlus (version 5.0). Prior to image analysis, I manually increased the contrast of the image to facilitate more accurate (and automated) estimates of otolith area, perimeter, axis (major) and axis (minor). Where an incomplete perimeter was drawn, the individual was not used for analyses, as this would either over- or under-estimate the magnitude of area and perimeter. Initially, I compiled three indices for FA analyses: the signed asymmetry index (i.e. keeping track of which side was greater/lesser), the unsigned asymmetry index, and the trait-size index. I calculated signed asymmetry as right minus left (R-L) for each variable. The unsigned asymmetry index is the absolute value of the signed asymmetry index $(|\mathrm{R}-\mathrm{L}|)$ for each variable. The magnitude of FA can be artificially inflated if it is correlated with the size of a trait (Palmer and Strobeck 2003). To test for a correlation between magnitude of asymmetry and trait-size (otolith size), I calculated the trait-size index as $(\mathrm{R}+\mathrm{L}) / 2$ for each variable of otolith asymmetry. Following the trait-size correlation analysis I compiled a residual FA index (see below).

\subsubsection{Assumptions of fluctuating asymmetry}

\section{Trait-size correlation}

I tested for a correlation between asymmetry and trait-size prior to testing the assumptions of FA. To do this, I used Spearman's Rank Correlation Coefficient to test the relationship between the unsigned asymmetry index and the trait-size index for 
each variable, which is suggested to be most appropriate for studies of FA (Palmer and Strobeck 2003). Where a significant relationship was detected, the residuals of the linear least-squares regression between the unsigned asymmetry index and the traitsize index were compiled into a signed residual asymmetry index and an unsigned residual asymmetry index and used in place of the raw data. This is assumed to remove variation due to the relationship with trait-size, and retains variation due to true FA (Lemberget and McCormick 2009). As a significant relationship between asymmetry and trait-size was found for all otolith variables in at least one site, I used the residual asymmetry index for each variable in the following analyses for consistency.

\section{Departure from normality}

To be sure that asymmetry is due to true FA and not another type (anti- or directional asymmetry), data must conform to a number of assumptions (Palmer and Strobeck 2003). Directional asymmetry results from a predisposed tendency to grow asymmetrically in one direction, such as in flatfishes, and is indicated by skew (Palmer 1996). Anti-symmetry results from a predisposition to grow asymmetrically in either direction, resulting in a bimodal distribution, and is indicated by kurtosis (Palmer 1996). True FA requires data to be distributed about a mean equal to 0 , as 0 indicates perfect symmetry (Palmer 1996). I tested the distribution of the signed residual asymmetry index by site and variable independently for skew, kurtosis, and mean $=0$. I tested for a mean $=0$ with a one-sample t-test. I calculated skew and an associated p-value for each variable in $\mathrm{R}$ ( $\mathrm{R}$ development core team 2012). Kurtosis was computed in R and critical values taken from Palmer and Strobeck (2003).

\subsubsection{Measurement error}

Values of FA are often very small relative to the size of a trait and can be easily confounded with measurement error (Palmer 1996). In order to account for measurement error, I measured 5 otolith pairs similar to those used in analyses multiple times for FA in the same 5 otolith variables measured above. For area, perimeter, axis (major), and axis (minor), I photographed each otolith three times at a different orientation, and computed automated measurements once for each new photograph. For weight, I weighed each otolith three times and separated each weighing with weighing of other otoliths and tare of the scales. I used nested analysis 
of variance to establish whether significant differences between sides (right or left otolith) and individuals (different fish) were detectable despite measurement error for each variable independently using asymmetry as a response variable, side nested within individual, and multiple measurements nested in side. Measurement error is represented by the residual error. I calculated variance components from the mean square for each variable according to Gotelli and Ellison (2004).

\subsubsection{Condition}

I used two methods to estimate physiological condition of the fish. First, I calculated Fulton's condition factor $(\mathrm{K})$ by the classic equation $\mathrm{K}=100 \times\left(\mathrm{W} / \mathrm{L}^{3}\right)$ (Froese 2006), where $\mathrm{W}=$ wet weight of an individual, $\mathrm{L}=$ total length, and the exponent 3 is an assumption that indicates isometric growth. Second, I calculated condition as the residuals of the best-fit line between $\log$ (weight) and $\log$ (length) by linear least-squares regression (referred to hereafter as the residuals of the lengthweight relationship), which is considered to be a more robust measure (Panfili et al. 2005)

\subsubsection{Analyses}

\section{Outliers}

I detected a large number of outliers during analyses of the assumptions of FA. These were present both in the raw data and in the residual asymmetry index. To establish outliers I used boxplots of the unsigned residual index and selected individuals who fell outside 1.5 times the interquartile range, or roughly 2 standard deviations, from the median for each variable of fluctuating asymmetry. I counted 18 outliers total. Of these, 11 were male and 7 female, 10 were from Wahine Park and 8 from Kau Bay, and all were larger than $150 \mathrm{~mm}$ (total length). While it can be acceptable to delete outliers on statistical grounds in studies of FA (e.g. Lemberget and McCormick 2009), being that it is deviations, particularly large deviations from 0 , that we are interested in, deleting outliers ultimately results in deleting the most interesting data points. The consequence of including outliers in the data set is that the distributions of FA displayed skew and kurtosis; however, it is unlikely that this is indicative of directional or anti-symmetry for the variables examined. Otoliths are used for a variety of vital functions that rely on balance or symmetry between the right and left (Gagliano et al. 2008), and it is safe to assume that deviations from 
symmetry would not be selected for and do not reflect anti-symmetry or directional asymmetry. I retained outliers for further analyses as they constituted an important contribution to the dataset. For comparison, I constructed a second dataset with these outliers removed and tested it for the assumptions of FA and for a relationship with condition, site, sex, and size class. In addition, I test both datasets for homogeneity of variances with Bartlett's test and assume that the magnitude of skew or kurtosis do no seriously violate the assumptions of normality for the following parametric statistical analyses. To examine the effect of retaining outliers, I report results from the complete dataset and discuss them in relation to results from the dataset with outliers removed.

Asymmetry, condition, and site

To assess the relationship between FA, condition, and site, I used analysis of covariance (ANCOVA) with site as a predictor variable, condition as a covariate, and asymmetry as a response variable. I ran ANCOVA for each asymmetry variable independently, and for each $\mathrm{K}$ and residuals of the length-weight relationship. As site was shown not to have a significant effect, I pooled samples from the two sites and used linear least-squares regression to test the relationship between condition and each variable of asymmetry. Where an obvious outlier affected the result, I removed the outlier and repeated the regression. I did this rather than rerunning the linear regression for each variable with the dataset that had 18 outliers removed because only two variables, area and axis (major), were clearly affected by outliers in the analysis directly involving condition. In addition, I compared condition (K) and condition as measured by the residuals of the length-weight relationship directly between sites using analysis of variance.

\section{Asymmetry, sex, and size}

As there was no detectable difference in FA between sites, I pooled sites to test for differences in asymmetry between males and females, and between two size classes, using analysis of variance (ANOVA). I selected two size classes, individuals $\geq 150 \mathrm{~mm}$, and individuals $<150 \mathrm{~mm}$, as this roughly represents the age of sex change at these sites (Chapter 2). 
Relative expression of fluctuating asymmetry in otolith variables

I used principal components analysis (PCA) to test the relative expression of FA in the 5 variables of otolith size, using the correlation matrix as this accounts for scaling of different units. The first principal component explained a large proportion of the variation (51.8\%) and I used scores from the first principal component axis as a composite index of FA. I compared this composite index between sites and against $\mathrm{K}$ and the residuals of the length-weight relationship with ANCOVA. The expression of asymmetry in these otolith variables is discussed.

I conducted all analysis in R statistical software (R development core team 2012).

\subsection{RESULTS}

\subsubsection{Assumptions of fluctuating asymmetry}

A total of 112 individuals (224 otoliths) were retained in the following analyses, with 47 from Wahine Park and 65 from Kau Bay. Of these, 25 males and 22 females were from Wahine Park, while 15 males and 50 females were from Kau Bay.

\section{Trait-size correlation}

There was a significant relationship between each variable of asymmetry and trait-size for all variables except perimeter and axis (minor) at Wahine Park, and axis (major) at Kau Bay (Table 3.1). For consistency, I used the residual index (residuals of the trait-size relationship, see Trait-size correlation in Methods) in all subsequent analyses. 
Table 3.1: Relationship between fluctuating asymmetry (FA) and trait-size of otoliths from spotties (Notolabrus celidotus) collected from Wahine Park and Kau Bay. Pvalues and rho are calculated from Spearman's Rank Correlation Coefficient for five variables of otolith size: area, perimeter, axis (major), axis (minor), and weight. Results are presented for each site separately and sites pooled. FA was significantly related to otolith size as measured in area and weight at both sites, in perimeter and axis (minor) at Kau Bay, and in axis (major) at Wahine Park. Results significant at $\alpha$ $=0.05$ are shown in bold.

\begin{tabular}{clrr}
\hline FA variable & \multicolumn{1}{c}{ Site } & $\boldsymbol{\rho}$ & $\mathbf{P}$ \\
\hline Area & Wahine Park & 0.33 & $\mathbf{0 . 0 2}$ \\
& Kau Bay & 0.4 & $<\mathbf{0 . 0 0 1}$ \\
& Pooled & 0.39 & $<\mathbf{0 . 0 0 1}$ \\
Perimeter & Wahine Park & 0.03 & 0.86 \\
& Kau Bay & 0.29 & $\mathbf{0 . 0 1 9}$ \\
& Pooled & 0.19 & $\mathbf{0 . 0 4 7}$ \\
Axis (major) & Wahine Park & 0.33 & $\mathbf{0 . 0 2}$ \\
& Kau Bay & 0.1 & 0.41 \\
Axis (minor) & Pooled & 0.28 & $\mathbf{0 . 0 0 3}$ \\
& Wahine Park & 0.12 & 0.43 \\
& Kau Bay & 0.33 & $\mathbf{0 . 0 0 8}$ \\
Weight & Pooled & 0.25 & $\mathbf{0 . 0 0 7}$ \\
& Wahine Park & 0.52 & $<\mathbf{0 . 0 0 1}$ \\
& Kau Bay & 0.49 & $<\mathbf{0 . 0 0 1}$ \\
& Pooled & 0.49 & $<\mathbf{0 . 0 0 1}$ \\
\hline
\end{tabular}

\section{Departure from normality}

All variables were significantly right-skewed except for area and perimeter at Wahine Park (Table 3.2). Area and perimeter were slightly platykurtotic at Wahine Park (values clumped near centre of distribution, indicated by negative value sign), and leptokurtotic at Kau Bay (values distributed in tails of distribution, indicated by positive sign; Table 3.3). All other variables were slightly leptokurtotic (Table 3.3). The mean of the distribution of each variable was not significantly different from 0 at either site (Table 3.4). When the dataset with outliers removed was tested, there was no significant skew for any variable, and only perimeter was slightly platykurtotic at Kau Bay $(-1.099$, significant at $\alpha=0.05)$. The mean was not significantly different from 0 for any variable except for perimeter at Kau Bay $(\mathrm{P}<0.001)$. When sites were pooled with outliers removed, perimeter was slightly right skewed $(0.95, \mathrm{P}<0.001)$, and no significant kurtosis was detected for any variable. 
Table 3.2: Skew in the distribution of fluctuating asymmetry (FA) values measured in otoliths of spotties (Notolabrus celidotus) for five variables of otolith size: area, perimeter, axis (major), axis (minor), and weight. Otoliths were collected from two sites, Kau Bay and Wahine Park, and skew and an associated p-value are presented for each site and for sites pooled. The distribution of all variables is significantly right skewed at Kau Bay and for the sites pooled, and significantly right skewed for axis (major), axis (minor), and weight at Wahine Park. Results significant at $\alpha=0.05$ are shown in bold.

\begin{tabular}{clrr}
\hline FA variable & \multicolumn{1}{c}{ Site } & Skew & P \\
\hline Area & Wahine Park & 0.39 & 0.14 \\
& Kau Bay & 3.72 & $\mathbf{0}$ \\
& Pooled & 3.29 & $\mathbf{0}$ \\
Perimeter & Wahine Park & 0.56 & 0.06 \\
& Kau Bay & 2.26 & $<\mathbf{0 . 0 0 1}$ \\
& Pooled & 1.56 & $<\mathbf{0 . 0 0 1}$ \\
& Wahine Park & 1.33 & $<\mathbf{0 . 0 0 1}$ \\
Axis (major) & Kau Bay & 3.25 & $<\mathbf{0 . 0 0 1}$ \\
& Pooled & 2.64 & $\mathbf{0}$ \\
Axis (minor) & Wahine Park & 0.76 & $\mathbf{0 . 0 2}$ \\
& Kau Bay & 1.22 & $<\mathbf{0 . 0 0 1}$ \\
& Pooled & 1.01 & $<\mathbf{0 . 0 0 1}$ \\
Weight & Wahine Park & 1.01 & $<\mathbf{0 . 0 0 1}$ \\
& Kau Bay & 1.19 & $<\mathbf{0 . 0 0 1}$ \\
& Pooled & 1.06 & $<\mathbf{0 . 0 0 1}$ \\
\hline
\end{tabular}

Table 3.3: Kurtosis in the distribution of fluctuating asymmetry values measured in otoliths of spotties (Notolabrus celidotus) for five variables of otolith size: area, perimeter (Perim), axis major (Amj), axis minor (Amn) and weight (W). Otoliths were collected from two sites, Kau Bay and Wahine Park, and significant kurtosis at $\alpha$ $=0.05$ is represented by $(* *)$ and for $\alpha=0.01$ by $(*)$. Significant kurtosis occurs for all variables at all sites except for perimeter and axis (minor) at Wahine Park. Platykurtosis is indicated by a negative sign and leptokurtosis by a positive sign. Critical values were taken from Palmer and Strobeck (2003).

\begin{tabular}{llllll}
\hline Site & Area & \multicolumn{1}{c}{ Perim } & \multicolumn{1}{c}{$\mathbf{A}(\mathbf{m j})$} & \multicolumn{1}{c}{$\mathbf{A}(\mathbf{m n})$} & \multicolumn{1}{c}{$\mathbf{W}$} \\
\hline Wahine Park & $-1.08^{*}$ & -0.76 & $2.39^{*}$ & 0.25 & $1.73^{* *}$ \\
Kau Bay & $20.6^{*}$ & $5.81^{*}$ & $16.8^{*}$ & $1.72^{* *}$ & $2.02^{*}$ \\
Pooled & $20.7^{* *}$ & $2.82^{* *}$ & $12.64^{* *}$ & $1.16^{*}$ & $2.09^{* *}$ \\
\hline
\end{tabular}


Table 3.4: Results from one sample t-tests for the mean level of fluctuating asymmetry measured in otoliths of spotties (Notolabrus celidotus). Five variables were measured for asymmetry: area, perimeter (Perim), axis major (Amj), axis minor (Amn) and weight (W). Samples were collected from two sites, Kau Bay and Wahine Park, and results are presented from each site and for sites pooled. The mean is not significantly different from 0 at any site or when sites are pooled.

\begin{tabular}{llllll}
\hline Site & Area & Perim & A(mj) & A(mn) & W \\
\hline Wahine Park & 0.4 & 0.2 & 0.5 & 0.6 & 0.6 \\
Kau Bay & 0.6 & 0.3 & 0.6 & 0.7 & 0.6 \\
Pooled & 1 & 1 & 1 & 1 & 1 \\
\hline
\end{tabular}

\subsubsection{Measurement error}

There was a significant difference between individual fish and between otolith side (right or left) for all variables despite the residual variation due to measurement error ( $\mathrm{p}<0.0001$ for area, perimeter, axis (major), axis (minor), and weight; ANOVA tables are presented in appendix B). Variance components indicated that residual variation due to measurement error never accounted for more than $0.21 \%$ of the variation present (Table 3.5). This suggests that measurement error is very small compared to differences between otoliths and individuals. I assume that differences between sides detected in this study are due to true FA and are not a consequence of measurement error. 
Table 3.5: Variance components computed from nested analysis of variance for each of five variables repeatedly measured in otoliths from spotties (Notolabrus celidotus): area, perimeter (Perim), axis major (Amj), axis minor (Amn), and weight (W). Repeated measures were nested in side (right or left) the otolith was extracted from, which was nested within individual fish. \% Individual indicates the variation attributed to differences between otoliths of different fish. \% Side indicates the variation attributed to differences between sides the otolith was extracted from. \% Residual indicates residual variation, in this case, variation due to error between repeated measurements. The residual variation due to measurement error does not account for more than $0.21 \%$ of the variation for any variable.

\begin{tabular}{llllll}
\hline Source of variation & Area & Perim & $\mathbf{A}(\mathbf{m j})$ & $\mathbf{A}(\mathbf{m n})$ & $\mathbf{W}$ \\
\hline \% Individual & 96.8 & 97.9 & 97.4 & 57.4 & 98.9 \\
\% Side & 3.12 & 1.85 & 2.55 & 42.6 & 1.09 \\
\% Residual & 0.077 & 0.21 & 0.038 & 0.014 & 0.016 \\
\hline
\end{tabular}

\subsubsection{Fluctuating asymmetry, condition, and site}

Bartlett's test indicated homogeneous variances for all the variables examined. There was a relationship between Fulton's condition factor $(\mathrm{K})$ and FA, which was not affected by site, as indicated by the 'Site: $\mathrm{K}$ ' interaction (Tables $3.6-3.10$ ). At 0.05 , all variables of FA were significantly correlated with $\mathrm{K}$, but asymmetry did not differ significantly between sites (Tables 3.6 - 3.10). Small changes were revealed when outliers were removed. There was a significant interaction between $\mathrm{K}$ and FA for area $\left(\mathrm{F}_{1,90}=4.68, \mathrm{P}=0.03\right)$, axis major $\left(\mathrm{F}_{1,90}=4.96, \mathrm{P}=0.03\right)$, and weight $\left(\mathrm{F}_{1,90}=\right.$ $5.45, \mathrm{P}=0.02)$ only, with still no effect of site present. I conclude that outliers were not primarily driving the correlation between $\mathrm{K}$ and FA. While asymmetry did not significantly differ between sites, there was a non-significant trend for Wahine Park to be more asymmetric despite removing outliers (Figures 3.1 and 3.2).

Condition as measured by the residuals of the length-weight relationship was not related to asymmetry of any variable (ANCOVA, $\mathrm{F}_{1,108}=0.012$ and $\mathrm{P}=0.9$ for area, $\mathrm{F}_{1,108}=0.46$ and $\mathrm{P}=0.5$ for perimeter, $\mathrm{F}_{1,108}=0.46$ and $\mathrm{P}=0.8$ for axis major, $F_{1,108}=0.57$ and $P=0.5$ for axis minor, $F_{1,108}=0.3$ and $P=0.6$ for weight), and did not vary between sites (ANCOVA, $\mathrm{F}_{1,108}=0.23$ and $\mathrm{P}=0.63$ for area, $\mathrm{F}_{1,108}=0.96$ and $\mathrm{P}=0.33$ for perimeter, $\mathrm{F}_{1,108}=0.47$ and $\mathrm{P}=0.49$ for axis major, $\mathrm{F}_{1,108}=0.56$ and 
$\mathrm{P}=0.46$ for axis minor, $\mathrm{F}_{1,108}=0.007$ and $\mathrm{P}=0.9$ for weight). None of these relationships were made significant by deleting outliers.

Table 3.6: Relationship between site, Fulton's condition factor $(\mathrm{K})$, and fluctuating asymmetry (FA) in the otoliths of spotties (Notolabrus celidotus). FA is measured in 5 variables of otolith size: area (a), perimeter (b), axis major (c), axis minor (d), and weight (e). Analysis of covariance was performed with site as a fixed factor, condition as a covariate, and asymmetry as a response. FA does not differ significantly between sites for any variable (interaction term 'Site'). FA is related to $\mathrm{K}$ (interaction term ' $\mathrm{K}$ ') but this relationship is not affected by site ('Site: $\mathrm{K}$ ' interaction). Relationships that are significant at $\alpha=0.05$ are in bold.

\begin{tabular}{|c|c|c|c|c|}
\hline $\begin{array}{l}\text { Source of } \\
\text { variation }\end{array}$ & df & MS & $\mathbf{F}$ & $\mathbf{P}$ \\
\hline \multicolumn{5}{|l|}{ a. Area } \\
\hline Site & 1 & $8.27 \times 10^{-05}$ & 0.017 & 0.895 \\
\hline $\mathrm{K}$ & 1 & 0.023 & 4.774 & 0.031 \\
\hline Site:K & 1 & 0.011 & 2.359 & 0.128 \\
\hline Residuals & 108 & 0.005 & & \\
\hline \multicolumn{5}{|c|}{ b. Perimeter } \\
\hline Site & 1 & 0.002 & 0.486 & 0.487 \\
\hline $\mathrm{K}$ & 1 & 0.041 & 8.246 & $<0.01$ \\
\hline Site:K & 1 & 0.015 & 2.965 & 0.088 \\
\hline Residuals & 108 & 0.005 & & \\
\hline \multicolumn{5}{|c|}{ c. Axis (major) } \\
\hline Site & 1 & $7.56 \times 10^{-05}$ & 0.076 & 0.784 \\
\hline $\mathrm{K}$ & 1 & 0.005 & 4.514 & 0.036 \\
\hline Site:K & 1 & 0.002 & 2.106 & 0.150 \\
\hline Residuals & 108 & 0.001 & & \\
\hline \multicolumn{5}{|c|}{ d. Axis (minor) } \\
\hline Site & 1 & 0.0002 & 0.741 & 0.391 \\
\hline $\mathrm{K}$ & 1 & 0.001 & 5.301 & 0.023 \\
\hline Site:K & 1 & $8.88 \times 10^{-06}$ & 0.036 & 0.850 \\
\hline Residuals & 108 & 0.0002 & & \\
\hline \multicolumn{5}{|l|}{ e. Weight } \\
\hline Site & 1 & $3.56 \times 10^{-09}$ & 1.458 & 0.230 \\
\hline $\mathrm{K}$ & 1 & $2.52 \times 10^{-08}$ & 10.33 & $<0.01$ \\
\hline Site:K & 1 & $6.05 \times 10^{-11}$ & 0.025 & 0.875 \\
\hline Residuals & 108 & $2.44 \times 10^{-09}$ & & \\
\hline
\end{tabular}



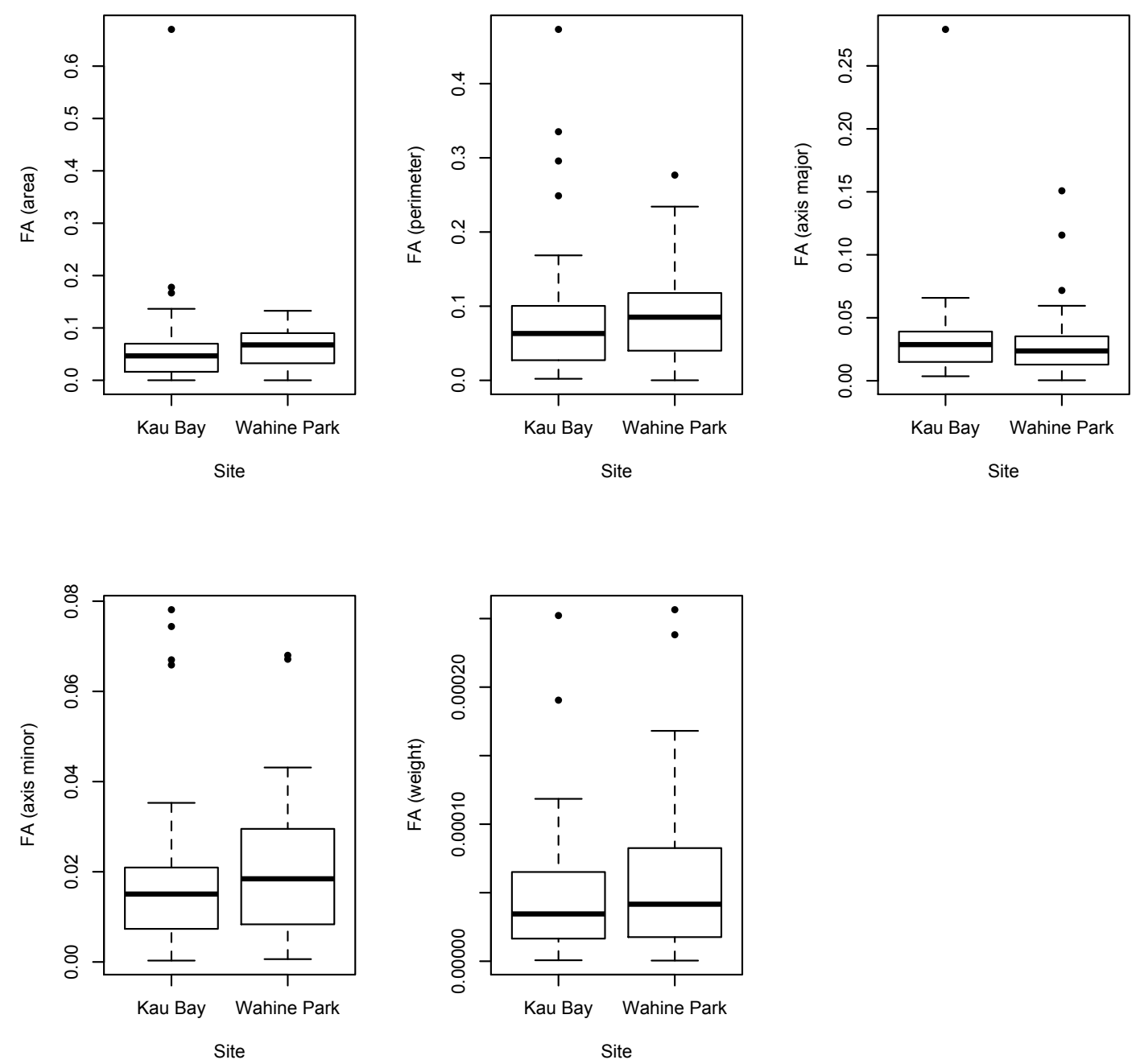

Figure 3.1: Boxplots showing outliers in the unsigned (absolute) distribution of residual fluctuating asymmetry (FA) indices measured in otoliths of spotties (Notolabrus celidotus) collected from Wahine Park and Kau Bay. FA did not differ significantly between sites, but there is a non-significant trend for it to be greater at Wahine Park, as measured in 5 variables of otolith size: area, perimeter, axis (major), axis (minor), and weight. Bold horizontal lines indicate median fluctuating asymmetry value for each variable. The top and bottom of each box shows the first and third quartiles and encompass the middle $50 \%$ of the data. The whiskers show the maximum and minimum value or 1.5 times the interquartile range depending on which is lower. 

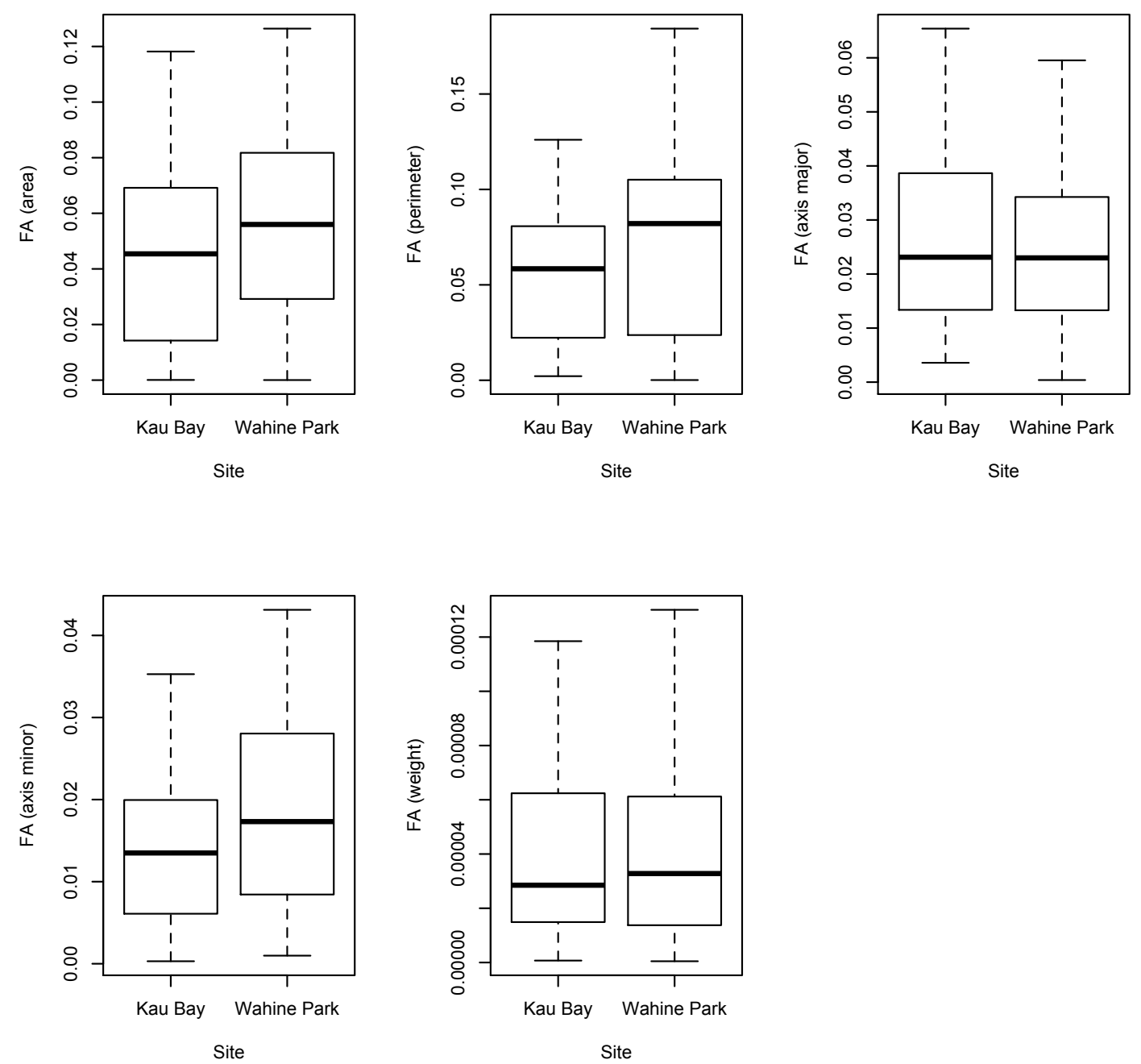

Figure 3.2: Boxplots showing the unsigned (absolute) distribution of residual fluctuating asymmetry (FA) indices measured in otoliths of spotties (Notolabrus celidotus) collected from Wahine Park and Kau Bay. FA does not differ significantly between sites but there is a non-significant trend for it to be greater at Wahine Park despite the removal of a number of outliers. FA is measured in 5 variables pertaining to otolith size: area, perimeter, axis (major), axis (minor), and weight. Bold horizontal lines indicate median fluctuating asymmetry value for each variable. The top and bottom of each box shows the first and third quartiles and encompass the middle $50 \%$ of the data. The whiskers show 1.5 times the interquartile range. 


\section{Condition (K) and fluctuating asymmetry}

Weight was most significantly correlated with $\mathrm{K}\left(\mathrm{R}^{2}=0.09, \mathrm{R}_{\mathrm{adj}}=0.08, \mathrm{P}=\right.$ $0.001)$, followed by perimeter $\left(\mathrm{R}^{2}=0.06, \mathrm{R}_{\mathrm{adj}}=0.05, \mathrm{P}=0.007\right)$ and axis minor $\left(\mathrm{R}^{2}=\right.$ $0.05, \mathrm{R}_{\mathrm{adj}}=0.04, \mathrm{P}=0.02$, Figure 3.3 ). Area was not significantly correlated with $\mathrm{K}$ when outliers were retained $\left(\mathrm{R}^{2}=0.03, \mathrm{R}_{\mathrm{adj}}=0.02, \mathrm{P}=0.07\right)$, but was when one major outlier was removed $\left(\mathrm{R}^{2}=0.06, \mathrm{R}_{\mathrm{adj}}=0.05, \mathrm{P}=0.01\right.$, Figure 3.4). Axis (major) was not significantly correlated with $\mathrm{K}\left(\mathrm{R}^{2}=0.02, \mathrm{R}_{\mathrm{adj}}=0.01, \mathrm{P}=0.1\right.$, Figure 3.3), but the relationship was slightly stronger when three outliers were removed $\left(\mathrm{R}^{2}=\right.$ 0.03, $\mathrm{R}_{\mathrm{adj}}=0.02, \mathrm{P}=0.07$, Figure 3.5).
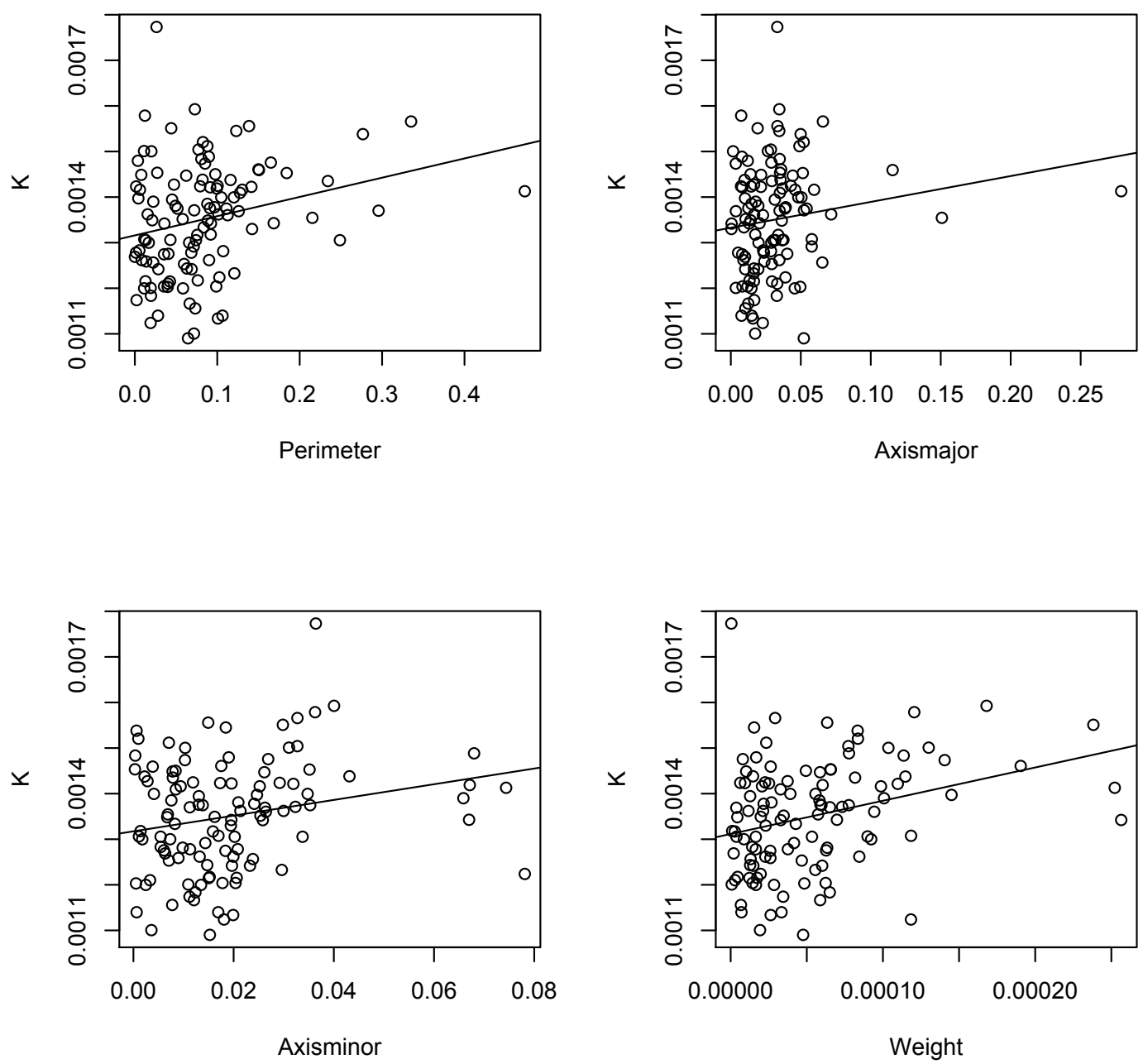

Figure 3.3: Linear least-squares regression between fluctuating asymmetry (FA) and Fulton's condition factor $(\mathrm{K})$ for 4 variables of otolith size: perimeter $(\mathrm{P}=0.007)$, axis (major) showing 3 outliers in far right of the distribution $(\mathrm{P}=0.1)$, axis (minor) $(\mathrm{P}=0.02)$, and weight $(\mathrm{P}=0.001)$. FA is measured from otoliths of spotties (Notolabrus celidotus). There is a positive relationship between $\mathrm{K}$ and FA for each variable. 
a.
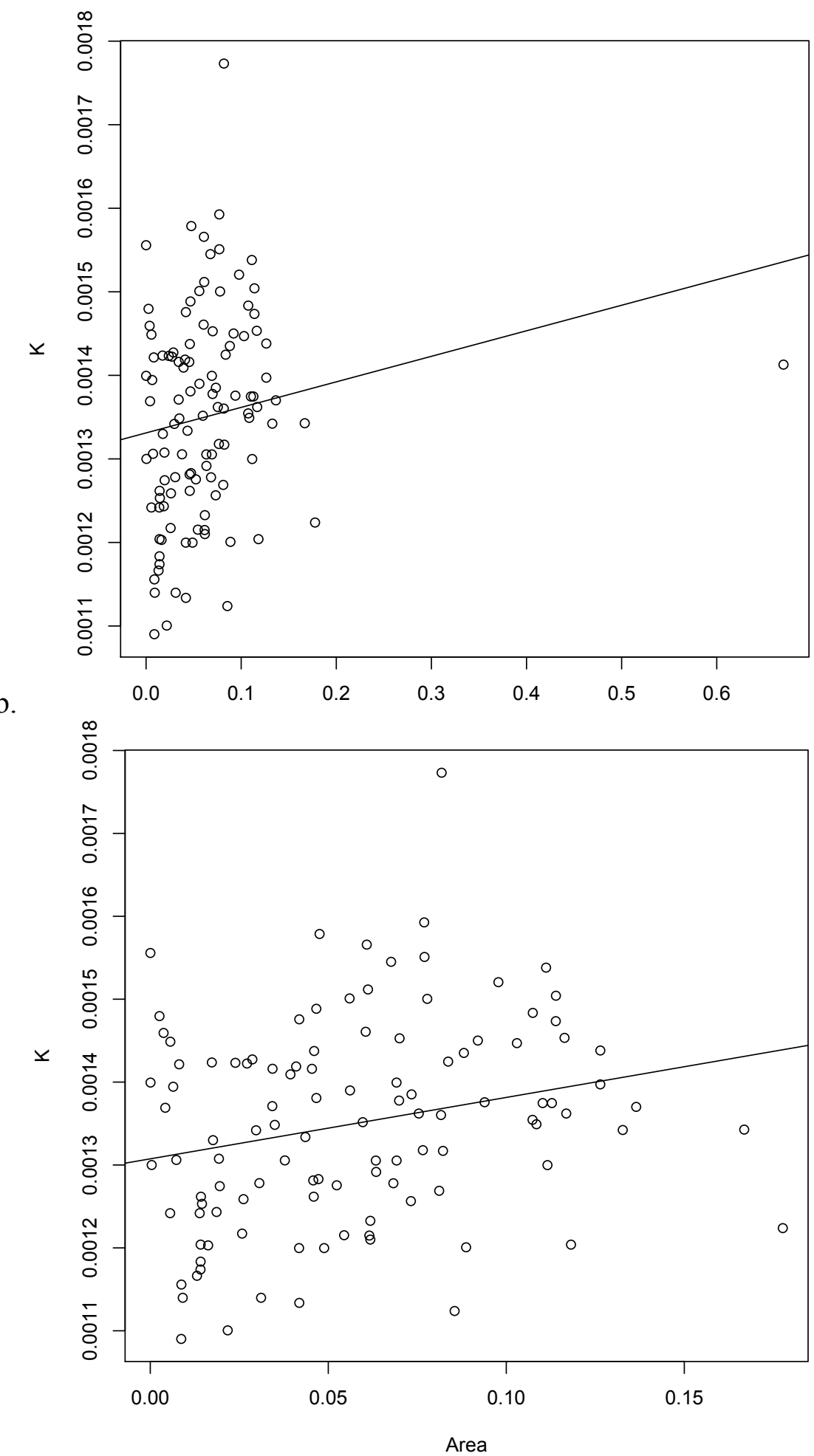

Figure 3.4: Linear least-squares regression between Fulton's condition factor $(\mathrm{K})$ and fluctuating asymmetry (FA) in area showing (a) relationship with outlier $(\mathrm{P}=0.07)$ and (b) relationship after the outlier is removed $(\mathrm{P}=0.01)$. FA is measured in otoliths of spotties (Notolabrus celidotus). The relationship is positive with and without the outlier, but more closely fits the data when the outlier is removed. 


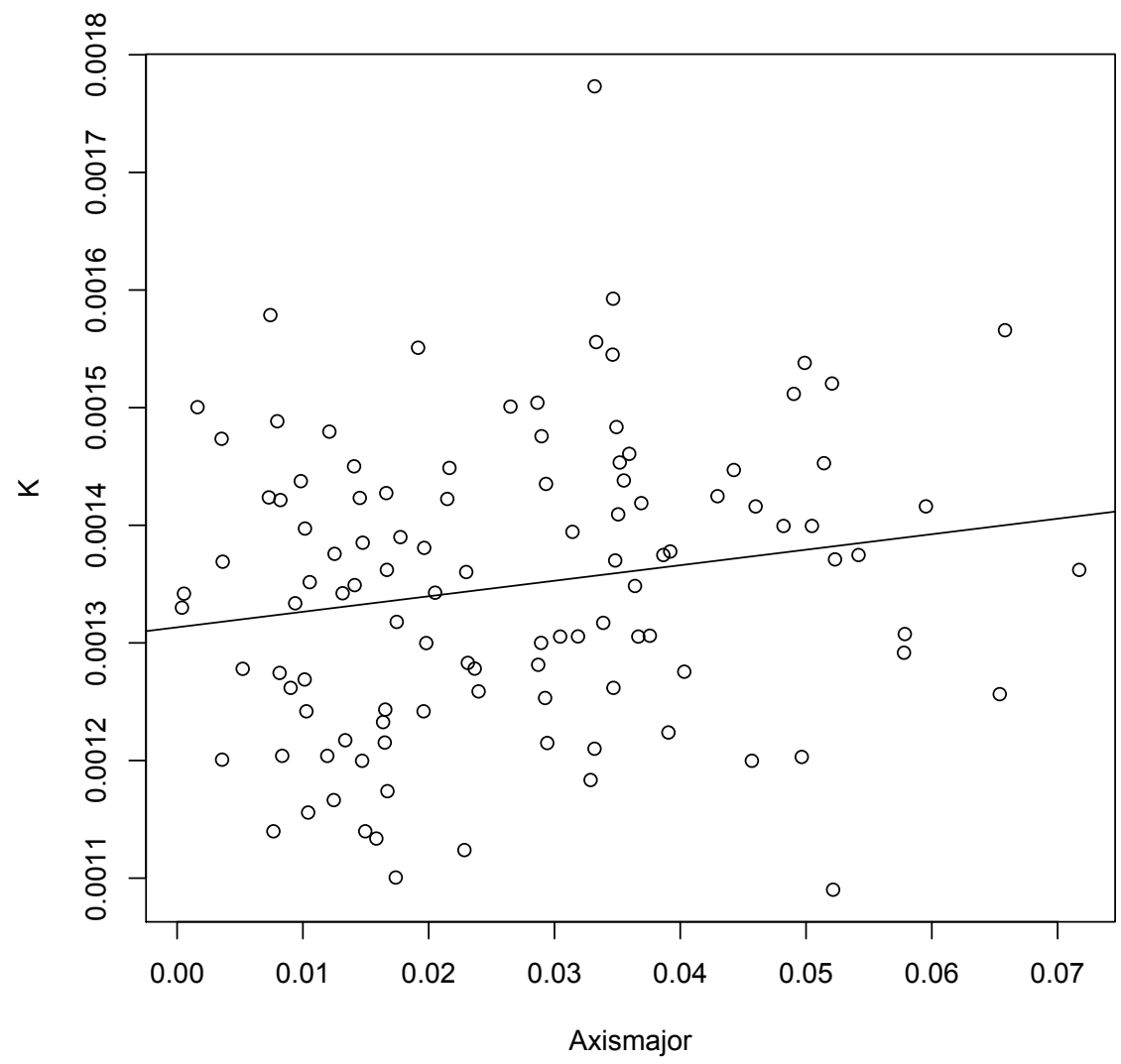

Figure 3.5: Linear least-squares regression between Fulton's condition factor $(\mathrm{K})$ and fluctuating asymmetry (FA) in axis (major) after three outliers were removed ( $\mathrm{P}=$ 0.07). FA is measured in otoliths of spotties (Notolabrus celidotus). There is a positive relationship between FA and condition (K).

\section{Condition and site}

$\mathrm{K}$ differed significantly between sites and was higher at Wahine Park (ANOVA, $\mathrm{F}_{1,110}=53.9, \mathrm{P}<0.001$, Table 3.7, Figure 3.6). Removing outliers did not change the significance of this relationship (ANOVA, $\mathrm{F}_{1,92}=49.2, \mathrm{P}<0.001$ ). The residuals of the length-weight relationship did not differ between sites (ANOVA, $\left.\mathrm{F}_{1,110}=0, \mathrm{P}=1.0\right)$. This relationship was not majorly affected by deleting outliers (ANOVA, $\mathrm{F}_{1,92}=0.02, \mathrm{P}=0.889$ ) and I conclude that outliers do not primarily drive the relationships between site and condition as measured by either $\mathrm{K}$ or the residuals of the length-weight relationship. 
Table 3.7: Fulton's condition factor $(\mathrm{K})$ measured in spotties (Notolabrus celidotus) differs significantly between two sites Kau Bay and Wahine Park (ANOVA). P-value significant at $\alpha=0.01$ is shown in bold.

\begin{tabular}{lrlrr}
\hline Source of variation & \multicolumn{1}{c}{ df } & MS & F & \multicolumn{1}{l}{ P } \\
\hline Site & 1 & $5.55 \times 10^{-07}$ & 53.88 & $<\mathbf{0 . 0 0 1}$ \\
Residuals & 110 & $1.03 \times 10^{-08}$ & & \\
\hline
\end{tabular}

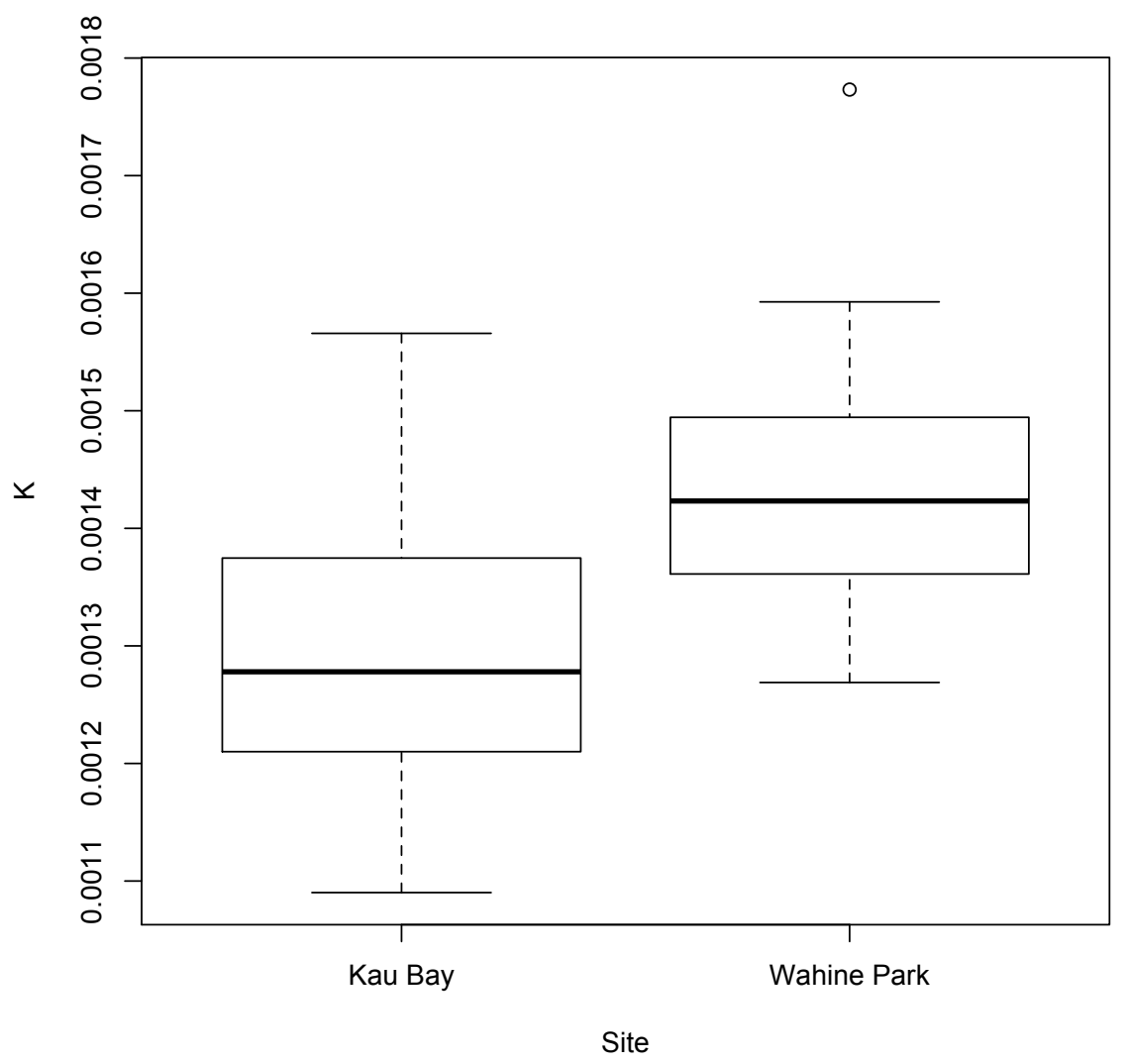

Figure 3.6: Boxplot showing the distribution of Fulton's condition factor $(\mathrm{K})$ measured in spotties (Notolabrus celidotus) at Kau Bay and Wahine Park. The bold horizontal line indicates the median value of $\mathrm{K}$ at each site. The top and bottom of each box show the first and third quartiles and encompass the middle $50 \%$ of the data. The whiskers show the maximum and minimum value for Kau Bay, and at Wahine Park they show the minimum value and 1.5 times the upper interquartile range due to the presence of an outlier. 


\subsubsection{Fluctuating asymmetry, size, and sex}

Given that there was no significant difference between sites for any variable, sites were pooled to examine differences between males and females and between two size classes. Individuals $\geq 150 \mathrm{~mm}$ (total length) were significantly more asymmetric than individuals $<150 \mathrm{~mm}$ for all variables (ANOVA, $\mathrm{F}_{1,110}=11.203$ and $\mathrm{P}=0.001$ for area, $F_{1,110}=12.1$ and $P<0.001$ for perimeter, $F_{1,110}=5.1$ and $P=0.026$ for axis major, $F_{1,110}=9.4$ and $\mathrm{P}=0.003$ for axis minor, $\mathrm{F}_{1,110}=12.9$ and $\mathrm{P}<0.001$ for weight). Significant interactions were retained when outliers were removed (ANOVA, $F_{1,92}=17.9$ and $P<0.001$ for area, $F_{1,92}=5.5$ and $P=0.02$ for perimeter, $F_{1,92}=4.8$ and $\mathrm{P}=0.03$ for axis major, $\mathrm{F}_{1,92}=5.2$ and $\mathrm{P}=0.02$ for axis minor, $\mathrm{F}_{1,92}=6.8$ and $\mathrm{P}=$ 0.01 for weight). Only weight differed significantly between sexes (ANOVA, $\mathrm{F}_{1,110}=$ 14.8 and $\mathrm{P}<0.001)$. When outliers were removed, all variables were significantly more asymmetric in males (ANOVA, $F_{1,92}=7.6$ and $\mathrm{P}=0.007$ for area, $\mathrm{F}_{1,92}=5.7$ and $\mathrm{P}=0.019$ for perimeter, $\mathrm{F}_{1,92}=13.1$ and $\mathrm{P}<0.001$ for axis major, $\mathrm{F}_{1,92}=9.9$ and $\mathrm{P}=0.002$ for axis minor, $\mathrm{F}_{1,92}=16.2$ and $\mathrm{P}<0.001$ for weight).

\subsubsection{Relative expression of fluctuating asymmetry in otolith variables}

The first, second, and third principal components explained 51.78\%, 18.16\%, and $15.45 \%$ of the variation respectively (Figure 3.7 ). When the first principal component was used as a composite index of FA, there was a positive relationship between $\mathrm{K}$ and asymmetry (ANCOVA, $\mathrm{F}_{1,108}=6.1$ and $\mathrm{P}=0.015$ ), which was not significantly affected by site (ANCOVA, $\mathrm{F}_{1,108}=3.45$ and $\mathrm{P}=0.065$ ), and no relationship between the residuals of the length-weight relationship and asymmetry (ANCOVA, $\mathrm{F}_{1,108}=0.04$ and $\mathrm{P}=0.84$ ). According to the first principal component axis, the magnitude of FA decreased for all otolith variables relative to one another, indicated by the consistency in the negative direction of the loadings of each variable (Figure 3.8). The second principal component indicated that as asymmetry in area, axis (minor), and weight increased, asymmetry in perimeter and axis (major) decreased (Figure 3.8). The third principal component suggested that asymmetry in perimeter and axis (minor) decreased as asymmetry in area, axis (major), and weight increased. 


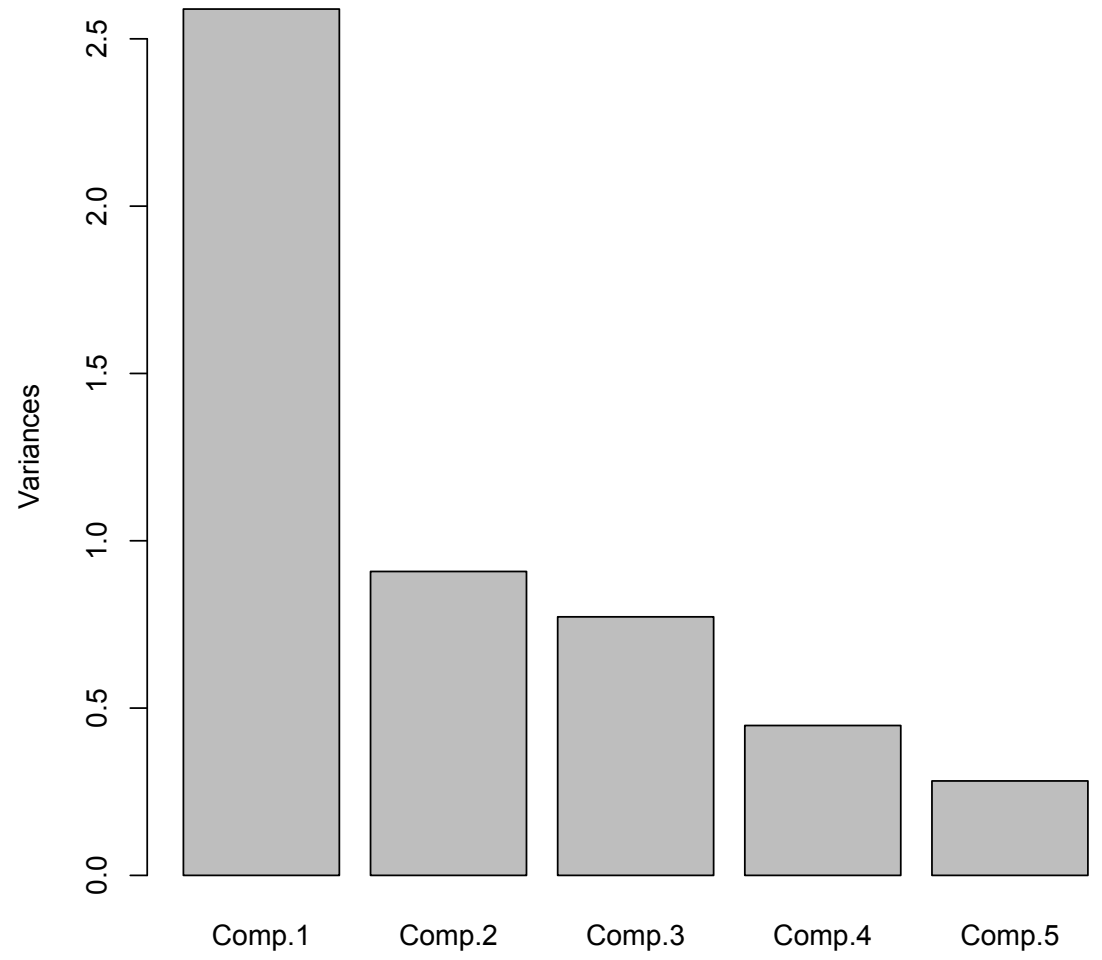

Figure 3.7: Scree plot for a principal components analysis incorporating 5 variables of fluctuating asymmetry measured in otoliths of spotties (Notolabrus celidotus). Bars indicate the relative importance of each principal component. The first three together explain $85 \%$ of the variation present. 


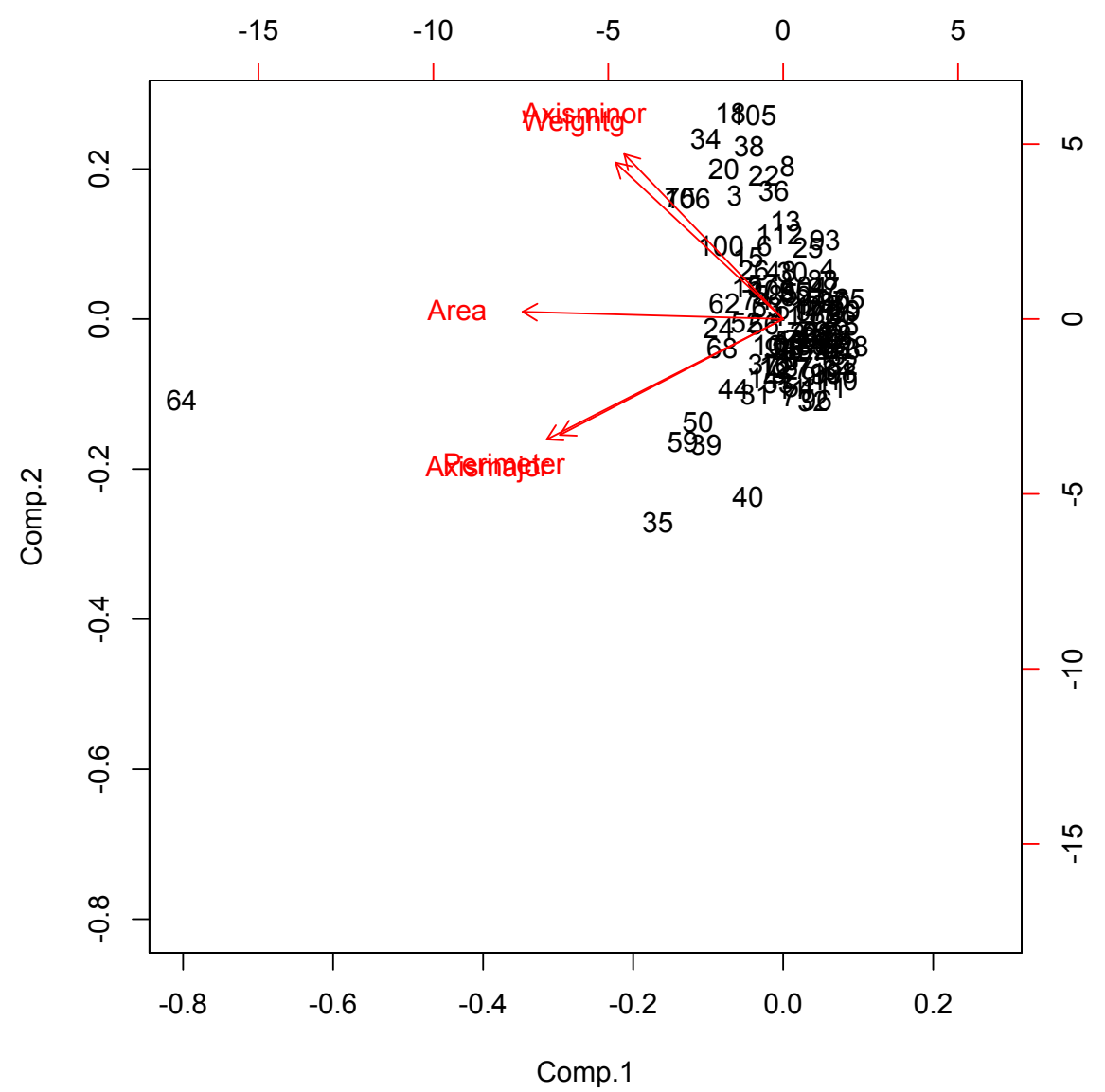

Figure 3.8: Loadings of each variable of fluctuating asymmetry (FA) along the first two principal components. The principal components analysis (PCA) incorporated 5 variables of FA measured in otoliths of spotties (Notolabrus celidotus). The first principal component (Comp. 1) explains 51.78\% of the variation and the second principal component (Comp. 2) explains $18.16 \%$ of the variation. All variables are negative for the first principal component indicating that FA decreases in each variable relative to the others. The second principal component suggests that asymmetry in area, axis (minor), and weight increase (indicated by positive loading) while asymmetry decreases in perimeter and axis (major) (indicated by negative loading). The arrows represent the loadings of the variables. The numbers represent the row in the original data-frame. The PCA was run for variables pooled between spotties collected from Kau Bay and Wahine Park. 


\subsection{DISCUSSION}

\subsubsection{Fluctuating asymmetry and condition}

The results suggest that FA is expressed more strongly in individuals in good physiological condition (Fulton's K), which is unintuitive and does not support my hypotheses. Patterns of correlation between FA and condition indices are inconsistent in literature. Both Grønkjaer and Sand (2003) and Somarakis and colleagues (1997) correlated increased FA with low nutritional condition and low scores of residual length-weight condition indices respectively in otoliths of larval fish, whereas neither Panfili and colleagues (2005) nor Urbach and colleagues (2007) were able to detect a relationship between FA and condition indices in adult populations of fish. The relationship between FA and condition may be confounded in this study by pooling samples across age classes. Length and weight, and the condition factors that rely on these measures, can fluctuate over short temporal scales, for example, due to breeding season or seasonal fluctuations in resource availability (Mello and Rose 2005, Sutton et al. 2000). While condition may reflect recent fluctuations in the relationship between length and weight, my measurements of FA effectively reflect a cumulative stress endured by an individual during its lifetime. In addition, both FA (Gagliano et al. 2008) and condition (Shoup and Wahl 2011) can lead to increased mortality. It is possible that in the populations investigated in this study, asymmetric individuals in poor physiological condition suffered higher mortality than asymmetric individuals in better physiological condition, leading to the slightly positive relationship between FA and condition detected. I suggest, as has Urbach and colleagues (2007), that as condition indices and FA appear to measure different aspects of physiological condition, the two cannot be used interchangeably to estimate condition (however, the two metrics may provide different, but complimentary information). My results suggest that care must be taken if FA is assumed to reflect current physiological condition or if it is used as an indication of recent stress, particularly in adult populations.

\subsubsection{Fluctuating asymmetry and life history traits}

In this study I expected that density-dependent resource limitation would be the primary environmental stressor driving differences in FA and condition between 
Wahine Park and Kau Bay. However, individuals assumed to be under densitydependent stress at Kau Bay tended to be less asymmetric than individuals living at low density at Wahine Park. Again, this pattern could be explained by higher mortality of asymmetric individuals as suggested above (see Fluctuating asymmetry and condition); asymmetric individuals at Wahine Park may have survived to adulthood more frequently than individuals from Kau Bay due to better condition (K). Additionally, slightly higher asymmetry at Wahine Park could be a reflection of carry-over effects from the pelagic larval duration. Triplefins are ecologically similar to spotties and the south coast of Wellington tends to attract lower quality triplefin recruits than the harbour (Shima and Swearer 2009). As asymmetry may be correlated with larval quality (Lemberget and McCormick 2009, Somarakis et al. 1997), it is possible that Wahine Park, which is situated at the harbour entrance on the south coast, is replenished by low quality recruits and asymmetries are retained into adulthood. The relationship between FA, larval quality, and location of recruitment, require further investigation in this species. Further, the relationship between FA and size (discussed in the next section) may also contribute to differences between sites. This study suggests that fish larger than $150 \mathrm{~mm}$ (total length) are more asymmetric than smaller fish, and as large fish were more frequently caught from Wahine Park than at Kau Bay (Chapter 2), the tendency of greater asymmetry at Wahine Park may be driven by this difference in size-frequency between locations.

\subsubsection{Fluctuating asymmetry, sex, and size}

The results suggest that individuals $150 \mathrm{~mm}$ (total length) or larger exhibit greater FA than smaller fish. Fluctuating asymmetry is expected to be more pronounced in large traits, for example, large otoliths compared to small otoliths; however, by using a residual asymmetry index (see Trait-size correlation in Methods), this pattern is presumably controlled for (Palmer and Strobeck 2003). This result suggests that otoliths are sensitive to developing FA late in life history in these populations, when somatic growth has slowed. These data further suggest that stressors influencing asymmetry late in development occur independent of site and may be expressed more strongly in males. This is contrary to my hypothesis that FA would be lower in males due to female mate-selection. I suggest that a period of fast growth after sex change coupled with male-male competition during subsequent breeding seasons may offer additional opportunities for asymmetries to arise in males. 
Serrano et al. (2008) showed that jaws of juvenile male deer were slightly more asymmetric than jaws of juvenile female deer and hypothesized that greater asymmetry would develop in males due to sex-specific trade-offs in reproduction and growth (males grow faster and to a larger size). A similar pattern may be present in protogynous reef fish, where males frequently undergo a period of rapid growth following sex change (Munday et al. 2009, Walker and McCormick 2004). This finding corroborates other studies that detected sex-dependent FA and suggested it was driven by sex-specific growth and energy demands in a species of fly (Bonduriansky 2009) and bird (Helle et al. 2010), but an in depth literature review revealed no other studies demonstrating sex-specific FA in otoliths of fishes. As males tended to be more asymmetric than females in this study, greater FA at Wahine Park could be explained by the higher proportion of males to females relative to Kau Bay (Chapter 2). The consequences of FA for competitive capability and mating success are a common theme in studies of FA (e.g. Bilcik and Estevez 2005, Urbach et al. 2007); however, asymmetry arising from competition in adult populations is rarely investigated. In addition, large females were more asymmetric than small, despite the tendency for males to be more asymmetric than females. Stressors and their influence on FA late in life history require further attention.

\subsubsection{Fluctuating asymmetry in otoliths}

In this study, FA measured in 5 variables of otolith size increased for each variable simultaneously (Figure 3.8; comp 1), and using a composite index of asymmetry detected the same positive relationship between $\mathrm{K}$ and FA as using individual indices for each variable. This differs from results reported by Panfili and colleagues (2005), who found that FA decreased in some variables of otolith size as it increased for others in otoliths of two estuarine fish species. Based on their result, Panfili and colleagues (2005) suggested that analysing multiple measurements of otolith size was akin to analysing multiple traits, but the results of this study suggests that this is not the case for spotties. As area and weight appeared to be most sensitive for detecting FA, this study corroborates the suggestion that shape descriptor variables will be most effective for detecting FA in otoliths (Palmer et al. 2010) and I suggest that future work should focus on measuring otolith shape. Further, these results suggest caution must be taken if only one variable of a trait is to be measured, as not all will express the same magnitude of FA (Lens et al. 2002). 


\subsubsection{Outliers}

Outliers did not appear to be primarily driving the relationship between FA and condition, or the lack of correlation between FA and site. Interestingly, outliers were not more common from either sex or site, but were all from individuals larger than $150 \mathrm{~mm}$ (total length). As the most extreme cases of FA in this study occurred in large fish, this reinforces my suggestion that further investigation is necessary to understand how and why FA arises late in development.

The difference between left and right otoliths in outliers was visible (Figure 3.9a). One individual that was excluded from all analyses deserves mention. This fish, collected from Wahine Park, was missing its right pelvic fin and the absence of obvious scar tissue implied it had been missing this fin throughout its lifespan. I believe this would constitute classification as directional asymmetry as one side would have been favoured throughout development. Accordingly, the two otoliths varied considerably in shape and opacity (Figure 3.9b). In the case of outliers retained in this study, no other such exceptions were noted. I assume all outliers reflect real cases of extreme FA, and suggest that outliers be given more attention in future studies of asymmetry as they represent particularly interesting data points.

\subsubsection{Conclusions}

Overall, this study suggests that FA in adult populations of spotties is a convoluted measure and may not be useful without developing knowledge of baseline levels of FA expressed naturally in populations. Fluctuating asymmetry in this study was inconsistently related to the condition indices measured and did not reflect a stressed life history characterised by density-dependent resource limitation. Fluctuating asymmetry was, however, greater in larger fish despite controlling for a relationship between trait-size and asymmetry. Late-life stressors require further investigation, particularly in protogynous reef fish where sex-specific growth may lead to differences in FA between males and females. The results support the notion that measuring otolith shape is important for detecting true FA in otoliths (Palmer et al. 2010); however, they do not support the suggestion that investigating different variables of otolith size is akin to measuring multiple traits for spotties (Panfili et al. 2005). Further research should focus on the relationship between FA, condition, and mortality, and aim to evaluate natural levels of FA in different stages of life history, if FA is to be used effectively as an indicator of stress in populations of reef fish. 
a.
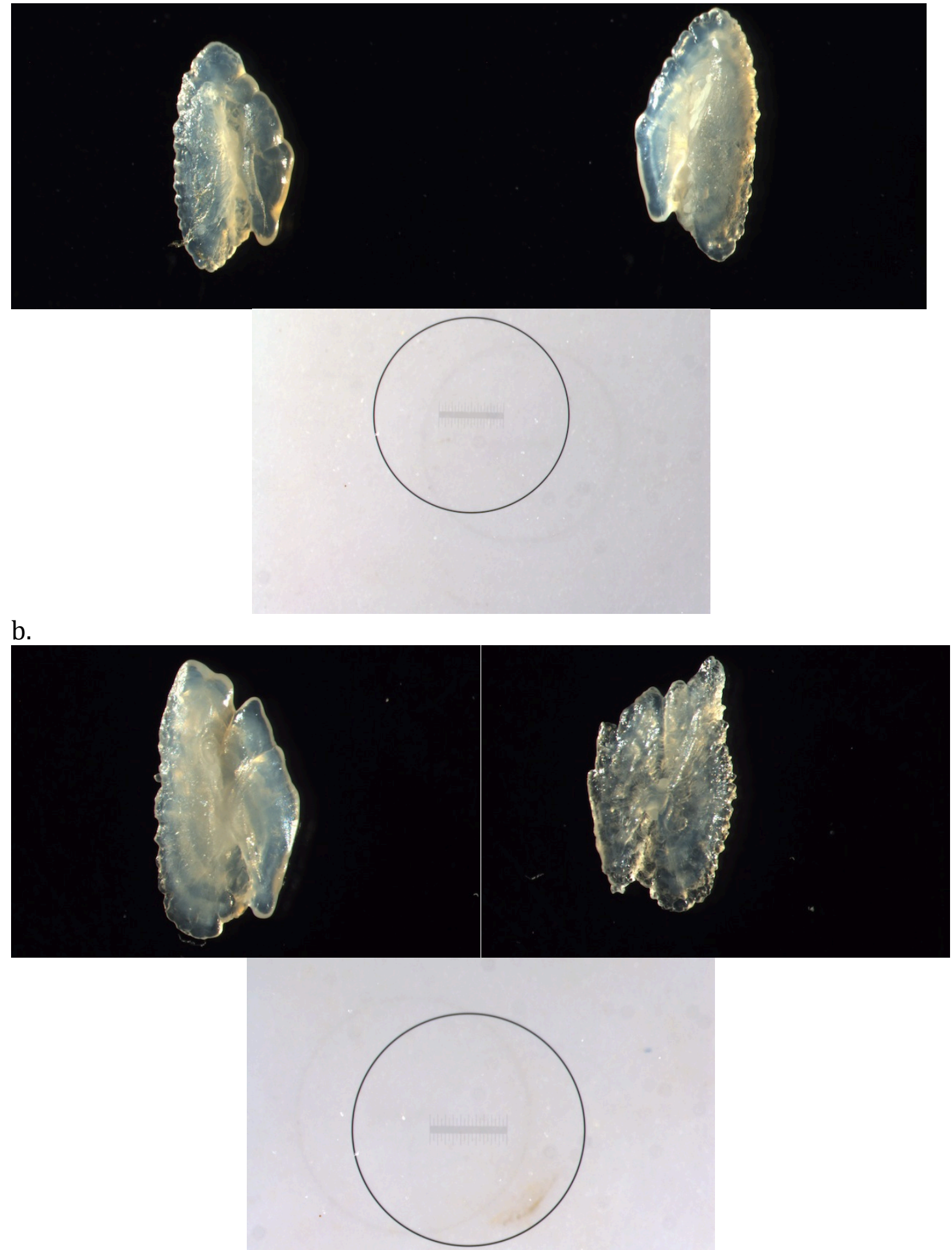

Figure 3.9: Asymmetry in otoliths collected from spotties (Notolabrus celidotus) showing (a) extreme fluctuating asymmetry between otoliths from an outlier collected at Kau Bay and (b) directional asymmetry between two otoliths from an individual collected at Wahine Park that was missing the right pelvic fin. The encircled line at the bottom of each (a) and (b) indicates $1 \mathrm{~mm}$ on the photos above. 


\section{Chapter 4: \\ Environmental drivers of variation in social structure of populations of Notolabrus celidotus}

\subsection{INTRODUCTION}

Environmental patterns and processes vary across a range of spatial and temporal scales (Bolliger et al. 2005, Emlen and Oring 1977, C. Moore et al. 2011). Heterogeneity in the physical environment, such as habitat composition and patchiness, substrate type, and topographic complexity, helps to shape the natural organisation and distribution of organisms (Schröder and Seppelt 2006, Wagner and Fortin 2005). In the marine environment, fish assemblages are sensitive to variation in the environmental landscape around them. Community structure can be altered by the presence of contiguous reef or patch reef (Ault and Johnson 1998) and specific features of habitat can be used to explain variation in species assemblages (GroberDunsmore et al. 2008). Friedlander and Parrish (1998), for example, integrated multiple measures of habitat (reef rugosity or relief, percent cover of substrate type, percent cover of algal species, depth, and location) to describe variation in species assemblage and found that location and habitat complexity (shelter, rugosity, and substratum cover) were critically important for explaining species diversity. In addition, physical environment may shape population density. Although magnitude of recruitment can lead to variation in density among separate locations (e.g. Jones 1980, Gust et al. 2002), Ault and Johnson (1998) reinforced that habitat, reef composition, and post-recruitment processes are also important in determining the density of a population.

Density is related to sex ratio and size-frequency in populations of hermaphroditic reef fish (Munday et al. 2006). Density, sex ratio, and size-frequency describe the social structure of a population, and shifts in social structure can reflect plasticity in mating strategy and the timing of sex change. As the physical environment can influence population density, it may also influence the social structure and mating strategy of populations of hermaphroditic reef fish, particularly for species that are habitat specialists in some aspect of their ecology. Caracanthus unipinna, for example, is an obligate coral-dwelling goby and can change sex from female to male (Wong et al. 2005). Wong and colleagues showed that individuals 
formed monogamous pair bonds on small coral heads where population density was low and the sex ratio was limited to one male and one female. However, on large coral heads, population density increased, the sex ratio became skewed towards females, and individuals engaged in polygyny (Wong et al. 2005). Alternatively, the black-eyed goby is not a habitat specialist but relies on the availability of a specific spawning habitat to attract mates (Breitburg 1987). Breitburg (1987) showed that interspecific competition for spawning territories limited the number of territories available to black-eyed gobies, and selected for populations characterised by femaleskewed sex ratios and fewer larger males than when interspecific competition was relieved. This exemplifies how an interaction between the physical environment and prevalence of other species can influence social structure and mating strategy. Understanding the relationship between social structure and environmental variables is important (Robertson and Warner 1978), but investigations of these interactions are rare (e.g. Lejeune 1987).

In northeastern New Zealand, topographic complexity and macroalgal cover can influence the abundance of reef fishes (Choat and Ayling 1987, Connell and Jones 1991, Kingett and Choat 1981), but associations between individual species and habitat are not well studied in many locations (Cole et al. 2012). This study takes advantage of a natural gradient in swell exposure to investigate the relationship between environmental variables and social structure of the protogynous (female first) hermaphrodite, the spotty (Notolabrus celidotus). The Wellington Harbour entrance on the south coast of Miramar Peninsula frequently experiences swells from $2-6 \mathrm{~m}$ and is characterised by deep bedrock habitat with a variety of algal species dispersed along the benthos. Conversely, there is an abundance of sandy habitat inside the harbour where the magnitude of swell decreases, and algal habitat is typically limited to shallow reefs. Spotties are described as a generalist species and exploit a variety of habitats and prey items (Davis 2010). Despite their generalist tendencies, though, a preference for specific spawning territories may limit the rate of sex change in some locations (Chapter 2), as males require open rocky area with central algal cover to attract females to spawn (Jones 1981). Furthermore, evidence suggests that sizefrequency of individuals is reduced (Choat and Ayling 1987), and population density increases, in the sheltered regions of exposure gradients (Davis 2010, Schiel and Hickford 2001). Studies indicate that juveniles display a strong preference for shallow algal habitat (Jones 1984a, Pérez-Matus and Shima 2010b), but rarely report the 
distribution of males and females, despite that this species displays clear sexual dimorphism.

Here, I investigate if population density, size-frequency, and sex ratio can be explained by variation in substratum type, topographic complexity, percent cover of substrate holders, and location along the length of the Wellington Harbour entrance. Specifically I ask: how well do environmental variables explain natural variation in the social structure of spotties? I hypothesize that 1) density will increase and sizefrequency will decrease with increasing proximity to the northern end of Miramar Peninsula, 2) density and size-frequency will be related to habitat type due to ontogenetic shifts in habitat preference; juveniles (small size-frequency) will be associated with rocky substrate and algal habitat while adults will be more generalist in habitat preference 3) high density will be correlated with algal habitat due to juvenile preference, and 4) sex ratio will be constrained by territory availability and be skewed towards females where desirable spawning territory is limiting (in sandy areas with low relief). The opportunity is taken to compare social structure of spotties with density of other fish species, as a correlation may suggest important interspecific competition.

\subsection{METHODS}

\subsubsection{Species and sampling}

Spotties are sexually dimorphic (Choat 1965, Chapter 1). The initial phase (female) displays a dark lateral spot while the terminal phase (male) displays a dorsal barring pattern; the terms 'initial phase' and 'terminal phase' are used as a small number of males sometimes retain the initial phase colour pattern (Jones 1980). Male spotties attract mates by actively defending spawning territories, and females select the territories they spawn in (Jones 1981). Jones (1981) suggests that the most desirable territories are characterised by an open rocky area with a large boulder and some central algal cover.

This study took place in Wellington during the spawning season for spotties in July 2012. I sampled 30 sites along the east coast of Miramar Peninsula between Kau Bay and Palmer Head (Figure 4.1). Miramar Peninsula is characterised by a gradient in swell exposure; Kau Bay is north-facing and protected from southerly swell while 
Palmer Head is on the south coast and frequently experiences swells from $2-6 \mathrm{~m}$. This presents a range of physical environments with bedrock and algae along the south coast being replaced by sand and shallow reef in the harbour (personal observation).

I used a stationary sampling method (Bohnsack and Bannerot 1986) to estimate spotty density, size-frequency, sex ratio, and environmental variables between Palmer Head and Kau Bay. Stationary sampling involves an observer remaining stationary while making observations in a set area and for a set amount of time (one station). This method allows multiple sites to be sampled quickly and can be effective for juvenile spotties as transects often underestimate small individuals sheltering in algae (Willis 2001). I sampled 30 sites over the course of two days with 15 sites that represented the southern half of the harbour gradient sampled on day one and 15 sites that represented the northern half of the harbour gradient sampled on day two (Figure 4.1). On a sampling day, I sampled sites in no particular order to reduce a confounding effect from time of day. The weather in Wellington can change rapidly and often unexpectedly. I chose two consecutive sampling days with similar marine forecasts to minimise confounding effects related to weather, time, or season. However, on each day of sampling, rising afternoon winds limited the time spent on the water. A portion of coastline furthest from the boat ramps was not extensively sampled due to this limitation in time (Figure 4.1). This area is characterised by a long flat sandy beach and sites at either end of this beach were sampled. I assumed that limiting the number of sites in this long sandy beach area did not greatly affect the results of this study. 


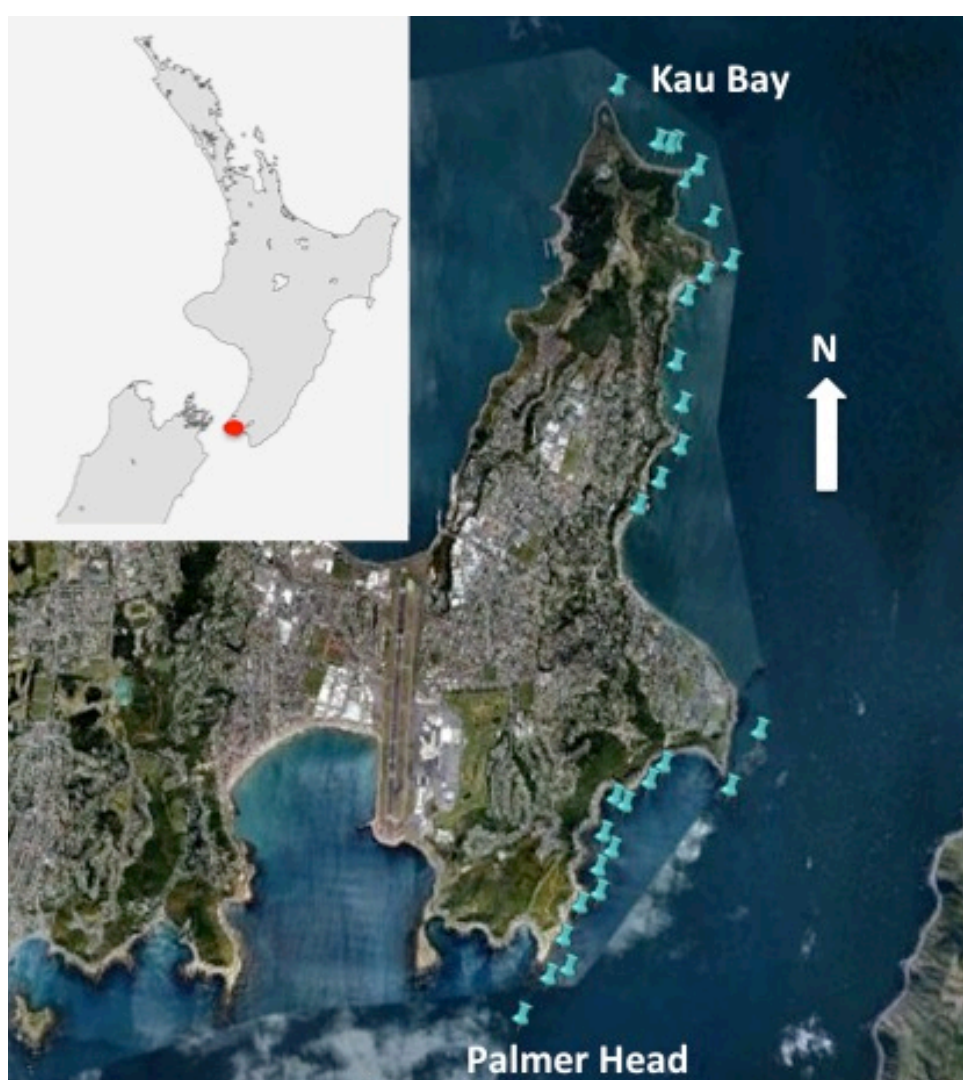

Figure 4.1: Exposure gradient extends along the east coast of the Miramar Peninsula at the Wellington Harbour entrance. Kau Bay is situated inside the sheltered harbour while Palmer Head is on the exposed south coast. Thirty study sites were placed randomly between Kau Bay and Palmer Head. An extended flat sandy beach in the centre of the gradient was not repeatedly sampled. Location of Miramar Peninsula in the North Island is shown in the upper left corner.

\subsubsection{Social structure}

I estimated fish length and abundance at all sites while one other diver estimated habitat variables. Myself and the other diver completed one fish station and four habitat stations at each site. For each fish station, I recorded total length ( $\mathrm{mm})$ and species of all fish that swam into an area $2 \mathrm{~m}$ by $2 \mathrm{~m}$ by $2 \mathrm{~m}$ directly in front of me for a period of 5 minutes. I calculated spotty density as the total number of spotties (juvenile, initial phase and terminal phase) recorded in one station (density per $2 \mathrm{~m}^{3}$ ). I calculated the operational sex ratio as the proportion of mature initial phase individuals relative to terminal phase individuals. This does not take into account any males masquerading as the initial phase, though the proportion of male initial phase 
fish is expected to be low (Chapter 2). Individuals $130 \mathrm{~mm}$ (total length) and larger were assumed to be mature (Chapter 2). I calculated each median size, upper size range, and lower size range, as measures of size-frequency for each station. The upper size range is the median plus one standard deviation, and the lower size range is the median minus one standard deviation. Behaviour of labrid fishes is not typically affected by the presence of divers (Denny 2005) and a period of acclimation prior to initiating counts was not taken. Accuracy of estimating total length of fish was determined by running a transect through plastic fish of known length prior to sampling, and my estimates closely matched known data (Chapter 2, Appendix A).

\subsubsection{Environment}

I included four habitat stations to each single fish station to increase the estimate of available habitat. Spotties swim about home ranges or territories that increase in area relative to their size (Jones 1981), thus surveying only one habitat station could underestimate the habitat used by individuals recorded in one station. I averaged the four habitat stations to yield data for one habitat station at each site prior to statistical analyses. I used six variables to describe environment: location, relief (topographic complexity), substrate, substrate holder, temperature, and density of other fish. I created a dummy variable for location by assigning each site a number that pertained to its position on the sampling gradient. The southern-most site $\left(41^{\circ} 20^{\prime} 59.58^{\prime}\right.$ 'S, $\left.174^{\circ} 49^{\prime} 6.66^{\prime \prime} \mathrm{E}\right)$ was number 1 and the northern-most $\left(41^{\circ} 17^{\prime} 3.32^{\prime}\right.$ 'S, $174^{\circ} 49^{\prime} 36.38^{\prime}$ 'E) site was number 30 . I used density of fish other than spotties in place of species richness or abundance indices as spotties were the most abundant fish detected and biased estimates of these indices.

I used three variables to describe habitat: relief, percent cover of substrate, and percent cover of substrate holders (attached living organisms). The other diver visually estimated these variables while I conducted fish estimates. Visual estimation of habitat can be more efficient and can be done more accurately and with less variability between estimates than traditional point-contact methods (Dethier et al. 1993).

Relief was used as a measure of topographic complexity and was recorded as a number (in centimetres) that represented the difference in height between the lowest and highest points within the station area. Jones (1981) suggested that the presence of a large boulder can increase desirability of spawning grounds, and thus relief may 
influence the distribution of males. Substrate was described by five variables: sand, cobble, gravel, boulder, and bedrock. At one site, "manmade" was added to the list of substrate types due to the presence of tyres in an otherwise sandy habitat. This site was later excluded as an outlier. Substrate holders (attached organisms) were recorded in the following categories: bare sand, gravel/broken shell, algal turf, Carpophyllum species, Macrocystis pyrifera, Ecklonia radiata, Lessonia variegata, Landsburgia, Marginariella, Undaria pinnatifida, fleshy red species, crustose coralline, articulated coralline, green algae, and animal (primarily ascidians, $\sim 2 \%$ sponges). I included sand and gravel/broken shell to describe areas where the substrate was not occupied by any attached living organism.

A Sensus ultra data logger recorded temperature at 10 second intervals, and numbers were averaged to obtain one temperature reading per site. The Sensus ultra began and ended recordings at $1 \mathrm{~m}$ depth and records to within $0.01^{\circ} \mathrm{C}$. Temperature was included as a variable because it appeared to differ between sampling days and may have confounded results. To account for ontogenetic shifts in the distribution of spotties (Jones 1980), I conducted stations at a variety of depths between 2 and $9 \mathrm{~m}$.

\subsubsection{Analyses}

I used a principal component analysis (PCA) for substrate variables to assess how different aspects of substrate were related and to create a set of independent substrate variables. I repeated the PCA for substrate holder variables. The first principal components of each analysis alone explained a considerable proportion of the variation and were used in subsequent analyses to represent each substrate and substrate holders. This was taken as sufficient representation of substrate and substrate holders and no further scores were tested in order to avoid overparameterisation.

I ran multiple regression with six explanatory variables: location, relief, substrate, substrate holder, temperature, and density of other fish. The best-fit models chosen were those that only contained predictor variables significant at $\alpha=0.05$. Five response variables were tested: density, operational sex ratio, median size, upper size range, and lower size range. I excluded all sites in which there were zero spotties for the multiple regressions involving operational sex ratio and size-frequency variables as response variables. Involving zero counts would artificially inflate the number of males detected, and it is meaningless to assess size where there were no spotties 
detected. For upper and lower size range analyses, I also excluded all sites where only one spotty was recorded, as it is meaningless to assess range where no range existed. Proportion data do not conform to the assumptions of a normal linear model because they have bounded limits (at 1 and 0 ) and therefore require a different analysis. I used multiple regression for generalised linear models with binomial errors for the analysis involving operational sex ratio.

Assumptions relating to homogeneity of variance, non-linearity, and leverage were checked during multiple regression on residual plots (Quinn and Keough 2002). Multiple regression was run forward, backward, and stepwise, yielding no difference in the best-fit model selected.

All analyses were conducted in R statistical software ( $\mathrm{R}$ development core team 2012).

\subsection{RESULTS}

One outlier consistently stood out in all distributions (Figure 4.2). This outlier was at a site that had a number of tyres clumped together in an otherwise sparse, flat, and sandy environment. This manmade habitat created substrate for algae and attracted fish. It was excluded from analyses as it was the only manmade substrate encountered and did not reflect natural conditions as indicated by other stations. 

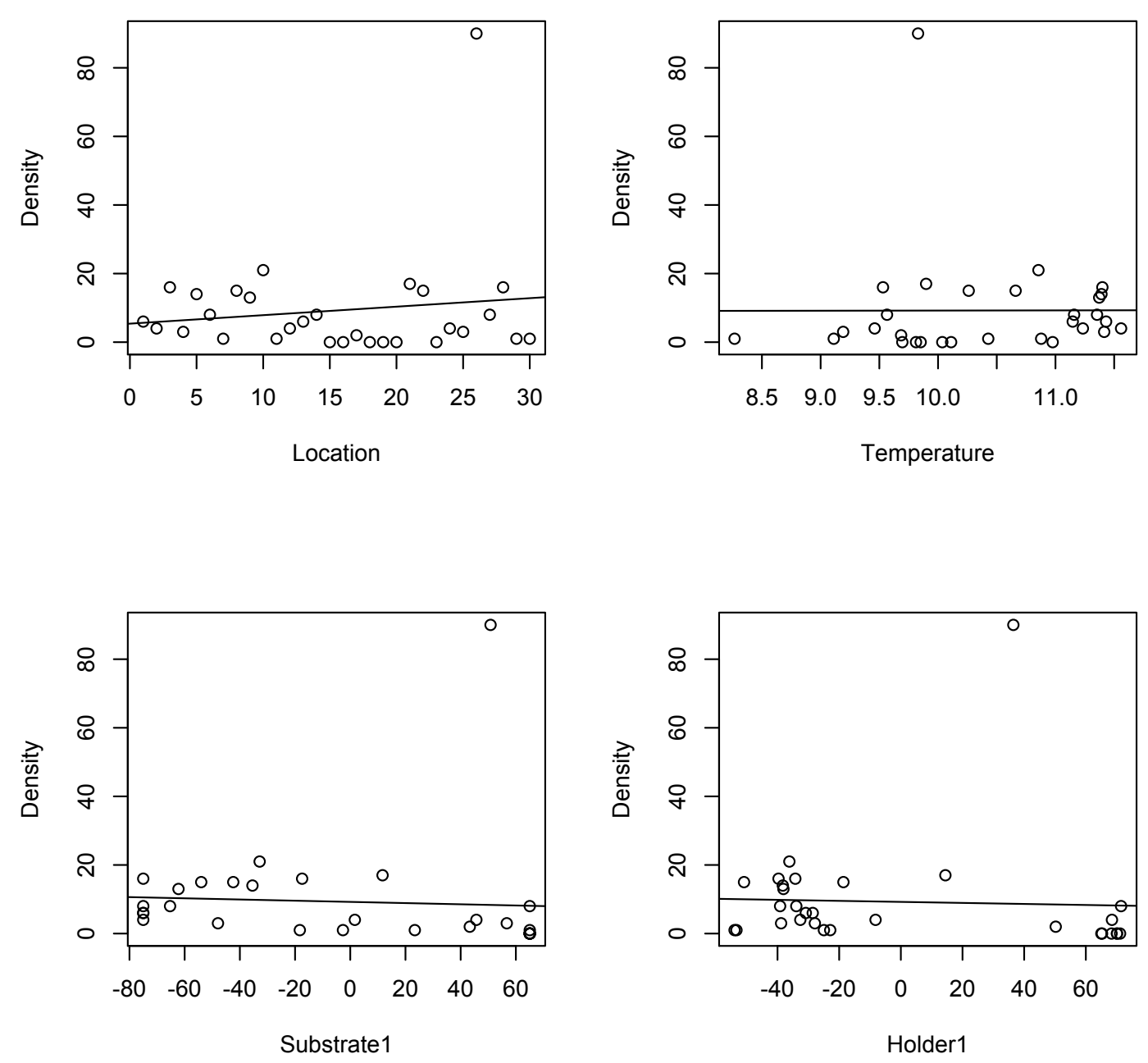

Figure 4.2: Linear least-squares regression between density of spotties (Notolabrus celidotus) and the four environmental variables location, temperature, substrate (Substrate1; principal component one) and substrate holder (Holder1; principal component one) indicating the presence of an outlier (at top of all plots).

\subsubsection{Habitat variables}

In the PCA involving substrate variables, the first principal component explained $62 \%$ of the variation, the second explained $22.5 \%$, and the third explained $15 \%$. The first principal component loaded strongly positively for bedrock and strongly negatively for sand (Figure 4.3). I used scores from the first component in multiple regression and treated these as a variable that scored substrate on a hardness 
gradient with negative values representing sand and positive values representing bedrock.

In the PCA involving substrate holders, the first principal component explained $56 \%$ of the variation, the second explained $17 \%$ of the variation, and the third explained $12.5 \%$ of the variation. The first principal component loaded strongly positively for bare sand, slightly positively for fleshy red algae and U. pinnatifida, and negatively for all brown algal variables, green algae, crustose and articulated coralline, and animal categories (Figure 4.4). I used scores from the first principal component in multiple regression and treated these as a variable that scored substrate holders on a gradient of habitat complexity; strongly negative numbers represented complex algal habitat and strongly positive numbers represented low complexity habitat or 'bare sand' (no substrate holders). 


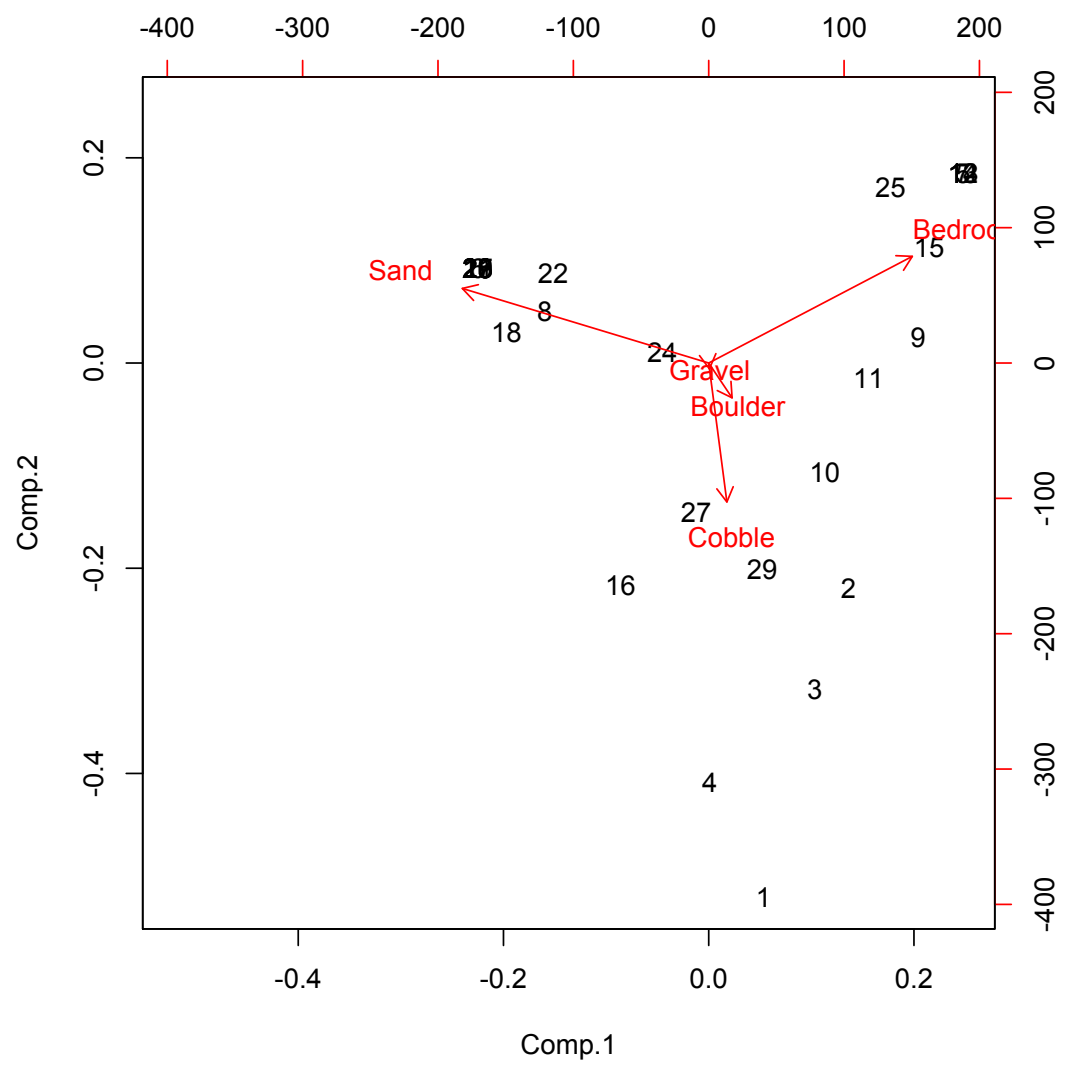

Figure 4.3: Loadings from principal components analysis (PCA) of 5 substrate variables (sand, gravel, cobble, boulder, bedrock) along the first two principal components axes. The first principal component (Comp. 1) explains 62\% of the variation and the second principal component (Comp. 2) explains $22.5 \%$ of the variation. Sand is negative along the first principal component axis indicating that sand is less common in areas where the substrate is comprised of gravel, cobble, bedrock and boulder. The second principal component suggests that bedrock and sand are common in areas where gravel, cobble, and boulder decrease. The arrows represent the loadings of the variables. The numbers represent the row in the original data-frame. The PCA was run for estimates of habitat made at depths between 2 and 9 $\mathrm{m}$ along the Miramar Peninsula in Wellington. 


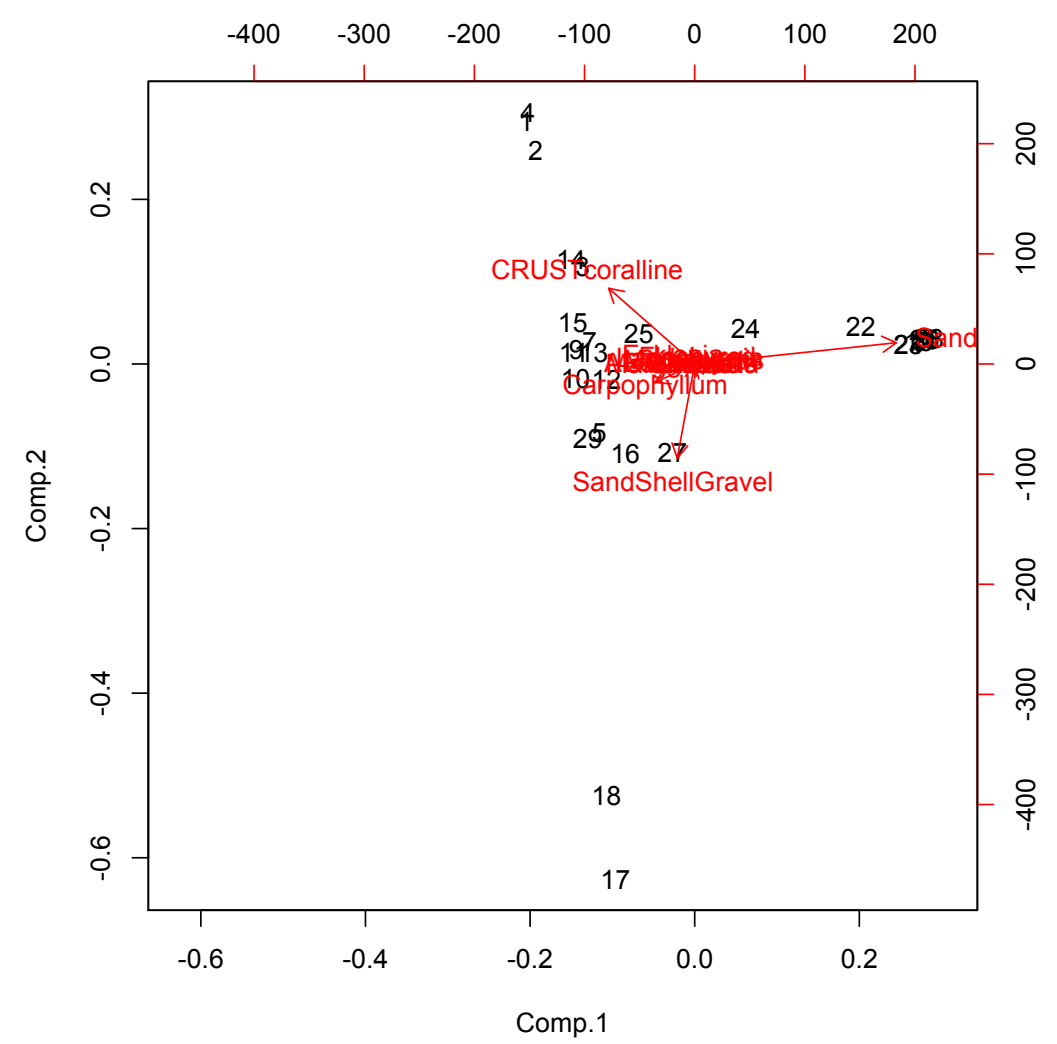

Figure 4.4: Loadings from principal components analysis (PCA) of substrate holder variables along the first two principal components axes (crustose coralline algae, fleshy red algae, bare rock, sand, or sand/shall/gravel where no substrate holders dominate the substrate, and a selection of brown algal species common in the study area). The first principal component (Comp. 1) explains $56 \%$ of the variation and the second principal component (Comp. 2) explains $17 \%$ of the variation. Algal species are negative along the first principal component axis, while sand (no substrate holder) is strongly positive. The first principal component indicates that sand and algal habitat occur in separate areas. The second principal component suggests that crustose coralline algae and sand/shell/gravel (no substrate holder) occur in separate areas, with intermediate areas characterised by sand and algal species. The arrows represent the loadings of the variables. The numbers represent the row in the original dataframe. The PCA was run for estimates of habitat made at depths between 2 and $9 \mathrm{~m}$ along the Miramar Peninsula in Wellington. 


\subsubsection{Social structure and environment}

Density was best explained by a model that incorporated substrate but explanatory power was low (32\% variation explained; Table 4.1$)$. The relationship between substrate and density was positive, indicating that density was higher in habitats characterised by hard substrate (boulder and bedrock). No variables were retained in the model to describe operational sex ratio.

Only temperature was useful for explaining size-frequency but the explanatory power was low for each variable (Table 4.1). Temperature explained $27 \%$ of the variation, $35 \%$ of the variation, and $25 \%$ of the variation for median size, lower size range, and upper size range respectively. The relationship between temperature and each size-frequency variable was positive, suggesting that median size, lower size range, and upper size range each increased with increasing temperature.

In no case was a model able to explain more than $32 \%$ of the variation. Only substrate and temperature were detected as significant predictor variables.

Table 4.1: Results of multiple regression run for four response variables describing the social structure of spotties (Notolabrus celidotus): density, median size, lower size range (median - $1 \mathrm{SD}$ ), and upper size range (median $+1 \mathrm{SD}$ ). Density was weakly explained by substrate type, and variables pertaining to size were weakly explained by temperature. All p-values are significant at $\alpha=0.05$ (shown in bold).

\begin{tabular}{lccccc}
\hline Response & Source of variation & $\mathbf{F}$ & $\mathbf{R}^{\mathbf{2}}$ & $\mathbf{R}_{\text {adj }}^{\mathbf{2}}$ & $\mathbf{P}$ \\
\hline Density & Substrate & 12.96 & 0.3243 & 0.2993 & $\mathbf{0 . 0 0 1}$ \\
Median & Temperature & 7.713 & 0.2686 & 0.2338 & $\mathbf{0 . 0 1 1}$ \\
Lower size range & Temperature & 9.14 & 0.3497 & 0.3114 & $\mathbf{0 . 0 0 8}$ \\
Upper size range & Temperature & 5.619 & 0.2484 & 0.2042 & $\mathbf{0 . 0 3 0}$ \\
\hline
\end{tabular}

\subsection{DISCUSSION}

This study aimed to investigate patterns of variation in social structure of spotties with respect to variation in their environment. The results suggest that density of spotties is positively correlated with rocky substrate and that size-frequency is smaller with decreasing temperature. No conclusions can be drawn relating operational sex ratio and environmental variables. 
The correlation between density and hard substrate differs from the expectation that density would increase in the harbour (where hard substrate was thought to be less abundant). Further, it contradicts the suggestions that spotties achieve their highest density over sandy areas with patch reef (Schiel and Hickford 2001) and that density of spotties is highest in sheltered locations (Choat and Ayling 1987, Davis 2010, Schiel and Hickford 2001, Chapter 2), as rocky habitat (where these results suggest spotties are more abundant) was thought to better characterise the exposed harbour entrance as opposed to sites within the sheltered harbour. Jones (1984a) suggested that large initial phase females associate primarily with bare rocky habitat, but only rocky reef appeared to be sampled. The relationship between density and substrate may be driven by a strong preference of juveniles for algal habitat (Jones 1984b), which requires rock for attachment, but this does not explain why relationships between density and algae, or size-frequency and algae, were not detected. These results seem inconclusive and suggest that a greater number of observations are needed in order to illuminate patterns of correlation between density and substrate.

The results suggest that smaller individuals were more common as temperature decreased. Low temperatures can lead to slow growth and subsequently smaller size-frequency (Yamahira and Conover 2002). In this study, lower temperatures were detected in the harbour, and could result in smaller size-frequency if sustained through time. Size-frequency, however, was not related to location and this study does not support the hypothesis that size-frequency is smaller in the harbour. I concluded previously that small size-frequency, slow growth, and reduced length-at-age in a harbour population of spotties, was driven by density-dependent processes rather than by temperature (Chapter 2), and the results of the present study do not change this conclusion. As Hooper (2008) found that spotties perform better at the lower rather than the upper limit of their thermal tolerance, it is unlikely that sizefrequency would be affected this strongly by a small shift in temperature. Alternatively, fish can become more active, aggressive, and feed more frequently at high temperature (Biro et al. 2010, Ratnasabapathi et al. 1992, Taniguchi et al. 1998) and small fish may be more vulnerable to predation at high temperature (Biro et al. 2007, Theodorou et al. 2012). The relationship between small size-frequency and low temperature may reflect the emergence of smaller individuals during a period of low predator activity. This largely hypothetical conclusion requires further investigation to 
be supported. Most likely, the results presented here were confounded by adverse weather on day 2 (see below).

The results do not support the hypothesis that sex ratio would be constrained by the presence of desirable spawning territory. The inability of this study to detect a relationship between sex ratio and environment may stem from the sampling design, rather than the absence of such a relationship. Many stations were excluded from this analysis when zero spotties were recorded. It is likely that meaningful results required a larger sample size. This topic deserves further investigation.

What the results of this study most clearly suggest is that the sampling design was insufficient for detecting patterns of correlation between social structure and environmental variables. These conclusions may be confounded by a change in the weather between sampling days. Water temperatures on day 2, during which the northern half of the gradient was sampled, were noticeably cooler than day 1, and unexpected adverse weather meant that the day warmed very slowly. On this day, there were very rarely fish observed in the earliest sampled and coldest stations, despite that a number of these stations fell in habitats conducive to spotties. Labrid fish characteristically take cover in the benthos to sleep for the night and are frequently the last fish to emerge in the morning (Hobson 1965, Robertson and Sheldon 1979). Many species of wrasse are sensitive to light regimes in developing their circadian rhythm (Gerkema et al. 2000, Hur et al. 2012, Iigo et al. 2003). It is possible that overcast weather on the second day of sampling delayed the emergence of spotties in the morning. It is difficult to assess whether the correlations detected here are due to true underlying patterns or to confounding effects of weather. The potential for confounding factors to impact the detection of relationships between social structure and the physical environment highlights the necessity of large sample sizes for examining these patterns. A similar study would benefit from spreading sites and sampling out across multiple days. 


\section{Chapter 5: General Discussion}

\subsection{Summary of findings}

The main aim of this thesis was to investigate how reproductive ecology and condition of a temperate protogynous hermaphrodite varied when sampled at a small spatial scale. This study focused on spotties, Notolabrus celidotus, inhabiting $9 \mathrm{~km}$ of coastline characterised by a gradient in swell exposure; the northern most area sampled was sheltered from southerly swell and characterised by sandy habitat with shallow algal cover, while the southern end frequently experiences swells from $2-6$ $\mathrm{m}$ and was characterised by deep bedrock habitat with algal patches dispersed along the benthos. This study concluded that 1) the predictions of the size advantage model pertaining to sex change, growth, and mortality, were supported in two populations of spotties examined at either end of this exposure gradient, 2) variation in social structure may indicate that the rate of sex change is limited in some locations, and 3) measures of stress and physiological condition inconsistently characterised the populations and indicate that these measures could not be used interchangeably in this study. In addition, a closer inspection of the relationship between social structure and the physical environment highlighted the necessity for large sample sizes when investigating patchy distributions. This chapter discusses the implications of these findings for the conservation of spotties and hermaphroditic reef fish in general.

The size advantage model predicts that early sex change will be correlated with slow growth, high mortality, or both (Warner 1988). Individuals sampled from Kau Bay in Wellington Harbour exhibited slower growth and higher mortality than individuals sampled from Wahine Park on the south coast of the harbour entrance. In line with predictions of the size advantage model, a portion of individuals at Kau Bay changed sex a year earlier and at smaller sizes than any individual collected from Wahine Park (Chapter 2). These results indicate that the size advantage model will be useful for understanding sex change in these populations. Additionally, they suggest that populations of spotties characterised by slow growth and high mortality in other locations can be expected to change sex earlier, though this hypothesis will require further investigation to be validated. Importantly, the timing of maturation appeared to be delayed at Kau Bay relative to Wahine Park, which was not predicted by the size advantage model, but was expected as maturation can be delayed by slow growth in this species (Jones 1980, Jones and Thompson 1980). This reinforces the notion that 
future applications of the size advantage model will be most useful when used in conjunction with species-specific knowledge (Warner 1988).

An investigation of social structure highlighted that the proportion of males relative to females was lower than expected at Kau Bay compared to Wahine Park. This result suggests that the rate of sex change is limited and may be constrained by a reduced supply of spawning territories where sandy habitat predominates. In this case, high density may not be an accurate indication of reproductive potential. Few studies call attention to the impact of spawning territory availability on the rate of sex change and reproductive output of a population (Breitburg 1987, Lejeune 1987). If future research reveals that territory availability plays a role in determining the number of individuals that change sex, then this will be a key consideration in the design of fisheries models and marine reserves for hermaphroditic reef fish species. A closer inspection of social structure and physical environment revealed inconclusive results in this study but highlighted that large sample sizes will be useful for detecting these patterns in future research. This topic remains open to investigation and will be important for determining the adaptability of reproductive strategy in hermaphrodites across a range of environmental conditions.

Spotties rely on separate seasons for spawning and sex change (Jones 1980). The small proportion of males detected in this study, and the potential for the rate of sex change to be limited, are thus of concern at Kau Bay as any males removed will not be replaced until the following sex change season. Furthermore, removing a small number of males may have a disproportionate effect on the reproductive potential of the population, as this could reduce reproductive output until after the next sex change season, when males are replaced and spawning activity resumes. These processes could affect fisheries species like the New Zealand butterfish (Trip et al. 2011b) and California sheephead (Warner 1975) that also rely on separate spawning and sex change seasons. In protogynous species, males tend to dominate the largest size classes and selective mortality from fishing pressure on these large size classes can disproportionately remove males from a population (Hamilton et al. 2007). If present, the coupled effects of selective mortality and limited rates of sex change could rapidly reduce the rate of recovery of fished populations. Understanding factors that can limit the rate of sex change in hermaphroditic reef fish may be critical to the successful regulation of species that are targets of fisheries. 
This study suggests that the proportion of initial phase males to terminal phase males was higher at Kau Bay than Wahine Park. In many hermaphroditic fish species, non-territorial initial phase males are common at high density and achieve a high rate of spawning success by interfering with the mating events of a dominant male (McCormick et al. 2010, Robertson and Warner 1978, Robertson et al. 1982, Warner and Robertson 1978). Such a process may increase the reproductive potential at Kau Bay, despite a paucity of desirable spawning territories and low number of terminal phase males. Jones (1980), however, observed that spawning interference by initial phase males was low for spotties at Leigh. Furthermore, although the ratio of initial phase males to terminal phase males was high at Kau Bay, the total number of initial phase males detected was low, and it is possible that instead of reproducing, these individuals were in the process of changing to the terminal phase colour pattern to compete for territories. Observational studies are required in these populations to assess the importance of spawning interference by initial phase males for the reproductive potential of the population.

Fulton's condition factor $(\mathrm{K})$ and fluctuating asymmetry were positively correlated in this study, contrary to expectations. Furthermore, slow growth and high mortality likely resulted from density-dependent stress at Kau Bay, but although $\mathrm{K}$ indicated reduced physiological condition, low levels of fluctuating asymmetry suggested individuals were less stressed at Kau Bay. The results highlight that fluctuating asymmetry and condition indices may not be interchangeable measures of stress in adult populations, but instead offer complementary information. Fluctuating asymmetry is likely to reflect cumulative stress throughout an individual's lifetime, whereas the condition indices measured here may indicate recent stress. It is possible that different phenotypes suffered different levels of mortality throughout their life history, for example, asymmetric individuals in poor physiological condition suffered higher mortality than asymmetric individuals in better physiological condition. Such a process could result in the positive relationship between fluctuating asymmetry and $\mathrm{K}$ detected here and may be important in future work. The results of this study are in line with inconsistent correlations between fluctuating asymmetry and condition indices reported in literature (Grønkjaer and Sand 2003, Lemberget and McCormick 2009, Somarakis et al. 1997). The conclusion is that fluctuating asymmetry and condition indices measure different aspects of physiological condition, as Urbach and 
colleagues (2007) similarly suggested, and these measures will need to be applied in future studies with careful consideration of the stressors they are assumed to reflect.

To successfully use fluctuating asymmetry as an indicator of stress at the population level, a baseline of naturally occurring levels of fluctuating asymmetry may need to be quantified prior to assessing the impact of an environmental stressor (Allenbach 2010). The research presented here supports this notion, as it was not possible to determine when asymmetries arose in an individual's development. Without prior knowledge, fluctuating asymmetry could not be correlated to a particular stressor, as it may have been an artifact of any past experience. The results suggest that stressors late in life history are as relevant to the development of fluctuating asymmetry in otoliths as stressors early in life history, and furthermore, that sex-specific expression of fluctuating asymmetry may be an important consideration for hermaphroditic species. These conclusions highlight that a cautious approach is required when estimating fluctuating asymmetry in adult sex-changing populations. This will be important in future studies if fluctuating asymmetry is to be applied to monitor stress as suggested (Clarke 1995, Allenbach 2011).

Fisheries management and marine reserve designs that account for sex changing life histories will be beneficial to the conservation of hermaphroditic reef fish (Chan et al. 2012). An important component of this concept is to understand how life history traits can vary across a range of spatial scales (Gust 2004). This thesis demonstrated that social structure, life history, and condition of a temperate protogynous hermaphrodite varied between populations separated by only $9 \mathrm{~km}$, a distance much smaller than the scale at which fisheries operate. The research presented here is among the first to call attention to sex-specific fluctuating asymmetry and the relationship between territory-limitation and sex change in hermaphroditic species. These findings present important considerations in fisheries management and marine reserve design for hermaphroditic reef fish. Reproductive ecology and the physical environment are complicated topics, and investigating how these two are related will further our understanding of the natural reproductive potential of populations. The knowledge gained through this research will contribute to the successful management of sex changing reef fish. 


\subsection{Future directions}

This thesis highlights a number of areas that would benefit from further investigation. The influence of spawning territory limitation on the rate of sex change and reproductive potential will be achieved by integrating observational studies with experimental manipulation of habitat and social structure. Understanding how the rate of sex change influences reproductive output in species that do not change sex yearround will be an important goal. This may be achieved by following experimental populations through time to determine the rate of sex change during the sex change season and following the removal of reproductive males. In addition, an understanding of how social structure is shaped by environmental variables will be useful for estimating the reproductive potential of populations across different locations. To investigate how the physical environment can influence social structure or sex change, sampling designs will need to account for the confounding influence of daily fluctuations in weather and temperature, and how the diurnal habits of fish relate to these factors. The ability to detect real patterns in social structure will require large sample sizes and be benefited from assessing a range of spatial scales.

In order for fluctuating asymmetry to be a useful tool for detecting stress in natural populations, future investigations should examine how trait-specific fluctuating asymmetry develops as a function of particular stressors that are relevant at distinct phases of an individual's life history. Investigations of fluctuating asymmetry will be benefited by integrating long-term studies with periodic measurements of fluctuating asymmetry to determine how asymmetries develop in different ontogenetic groups of a population. This will help quantify baselines of natural fluctuating asymmetry in adult populations. In addition, assessing the rate of mortality on specific phenotypes of fluctuating asymmetry or condition may clarify the relationship between fluctuating asymmetry and condition indices.

Furthering our understanding of how sex-changing species vary naturally across heterogeneous landscapes will be important in the spatial design of fisheries management and marine reserves. A number of areas remain open to investigation and developing our knowledge in these areas will benefit the conservation of hermaphroditic species. 


\section{Literature cited}

Adreani, M., Erisman, B., \& Warner, R. (2004). Courtship and spawning behavior in the California sheephead, Semicossyphus pulcher (Pisces: labridae). Environmental Biology of Fishes, 71, 13-19.

Afonso, P., Fontes, J., Holland, K., \& Santos, R. (2008). Social status determines behaviour and habitat usage in a temperate parrotfish: implications for marine reserve design. Marine Ecology Progress Series, 359, 215-227.

Allenbach, D. (2010). Fluctuating asymmetry and exogenous stress in fishes: a review. Reviews in Fish Biology and Fisheries, 21, 355-376.

Alonzo, S., Ish, T., \& Key, M. (2008). The importance of incorporating protogynous sex change into stock assessments. Bulletin of Marine Science, 83, 163-179.

Anderson, D., Link, W., Johnson, D., \& Burnham, K. (2001). Suggestions for presenting the results of an analysis. The Journal of Wildlife Management, 65, $373-378$.

Anderson, M., \& Millar, R. (2004). Spatial variation and effects of habitat on temperate reef fish assemblages in northeastern New Zealand. Journal of Experimental Marine Biology and Ecology, 305, 191-221.

Ault, T., \& Johnson, C. (1998). Spatially and temporally predictable fish communities on coral reefs. Ecological Monographs, 68, 25 - 50.

Baty, F., \& Delignette-Muller, M. (2011). NLStools: tools for nonlinear regression diagnostics.

Bergstrom, C., \& Reimchen, T. (2000). Functional implications of fluctuating asymmetry among endemic populations Gasterosteus aculeatus. Behaviour, 137, $1097-1112$.

Bilcik, B., \& Estevez, I. (2005). Impact of male-male competition and morphological traits on mating strategies and reproductive success in broiler breeders. Applied Animal Behaviour Science, 92, 307-323.

Biro, P., Beckmann, C., \& Stamps, J. (2010). Small within-day increases in temperature affects boldness and alters personality in coral reef fish. Proceedings of the Royal Society in Biological Sciences, 277, 71-7.

Biro, P., Post, J., \& Booth, D. (2007). Mechanisms for climate-induced mortality of fish populations in whole-lake experiments. Proceedings of the National Academy of Sciences of the United States of America, 104, 9715-9.

Bjorksten, T., Fowler, K., \& Pomiankowski, A. (2000). What does sexual trait FA tell us about stress? Trends in Ecology and Evolution, 15, 163-166. 
Blanckenhorn, W., Reusch, T., \& Mtihlhauser, C. (1998). Fluctuating asymmetry, body size and sexual selection in the dung fly Sepsis cynipsea - testing the good genes assumptions and predictions. Journal of Evolutionary Biology, 11, 735 753.

Bohnsack, J., \& Bannerot, S. (1986). A stationary visual census technique for quantitatively assessing community structure of coral reef fishes. NOAA Technical Report NMFS 41, 1 - 15.

Bolliger, J., Lischke, H., \& Green, D. (2005). Simulating the spatial and temporal dynamics of landscapes using generic and complex models. Ecological Complexity, 2, 107-116.

Bonduriansky, R. (2009). Condition dependence of developmental stability in the sexually dimorphic fly Telostylinus angusticollis (Diptera: Neriidae). Journal of Evolutionary Biology, 22, 861-72.

Breitburg, D. (1987). Interspecific competition and the abundance of nest sites: factors affecting sexual selection. Ecology, 68, $1844-1855$.

Brulé, T., Renán, X., Colás-Marrufo, T., Hauyon, Y., Tuz-Sulub, A., \& Déniel, C. (2003). Reproduction in the protogynous black grouper (Mycteroperca bonaci (Poey)) from the southern Gulf of Mexico. Fishery Bulletin, 101, 463 - 475.

Burnham, K., \& Anderson, D. (1998). Model selection and inference: a practical information-theoretic approach. New York: Springer-Verlag, New York.

Campbell, B., Emlen, J., \& Hershberger, W. (1998). Thermal induced chronic developmental stress in coho salmon: integrating measures of mortality, early growth, and developmental instability. Oikos, 81, $398-410$.

Carbines, G. (2003). Age, growth, movement and reproductive biology of blue cod (Parapercis colias - Pinguipedidae): Implications for fisheries management in the South Island of New Zealand. University of Otago.

Carscadden, J., \& Frank, K. (2002). Temporal variability in the condition factors of Newfoundland capelin (Mallotus villosus) during the past two decades. ICES Journal of Marine Science, 59, 950-958.

Caselle, J., Hamilton, S., Schroeder, D., Love, M., Standish, J., Rosales-Casián, J., \& Sosa-Nishizaki, O. (2011). Geographic variation in density, demography, and life history traits of a harvested, sex-changing, temperate reef fish. Canadian Journal of Fisheries and Aquatic Sciences, 68, 288-303.

Chan, N., Connolly, S., \& Mapstone, B. (2012). Effects of sex change on the implications of marine reserves for fisheries. Ecological Applications, 22, 77891.

Chapman, A. D. G., \& Robson, D. S. (1960). The analysis of a catch curve. Biometrics, 16, 354-368. 
Charnov, E. (1979). The genetical evolution of patterns of sexuality: Darwinian fitness. American Naturalist, 113, $465-480$.

Charnov, E. (1982). Alternative life-histories in protogynous fishes: A general evolutionary theory. Marine Ecology Progress Series, 9, 305-307.

Charnov, E., Gotshall, D., \& Robinson, J. (1978). Sex ratio: adaptive response to population fluctuations in pandalid shrimp. Science, 200, 204-206.

Choat, J. (1965). Sexual dimorphism in the labrid fish Pseudolabrus celidotus (Bloch and Schneider). Pacific Science, 29, 451 - 457.

Choat, J., \& Ayling, A. (1987). The relationship between habitat structure and fish faunas on New Zealand reefs. Journal of Experimental Marine Biology and Ecology, 110, 257-284.

Clarke, G. (1995). Relationships between developmental stability and fitness: application for conservation biology. Conservation Biology, 9, 18 - 24 .

Clifton, K. (1995). Asynchronous food availability on neighboring Caribbean coral reefs determines seasonal patterns of growth and reproduction for the herbivorous parrotfish Scarus iserti. Marine Ecology Progress Series, 116, 39 46.

Clua, E., \& Legendre, P. (2008). Shifting dominance among Scarid species on reefs representing a gradient of fishing pressure. Aquatic Living Resources, 21, 339348.

Cole, A. (2010). Cleaning to corallivory: ontogenetic shifts in feeding ecology of tubelip wrasse. Coral Reefs, 29, 125-129.

Cole, R., Davey, N., Carbines, G., \& Stewart, R. (2012). Fish-habitat associations in New Zealand: geographical contrasts. Marine Ecology Progress Series, 450, $131-145$.

Connell, S., \& Jones, G. (1991). The influence of habitat complexity on postrecruitment processes in a temperate reef fish population. Journal of Experimental Marine Biology and Ecology, 151, 271-294.

Cowen, R. (1990). Sex change and life history patterns of the labrid, Semicossyphus pulcher, across an environmental gradient. Copeia, 1990, $787-795$.

Davis, J. (2010). Niche partitioning in the Fiordland wrasse guild. Unveristy of Otago.

DeMartini, E. E., Everson, A. R., \& Nichols, R. S. (2010). Estimates of body sizes at maturation and at sex change, and the spawning seasonality and sex ratio of the endemic Hawaiian grouper Hyporthodus quernus , F . Epinephelldae ). Fishery Bulletin, 109, 123-134. 
Denny, C. M. (2005). Distribution and abundance of labrids in northeastern New Zealand: the relationship between depth, exposure and pectoral fin aspect ratio. Environmental Biology of Fishes, 72, 33-43.

Dethier, M., Graham, E., Cohen, S., \& Tear, L. (1993). Visual versus random-point percent cover estimations: "objective" is not always better. Marine Ecology Progress Series, 96, 93-100.

Dunn, A., Francis, R., \& Doonan, I. (2002). Comparison of the Chapman-Robson and regression estimators of $Z$ from catch-curve data when non-sampling stochastic error is present. Fisheries Research, 59, 149-159.

Ellis, R. D., \& Powers, J. E. (2012). Gag grouper, marine reserves, and densitydependent sex change in the Gulf of Mexico. Fisheries Research, 115-116, 8998.

Emlen, S., \& Oring, L. (1977). Ecology, sexual selection, and the evolution of mating systems. Science, 197, $215-223$.

Figuerola, B., Maceda-Veiga, A., \& Sostoa, A. (2012). Assessing the effects of sewage effluents in a Mediterranean creek: fish population features and biotic indices. Hydrobiologia, 694, 75-86.

Folkvord, A., Blom, G., Johannessen, A., \& Moksness, E. (2000). Growth-dependent age estimation in herring (Clupea harengus L.) larvae. Fisheries Research, 46, 91-103.

Francis, M. (2001) Coastal Fishes of New Zealand: An Identification Guide. Reed

Friedlander, A., \& Parrish, J. (1998). Habitat characteristics affecting fish assemblages on a Hawaiian coral reef. Journal of Experimental Marine Biology and Ecology, 224, 1-30.

Froese, R. (2006). Cube law, condition factor and weight-length relationships: history, meta-analysis and recommendations. Journal of Applied Ichthyology, 22, 241253.

Gagliano, M., Depczynski, M., Simpson, S. D., \& Moore, J. a Y. (2008). Dispersal without errors: symmetrical ears tune into the right frequency for survival. Proceedings of the Royal Society in Biological Sciences, 275, 527-34.

Gerkema, M., Videler, J., Wiljes, J., Van Lavieren, H., Gerritsen, H., \& Karel, M. (2000). Photic entrainment of circadian activity patterns in the tropical labrid fish Halichoeres chrysus. Chronobiology International, 17, 613-622.

Ghiselin, M. T. (1969). The evolution of hermaphroditism among animals. The Quarterly Review of Biology, 44, 189-208.

Gotelli, N. J., \& Ellison, A. M. (2004). A primer of ecological statistics. Sinauer Associates, Inc. 
Grober-Dunsmore, R., Frazer, T., Beets, J., Lindberg, W., Zwick, P., \& Funicelli, N. (2008). Influence of landscape structure on reef fish assemblages. Landscape Ecology, 23, 37-53.

Grønkjaer, P., \& Sand, M. K. (2003). Fluctuating asymmetry and nutritional condition of Baltic cod (Gadus morhua) larvae. Marine Biology, 143, 191-197.

Gust, N. (2004). Variation in the population biology of protogynous coral reef fishes over tens of kilometres. Canadian Journal of Fisheries and Aquatic Sciences, 61, $205-218$.

Gust, N., Choat, J., \& Ackerman, J. (2002). Demographic plasticity in tropical reef fishes. Marine Biology, 140, 1039-1051.

Haddon, M. (2001). Modeling and quantitative methods in fisheries. CRC Press.

Hamilton, S., Caselle, J., Lantz, C., Egloff, T., Kondo, E., Newsome, S., Loke-Smith, $\mathrm{K}$., et al. (2011). Extensive geographic and ontogenetic variation characterizes the trophic ecology of a temperate reef fish on southern California (USA) rocky reefs. Marine Ecology Progress Series, 429, 227-244.

Hamilton, S., Caselle, J., Standish, J., Schroeder, D., Love, M., Rosales-Casian, J., \& Sosa-Nishizaki, O. (2007). Size-selective harvesting alters life histories of a temperate sex-changing fish. Ecological Applications, 17, 2268-80.

Hawkins, J. P., \& Roberts, C. M. (2004). Effects of artisanal fishing on Caribbean coral reefs. Conservation Biology, 18, 215-226.

Hawkins, J., \& Roberts, C. M. (2003). Effects of fishing on sex-changing Caribbean parrotfishes. Biological Conservation, 115, 213-226.

Helle, S., Suorsa, P., Huhta, E., \& Hakkarainen, H. (2010). Fluctuating feather asymmetry in relation to corticosterone levels is sex-dependent in Eurasian treecreeper (Certhia familiaris) nestlings. Biology letters, 6, 521-4.

Hobson, E. (1965). Diurnal-nocturnal activity of some inshore fishes in the Gulf of California. Copeia, 1965, $291-302$.

Hooper, J. (2008). The effect of temperature change on the New Zealand marine, fish Notolabrus celidotus. University of Canterbury.

Hur, S., Takeuchi, Y., Itoh, H., Uchimura, M., Takahashi, K., Kang, H., Lee, Y., et al. (2012). Fish sleeping under sandy bottom: interplay of melatonin and clock genes. General and Comparative Endocrinology, 177, 37-45.

Iigo, M., Sato, M., Ikeda, E., Kawasaki, S., Noguchi, F., \& Nishi, G. (2003). Effects of photic environment on ocular melatonin contents in a labrid teleost, the wrasse Halichoeres tenuispinnis. General and Comparative Endocrinology, 133, 252259. 
Jones, G. (1980). Growth and Reproduction in the Protogynous Hermaphrodite Pseudolabrus celidotus (Pisces: Labridae) in New Zealand. Copeia, 1980, 660 675.

Jones, G. (1981). Spawning-site choice by female Pseudolabrus celidotus (Pisces: Labridae) and its influence on the mating system. Behavioral Ecology and Sociobiology, 8, 129-142.

Jones, G. (1984a). The influence of habitat and behavioural interactions on the local distribution of the wrasse, Pseudolabrus celidotus. Environmental Biology of FIshes, 10, 43-58.

Jones, G. (1984b). Population ecology of the temperate reef fish Pseudolabrus celidotus Bloch and Sneider (Pisces: Labridae). I. Factors influencing recruitment. Journal of Experimental Marine Biology and Ecology, 75, 257 276.

Jones, G. (1984c). Population ecology of the temperate reef fish Pseudolabrus celidotus Bloch and Sneider (Pisces: Labridae). II Factors influencing adult density. Journal of Experimental Marine Biology and Ecology, 75, 277-303.

Jones, G., \& Thompson, S. M. (1980). Social inhibition of maturation in females of the temperate wrasse Pseudolabrus celidotus and a comparison with the blennioid Tripterygion varium. Marine Biology, 59, 247-256.

Kingett, P., \& Choat, J. (1981). Analysis of density and distribution patterns in Chrysophrys auratus (Pisces: Sparidae) within a reef environment: an experimental approach. Marine Ecology Progress Series, 5, 283-290.

Kleczkowski, M., Babcock, R., \& Clapin, G. (2008). Density and size of reef fishes in and around a temperate marine reserve. Marine and Freshwater Research, 59, $165-176$.

Kodric-brown, A. (1997). Sexual selection, stabilizing selection and fluctuating asymmetry in two populations of pupfish (Cyprinodon pecosensis). Biological Journal of the Linnean Society, 62, 553-566.

Koops, M., Hutchings, J. a., \& McIntyre, T. M. (2004). Testing hypotheses about fecundity, body size and maternal condition in fishes. Fish and Fisheries, 5, $120-130$.

Kopp, D., Bouchon-Navaro, Y., Louis, M., Mouillot, D., \& Bouchon, C. (2010). Herbivorous fishes and the potential of Caribbean marine reserves to preserve coral reef ecosystems. Aquatic Conservation: Marine and Freshwater Ecosystems, 20, 516-524.

Lambert, Y., \& Dutil, J.-D. (1997). Condition and energy reserves of Atlantic cod (Gadus morhua) during the collapse of the northern Gulf of St. Lawrence stock. Canadian Journal of Fisheries and Aquatic Sciences, 54, 2388-2400. 
Leigh, E. G., Charnov, E., \& Warner, R. R. (1976). Sex ratio, sex change, and natural selection. Proceedings of the National Academy of Sciences of the United States of America, 73, 3656-60.

Lejeune, P. (1987). The effect of local stock density on social behavior and sex change in the Mediterranean labrid Coris julis. Environmental Biology of Fishes, $18,135-141$.

Lemberget, T., \& McCormick, M. (2009). Replenishment success linked to fluctuating asymmetry in larval fish. Oecologia, 159, 83-93.

Lens, L., Van Dongen, S., Kark, S., \& Matthysen, E. (2002). Fluctuating asymmetry as an indicator of fitness: can we bridge the gap between studies? Biological Reviews of the Cambridge Philosophical Society, 77, 27-38.

Lloret, J., Muñoz, M., \& Casadevall, M. (2012). Threats posed by artisanal fisheries to the reproduction of coastal fish species in a Mediterranean marine protected area. Estuarine, Coastal and Shelf Science, 113, 133-140.

Marshall, C. T., \& Frank, K. T. (1999). The effect of interannual variation in growth and condition on haddock recruitment. Canadian Journal of Fisheries and Aquatic Sciences, 56, 347-355.

McCormick, M., Ryen, C., Munday, P., \& Walker, S. (2010). Differing mechanisms underlie sexual size-dimorphism in two populations of a sex-changing fish. PloS one, 5 , e10616.

Mello, L., \& Rose, G. (2005). Seasonal cycles in weight and condition in Atlantic cod (Gadus morhua L.) in relation to fisheries. ICES Journal of Marine Science, 62, 1006-1015.

Moore, B., Welch, D., \& Simpfendorfer, C. (2011). Spatial patterns in the demography of a large estuarine teleost: king threadfin, Polydactylus macrochir. Marine and Freshwater Research, 62, 937.

Moore, C., Van Niel, K., \& Harvey, E. (2011). The effect of landscape composition and configuration on the spatial distribution of temperate demersal fish. Ecography, 34, 425-435.

Mumby, P. J. (2006). The impact of exploiting grazers (Scaridae) on the dynamics of Caribbean coral reefs. Ecological Applications, 16, 747-69.

Munday, P., Buston, P., \& Warner, R. (2006). Diversity and flexibility of sex-change strategies in animals. Trends in Ecology and Evolution, 21, 89-95.

Munday, P., Ryen, C., McCormick, M., \& Walker, S. (2009). Growth acceleration, behaviour and otolith check marks associated with sex change in the wrasse Halichoeres miniatus. Coral Reefs, 28, 623-634. 
Muñoz, R. C., \& Warner, R. R. (2004). Testing a new version of the size-advantage hypothesis for sex change: sperm competition and size-skew effects in the bucktooth parrotfish, Sparisoma radians. Behavioral Ecology, 15, 129-136.

Muñoz, R., \& Warner, R. (2003a). Alternative contexts of sex change with social control in the bucktooth parrotfish, Sparisoma radians. Environmental Biology of Fishes, 68, 307-319.

Muñoz, R., \& Warner, R. (2003b). A new version of the size-advantage hypothesis for sex change: incorporating sperm competition and size-fecundity skew. The American Naturalist, 161, 749-61.

Møller, A. (1994). Sexual selection in the barn swallow (Hirundo rustica). IV. Patterns of fluctuating asymmetry and selection against asymmetry. Evolution, $48,658-670$.

Ning, N., Hladyz, S., Gawne, B., Maffei, S., Price, A., \& Nielsen, D. (2012). Morphological, physiological and behavioural response patterns of carp gudgeon Hypseleotris spp. to food deprivation: implications for assessing health. Journal of fish biology, 80, 218-24.

Ogle, D. H. (2012a). NCStats: helper functions for statistics at Northland College. Rpackage version 3.0.

Ogle, D. H. (2012b). FSA: Fisheries stock analysis. R-package version 0.3-0.

Ong, L., \& Holland, K. N. (2010). Bioerosion of coral reefs by two Hawaiian parrotfishes: species, size differences and fishery implications. Marine Biology, 157, 1313-1323.

Ovegård, M., Berndt, K., \& Lunneryd, S.-G. (2012). Condition indices of Atlantic cod (Gadus morhua) biased by capturing method. ICES Journal of Marine Science, 69, 1781-1788.

Palmer, A. (1996). Waltzing with asymmetry. BioScience, 46, 518 - 532.

Palmer, A., \& Strobeck, C. (2003). Fluctuating asymmetry analyses revisited. Polak, M. (Ed.), Developmental Instability. Causes and Consequences. (pp. 279 - 319). New York: Oxford University Press.

Palmer, M., Linde, M., \& Morales-Nin, B. (2010). Disentangling fluctuating asymmetry from otolith shape. Marine Ecology Progress Series, 399, 261-272.

Panfili, J., Durand, J., Diop, K., Gouréne, B., \& Simier, M. (2005). Fluctuating asymmetry in fish otoliths and heterozygosity in stressful estuarine environments (West Africa). Marine and Freshwater Research, 56, 505-516.

Pankhurst, N. (1989). The relationship of ocular morphology to feeding modes and activity periods in shallow marine teleosts from New Zealand. Environmental Biology of Fishes, 26, 201-211. 
Pigliucci, M. (2001). Phenotypic plasticity: beyond nature and nurture. John Hopkins University Press.

Pinca, S., Kronen, M., Magron, F., McArdle, B., Vigliola, L., Kulbicki, M., \& Andréfouët, S. (2012). Relative importance of habitat and fishing in influencing reef fish communities across seventeen Pacific Island Countries and Territories. Fish and Fisheries, 13, 361-379.

Policansky, D. (1982). Sex change in plants and animals. Annual Review of Ecology and Systematics, 13, 471-495.

Pérez-Matus, A., \& Shima, J. (2010a). Density- and trait-mediated effects of fish predators on amphipod grazers: potential indirect benefits for the giant kelp Macrocystis pyrifera. Marine Ecology Progress Series, 417, 151-158.

Pérez-Matus, A., \& Shima, J. (2010b). Disentangling the effects of macroalgae on the abundance of temperate reef fishes. Journal of Experimental Marine Biology and Ecology, 388, 1-10.

Quinn, G., \& Keough, M. (2002). Experimental design and data analysis for biologists. Cambridge University Press.

R Development Core Team. (2012). R: A language and environment for stastical computing. Vienna, Austra: R Foundation for Stastical Computing. doi:ISBN 3900051-07-0

Rasmuson, M. (2002). Fluctuating asymmetry--indicator of what? Hereditas, 136, 177-83.

Ratnasabapathi, D., Burns, J., \& Souchek, R. (1992). Effects of temperature and prior residence on territorial aggression in the convict cichlid Cichlasoma nigrofasciatum. Aggressive Behaviour, 18, 365-372.

Robertson, D. (1972). Social control of sex reversal in a coral-reef fish. Science, 177, $1007-1009$.

Robertson, D., \& Sheldon, J. (1979). Competitive interactions and the availability of sleeping sites for a diuranl coral reef fish. Journal of Experimental Marine Biology and Ecology, 40, 285-298.

Robertson, D., \& Warner, R. (1978). Sexual patterns in the Labroid fishes of the Western Caribbean, II: The Parrotfishes (Scaridae). Smithsonian Contributions to Zoology, 255, $1-26$.

Robertson, R., Reinboth, R., \& Bruce, R. (1982). Gonochorism, protogynous sex change and spawning in three sparisomatinine parrotfishes from the western Indian Ocean. Bulletin of Marine Science, 32, 868-879. 
Roy, B. A., \& Stanton, M. L. (1999). Asymmetry of wild mustard, Sinapis arvensis (Brassicaceae), in response to severe physiological stresses. Journal of Evolutionary Biology, 12, 440-449.

Russ, G. (1991). Coral reef fisheries: effects and yields. In P. Sale (Ed.), The Ecology of Fishes on Coral Reefs (pp. 601 - 635). Academic Press.

Rätz, H.-J., \& Lloret, J. (2003). Variation in fish condition between Atlantic cod (Gadus morhua) stocks, the effect on their productivity and management implications. Fisheries Research, 60, 369-380.

Sakai, Y. (1997). Alternative spawning tactics of female angelfish according to two different contexts of sex change. Behavioral Ecology, 8, 372-377.

Sala-Bozano, M., \& Mariani, S. (2011). Life history variation in a marine teleost across a heterogeneous seascape. Estuarine, Coastal and Shelf Science, 92, 555563.

Scheiner, S. (1993). Genetics and evolution of phenotypic plasticity. Annual Review of Ecology and Systematics, 24, 35-68.

Schiel, D. R., \& Hickford, M. J. H. (2001). Biological structure of nearshore rocky subtidal habitats in southern New Zealand. Science for Conservation, 182, 1 54.

Schröder, B., \& Seppelt, R. (2006). Analysis of pattern-process interactions based on landscape models-Overview, general concepts, and methodological issues. Ecological Modelling, 199, 505-516.

Schärer, L., \& Vizoso, D. (2003). Earlier sex change in infected individuals of the protogynous reef fish Thalassoma bifasciatum. Behavioral Ecology and Sociobiology, 55, 137-143.

Scott, S. (2010). Phylogeography of the common New Zealand wrasse species, Notolabrus celidotus, and the phylogenetics of the pseudolabrine tribe. Victoria University of Wellington.

Serrano, E., Angibault, J.-M., Cargnelutti, B., \& Hewison, a J. M. (2008). Density dependence of developmental instability in a dimorphic ungulate. Biology Letters, 4, 512-4.

Shapiro, D. (1987). Differentiation and evolution of sex change in fishes. Bioscience, $37,490-497$.

Shima, J., \& Swearer, S. (2009). Spatially variable larval histories may shape recruitment rates of a temperate reef fish. Marine Ecology Progress Series, 394, 223-229. 
Shoup, D., \& Wahl, D. (2011). Body size, food, and temperature affect overwinter survival of age-0 bluegills. Transactions of the American Fisheries Society, 140, 1298-1304.

Somarakis, S., Kostikas, I., Peristeraki, N., \& Tsimenides, N. (1997). Fluctuating asymmetry in the otoliths of larval anchovy Engraulis encrasicolus and the use of developmental instability as an indicator of condition in larval fish. Marine Ecology Progress Series, 151, 191 - 203.

Stearns, S. (1976). Life-history tactics: a review of the ideas. Quarterly Review of Biology, 51, 3 - 47.

Stearns, S. (1977). The evolution of life history traits: a critique of the theory and a review of the data. Annual Review of Ecology and Systematics, 8, 145-171.

Sutton, S., Bult, T., \& Haedrich, R. (2000). Relationships among fat weight, body weight, water weight, and condition factors in wild Atlantic salmon parr. Transactions of the American Fisheries Society, 129, 527 - 538.

Taniguchi, Y., Rahel, F., Novinger, D., \& Gerow, K. (1998). Temperature mediation of competitive interactions among three fish species that replace each other along longitudinal stream gradients. Canadian Journal of Fisheries and Aquatic Sciences, 55, $1894-1901$.

Theodorou, P., Ólafsdóttir, G., \& Snorrason, S. (2012). Reaching the limit: constrained behavioural flexibility of juvenile Atlantic cod (Gadus morhua) at current coastal temperatures. Journal of Experimental Marine Biology and Ecology, 413, 192-197.

Trip, E., Clements, K., Raubenheimer, D., \& Choat, J. (2011a). Reproductive biology of an odacine labrid, Odax pullus. Journal of Fish Biology, 78, 741-61.

Trip, E., Raubenheimer, D., Clements, K., \& Choat, J. (2011b). Reproductive demography of a temperate protogynous and herbivorous fish, Odax pullus (Labridae, Odacini). Marine and Freshwater Research, 62, 176-186.

Urbach, D., Bittner, D., Lenz, T. L., Bernet, D., Wahli, T., \& Wedekind, C. (2007). Sperm velocity in an Alpine whitefish: effects of age, size, condition, fluctuating asymmetry and gonad abnormalities. Journal of Fish Biology, 71, 672-683.

Van der Oost, R., Beyer, J., \& Vermeulen, N. P. E. (2003). Fish bioaccumulation and biomarkers in environmental risk assessment: a review. Environmental Toxicology and Pharmacology, 13, 57-149.

Vignon, M., \& Morat, F. (2010). Environmental and genetic determinant of otolith shape revealed by a non-indigenous tropical fish. Marine Ecology Progress Series, 411, 231-241.

Wagner, H., \& Fortin, M. (2005). Spatial analysis of landscapes: concepts and statistics. Ecology, 86, 1975-1987. 
Walker, S., \& McCormick, M. (2004). Otolith-check formation and accelerated growth associated with sex change in an annual protogynous tropical fish. Marine Ecology Progress Series, 266, 201-212.

Warner, R. (1975). The adaptive significance of sequential hermaphroditism in animals. American Naturalist, 109, $61-82$.

Warner, R. (1982). Mating systems, sex change and sexual demography in the rainbow wrasse, Thalassoma lucasanum. Copeia, 1982, 653-661.

Warner, R. (1988). Sex change in fishes: hypotheses, evidence, and objections. Environmental Biology of Fishes, 22, 81-90.

Warner, R. (1991). The use of phenotypic plasticity in coral reef fishes as tests of theory in evolutionary ecology. In P. Sale (Ed.), The Ecology of Fishes on Coral Reefs (pp. 387 -398). Academic Press.

Warner, R., \& Hoffman, S. (1980). Population density and the economics of territorial defense in a coral reef fish. Ecology, 61, $772-780$.

Warner, R., \& Robertson, D. (1978). Sexual patterns in the Labroid fishes of the Western Caribbean, I: The Wrasses (Labridae). Smithsonian Contributions to Zoology, 254, 1 - 26.

Warner, R., Robertson, D., \& Jr, E. L. (1975). Sex change and sexual selection. Science, 190, 633-638.

Williams, A., Mapstone, B., \& Davies, C. (2007). Spatial and interannual patterns in growth of an exploited coral-reef fish. Journal of Fish Biology, 71, 970-992.

Willis, T. (2001). Visual census methods underestimate density and diversity of cryptic reef fishes. Journal of Fish Biology, 59, 1408-1411.

Willis, T., \& Anderson, M. (2003). Structure of cryptic reef fish assemblages: relationships with habitat characteristics and predator density, 257, 209-221.

Wilson, D., \& McCormick, M. (1997). Spatial and temporal validation of settlementmarks in the otoliths of tropical reef fishes. Marine Ecology Progress Series, $153,259-271$.

Wong, M., Munday, P., \& Jones, G. (2005). Habitat patch size, facultative monogamy and sex change in a coral-dwelling fish, Caracanthus unipinna. Environmental Biology of Fishes, 74, 141-150.

Woods, R., Sgró, C., Hercus, M., \& Hoffmann, A. (1999). The association between fluctuating asymmetry, trait variability, trait heritability, and stress: a multiply replicated experiment on combined stresses in Drosophila melanogaster. Evolution, 53, 493 - 505. 
Yamahira, K., \& Conover, D. (2002). Intra- vs . interspecific latitudinal variation in growth: adaptation to temperature or seasonality? Ecology, 83, 1252-1262. 


\section{Appendix A: Accuracy of visually estimating fish length}

Appendix A.1: Linear least-squares regression between visual estimates of total length of fish and known lengths for plastic fish estimated on transect underwater. Estimates are presented for (a) myself $\left(\mathrm{R}^{2}=0.98\right)$ and $(\mathrm{b})$ one other diver $\left(\mathrm{R}^{2}=0.98\right)$. The estimated lengths closely reflect the known data and indicate that fish length can be reasonably accurately estimated underwater.

(a)

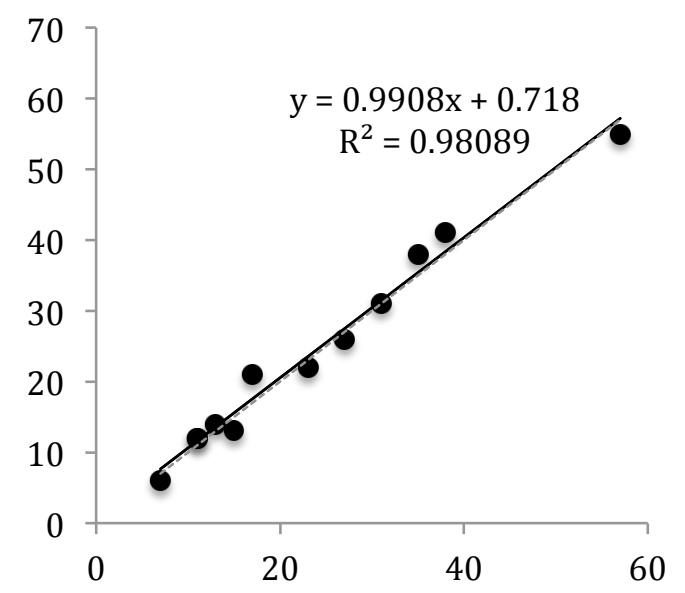

(b)

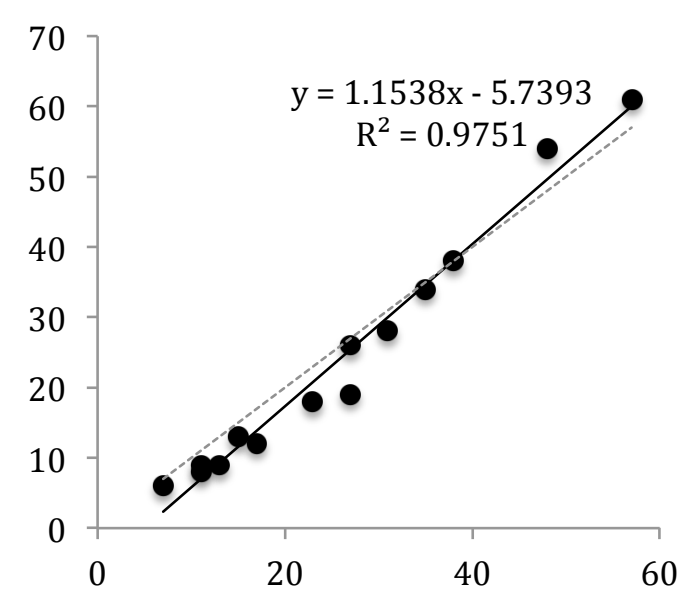




\section{Appendix B: Measurement error in estimates of fluctuating asymmetry}

Appendix B.1: Nested analysis of variance for repeated measurements of fluctuating asymmetry in 5 variables of otolith size: area, perimeter, axis (major), axis (minor), and weight. Repeated measurements of fluctuating asymmetry are nested in otolith side (right or left), which is nested in individual (that otoliths were extracted from). The results indicate that there is a significant difference between individuals and otolith sides despite the residual variation due to measurement error. This suggests that measurement error is low and estimates of fluctuating asymmetry like reflect true fluctuating asymmetry.

\begin{tabular}{lrrrr}
\hline Source of variation & df & MS & \multicolumn{1}{l}{ F } & P \\
a. Area & & & & \\
$\quad$ Individual & 4 & 0.541 & 6377.2 & $<\mathbf{0 . 0 0 1}$ \\
$\quad$ Individual:Side & 5 & 0.007 & 82.3 & $<\mathbf{0 . 0 0 1}$ \\
$\quad$ Residuals & 20 & $8.49 \times 10^{-05}$ & & \\
b. Perimeter & & & & \\
$\quad$ Individual & 4 & 1.102 & 2321.1 & $<\mathbf{0 . 0 0 1}$ \\
$\quad$ Individual:Side & 5 & 0.009 & 18.4 & $<\mathbf{0 . 0 0 1}$ \\
$\quad$ Residuals & 20 & 0.0005 & & \\
c. Axis (major) & & & & \\
$\quad$ Individual & 4 & 0.139 & 2643.7 & $<\mathbf{0 . 0 0 1}$ \\
$\quad$ Individual:Side & 5 & 0.003 & 58.3 & $<\mathbf{0 . 0 0 1}$ \\
$\quad$ Residuals & 20 & $5.26 \times 10^{-05}$ & & \\
d. Axis (minor) & & & & \\
$\quad$ Individual & 4 & 0.025 & 4300.3 & $<\mathbf{0 . 0 0 1}$ \\
$\quad$ Individual:Side & 5 & 0.002 & 296.8 & $<\mathbf{0 . 0 0 1}$ \\
$\quad$ Residuals & 20 & $5.76 \times 10^{-06}$ & & \\
$\boldsymbol{e}$. Weight & & & & \\
$\quad$ Individual & 4 & $8.19 \times 10^{-07}$ & 6139.8 & $<\mathbf{0 . 0 0 1}$ \\
$\quad$ Individual:Side & 5 & $8.98 \times 10^{-09}$ & 67.4 & $<\mathbf{0 . 0 0 1}$ \\
$\quad$ Residuals & 20 & $1.33 \times 10^{-10}$ & & \\
\hline
\end{tabular}


